\title{
AVALIAÇÃO DO ESTADO NUTRICIONAL DA VIDEIRA 'ITÁLIA',EM TRÊS ESTÁDIOS DE DESENVOLVIMENTO, NA REGIÃO DE JALES-SP, UTILIZANDO O MÉTODO DRIS
}

\author{
MÁRSIA ANTONIÊTA DE SOUZA GUILHERME \\ Engenheira Agrônoma
}

Orientador: Pesquisador Científico Dr. MAURILO MONTEIRO TERRA

Dissertação apresentada à Escola Superior de Agricultura "Luiz de Queiroz", da Universidade de São Paulo, para obtenção do título de Mestre em Agronomia, Área de Concentração: Solos e Nutrição de Plantas.

PIRACICABA

Estado de São Paulo - Brasil

Julho - 1995 
Dados Internacionais de Catalogaçã̃o na Plbíicação (CIP)

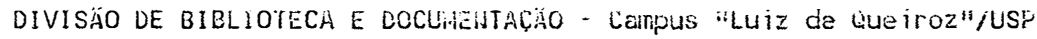

\section{Guitherme, Mársia Antoniêta de Souza}

Avaliação do estado nutricional da videira "Itália", eili três es tádios de desenvolvimento, na região de Jales-SP, utilizando o méto do DRIS. Piracicaba, 1995.

$81 p$.

Diss. (Hestro; - ESALG

bibliografia.

1. iJutriente em uva - Avaliaçăo - î́todo 2. Uva I cália - Desenvol vimento - Jales, SP 3 . Uva Itália - Nutrição - Jales, SP I. Escola Superior de Agricultura Luiz de Queiroz, Piracicaba

CDD 634.83 
AVALIAÇÃO DO ESTADO NUTRICIONAL DA VIDEIRA 'ITÁLIA',EM TRÊS ESTÁDIOS DE DESENVOLVIMENTO, NA REGIÃO DE JALES-SP, UTILIZANDO O MÉTODO DRIS

MÁRSIA ANTONIETA DE SOUZA GUILHERME

Aprovada em: 30.09 .1995

Comissão Julgadora:

PqC Dr. Maurilo Monteiro Terra IAC/SAASP

Prof. Dr. Moacyr de Oliveira C. do Brasil Sobrinho ESALQ/USP

PqC Dr. Ondino Cleante Bataglia IAC/SAASP

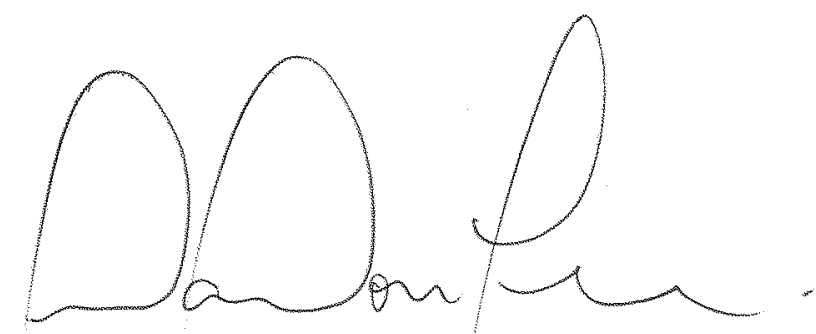

PqC Dr. MAURILO MONTEIRO TERRA Orientador 


\section{HOMENAGEM}

INSTITUTO AGRONÔMICO DE CAMPINAS

ESCOLA SUPERIOR DE AGRICULTURA "LUIZ DE QUEIROZ"

FUNDAÇÃO dE AMPARO À PESQUISA dO ESTADO dE SÃo PAULO-FAPESP. 
Aos meus pais, Antônia e Guilherme, pelo incentivo constante à minha formaçâo educacional e profissional, 


\section{AGRADECIMENTOS}

O autor expressa os seus agradecimentos:

- Ao Pesquisador Científico Dr. Maurilo Monteiro Terra pela orientação e incentivo durante a realização e confecção do presente trabalho.

- Aos viticultores da região de Jales, SP, em cujas propriedades foram realizados os experimentos.

- Ao Engenheiro Agrícola Wagner Rodrigues dos Santos pela colaboração, execução e orientação na discussão do método DRIS.

- Ao meu particular amigo e colega Ivan FerdinandoGergoletti pelo auxílio e estímulo à realização deste trabalho.

. Ao Prof. Titular Antônio Roque Dechen, da ESALQ-USP, pela colaboração na revisão de literatura.

- Ao funcionário da Seção de Viticultura, do Instituto Agronômico, Nereu Pedro dos Santos e a todos que, direta ou indiretamente, contribuiram para a realização deste trabalho. 


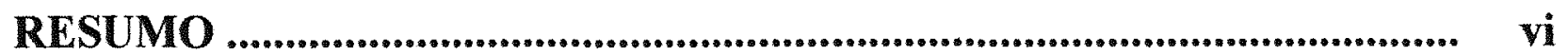

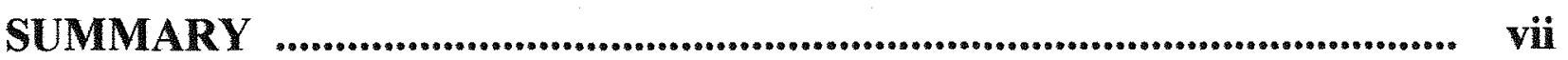

1. INTRODUÇÃO _................................................................................................. 1

2. REVISÃO DE LITERATURA .................................................................. 3

2.1. Concentração e Relação de Nutrientes na Folha ................... . 3

2.2. Sistema Integrado de Diagnose e Recomendação (DRIS) .... 13

3. MATERIAL E MÉTODOS _................................................................... 18

4. RESULTADOS E DISCUSSÃO _.............................................................. 21

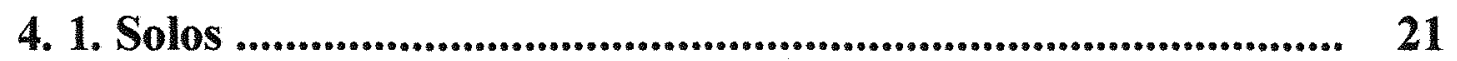

4. 1. 1. Análise Granulométrica .................................................. 21

4.1.2. Macronutríentes ........................................................................ 21

4.1.3. Micronutrientes ............................................................................ $\quad 30$

4. 2. Folhas .................................................................................... 31

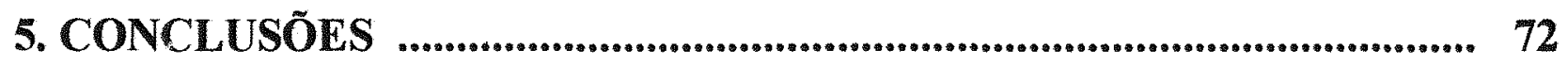

REFERÊNCIAS BIBLIOGRÁFICAS....................................................... 74

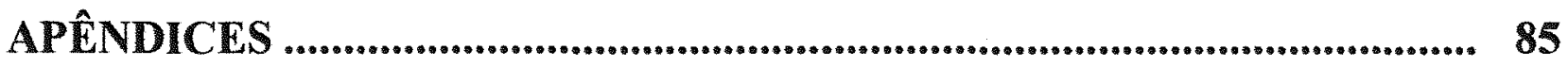


AVALIAÇÃO DO ESTADO NUTRICIONAL DA VIDEIRA 'ITÁLIA',EM TRÊS ESTÁDIOS DE DESENVOLVIMENTO, NA REGIÃO DE JALES-SP, UTILIZANDO O MÉTODO DRIS

\section{MÁRSIA ANTONIETA DE SOUZA GUILHERME}

Aprovada em: 30.09 .1995

Comissão Julgadora:

PqC Dr. Maurilo Monteiro Terra

IAC/SAASP

Prof. Dr. Moacyr de Oliveira C. do Brasil Sobrinho

ESALQ/USP

PqC Dr. Ondino Cleante Bataglia

IAC/SAASP

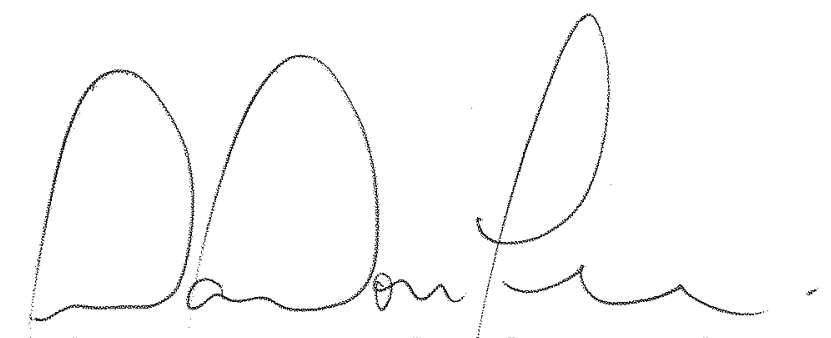

PqC Dr. MAURILO MONTEIRO TERRA

Orientador 

TRÊS ESTÁDIOS DE DESENVOLVIMENTO, NA REGIÃO DE JALES-SP, UTILIZANDO O MÉTODO DRIS

\author{
Autora: MÁRSIA ANTONIÊTA DE SOUZA GUILHERME \\ Orientador: PESQUISADOR CIENTÍFICO DR. MAURILO MONTEIRO TERRA
}

\title{
RESUMO
}

Objetivando a avaliação do estado nutricional da videira cv. Itália na região de Jales, SP, utilizando o Sistema Integrado de Diagnose e Recomendação (DRIS), realizou-se, no ano de 1991, um levantamento nutricional em vinte vinhedos em produçãao dessa região, que apresentavam práticas culturais semelhantes.

O levantamento nutricional dos vinhedos selecionados consistiu nas coletas de amostras de solo, nas profundidades de $0-20 \mathrm{~cm}$ e $20-40 \mathrm{~cm}$, nas coletas de amostras de folhas (limbo e pecíolo) em três estádios de desenvolvimento da planta (no florescimento, quando os frutos estavam entre ervilha e meia-baga e no início da maturação dos frutos) e na produção dos vinhedos amostrados.

Com o resultado dessa avaliação, através do método DRIS, concluiu-se que o método é adequado para a videira em questão, pois permitiu obter infornações a respeito do melhor órgão de amostragem, melhor época de amostragem, desordens nutricionais e índices de referência para balanço nutricional.

O limbo foi considerado melhor órgão de amostragem que o pecíolo, pois os índices de balanço nutricional estavam mais ajustados do que os índices do pecíolo.

O método confirma que tanto o florescimento quanto o início da maturação dos frutos podem ser consideradas épocas adequadas para amostragem de folhas de videira, por serem os dados obtidos, nesses dois estádios de desenvolvimento, mais ajustados do que os dados no estádio em que os frutos se encontravam entre ervilha e meia-baga.

Finalmente, o método DRIS pemitiu determinar que os vinhedos estudados, em geral, apresentaram deficiência dos macronutrientes, principalmente de potássio, magnésio e enxofre. Quanto aos micronutrientes, a problemática se deu por excesso dos mesmos, principalmente para o cobre. 
AVALIAÇÃO DO ESTADO NUTRICIONAL DA VIDEIRA 'ITÁLIA',EM TRÊS ESTÁDIOS DE DESENVOLVIMENTO, NA REGIÃO DE JALES-SP, UTILIZANDO O MÉTODO DRIS

Author: MÀRSIA ANTONIÊTA DE SOUZA GUILHERME

Adviser: DR. MAURILO MONTEIRO TERRA

\section{SUMMARY}

It was evaluated the nutritional condition of grapevine $\mathrm{cv}$. Itália in the region centered at Jales, SP, using the Diagnosis and Recommendation Integrated System (DRIS).

In 1991, 20 bearing vineyards in that region, using similar cultural practices, were surveyed nutritionally.

The survey consisted in: (a) colecting soil samples at $\mathrm{O}-2 \mathrm{Ocm}$ and 20-4Ocm; (b) colecting leaf samples (blade and petiole) at three different developing phases (at bloom, between pea and half-berry, and at veraison); and (c ) evaluating grape yield.

Using DRIS for this evaluation showed that the system is adequate for grapevine culture, permitting the obtention of information on the sampling tissue, nutritional disorders and reference indexes for the nutritional balance.

Leaf blade showed to be better sampling tissue than petiole, with much more consistent nutritional balance indexes.

The method confirmed that both blooming and veraison are adequate stages for sampling grapevine leaves. Data obtained in those two dates were much more consistent than those obtained when the berries were between sizes of pea and half-berry.

Finally, DRIS allowed to determine that the studied vineyards presented, in general, macronutrients deficiencies, mainly of potassium, magnesium and sulfur. Dealing with micronutrients, on the contray, the problem was of excess, mainly of cupper. 


\section{INTRODUÇÃO}

A viticultura do Estado de São Paulo representa um expressivo segmento da atividade agrícola paulista e o valor da sua produção ocupa o $16^{\mathrm{a}}$ posição entre os produtos de origem vegetal, correspondente a $122.810 \mathrm{t} / \mathrm{ha}$ no ano de 1991, segundo o Anuário Estatístico do Brasil referente ao ano de 1993. Esta atividade agrícola encontra-se difundida por todo o Estado, sendo a maior parte da produção destinada a uvas rústicas e finas de mesa.

Atualmente a viticultura vem encontrando grande oportunidade de expansão tanto no Estado de São Paulo como no Brasil, devido ao incremento da demanda de exportação de uvas finas de mesa, principalmente dos cultivares Itália e Rubi.

A região noroeste do Estado de São Paulo onde se encontra o município de Jales, não tradicional no cultivo de uvas finas de mesa, teve um incremento significativo na década de 80, chegando a crescer $100 \%$ de 1989 a 1992. Esse fato pode ser comprovado pelo aumento do número de pés de uva cultivar Itália, em produção, passando de 6.060 a 21.096 no período de 1980 a 1992 . A expansão da viticultura nessa região se justifica pelas condições climáticas favoráveis e pela grande aceitação do produto no mercado, em consequência de sua excelente qualidade (TERRA et al.,1993).

O clima da região noroeste, situada na latitude $20^{\circ} \mathrm{S}$, é peculiar e diferente das demais regiões vitícolas paulistas, sendo as temperaturas médias nessa região sempre maiores que $12,5^{\circ} \mathrm{C}$. Dessa forma, a probabilidade de ocorrência de geadas na região é baixa (cerca de $10 \%$ ), a videira não passa por um período de dormência, como é comum nas regiões vitícolas com temperaturas médias mais baixas e, portanto, se associada com irrigação durante a estação seca, a videira vegeta o ano inteiro. Consequentemente, a colheita pode ser realizada nos meses de entresafra das regiões tradicionais, resultando em maior rendimento financeiro e também em utilização de mão-de-obra ociosa em outras culturas.

A videira 'Itália' é um cultivar exigente, do ponto de vista nutricional, tanto em qualidade como em quantidade de nutrientes. Por outro lado, a adubação desse cultivar, principalmente em regiões recém exploradas como é o caso da região de Jales, tem sido feita de forma desequilibrada, gerando problemas sérios de nutrição.

O método de levantamento do estado nutricional, Sistema Integrado de Diagnose e Recomendação - DRIS, utiliza dados de concentração de nutrientes obtidos através da análise de tecidos (ZAMBELLO, 1979) e avalia o estado nutricional da cultura pelas relações de nutrientes, considerado um parâmetro 
importante para a cultura da videira, principalmente as relações $\mathrm{K} / \mathrm{Mg}, \mathrm{Ca} / \mathrm{Mg}$ e $\mathrm{Ca} / \mathrm{K}$.

O presente trabalho teve por objetivo avaliar o estado nutricional da videira cv. Itália, em três estádios de desenvolvimento, na região de Jales, utilizando o Sistema Integrado de Diagnose e Recomendação (DRIS), através da realização de um levantamento nutricional em vinhedos em produção, que apresentaram práticas culturais semelhantes. 


\section{REVISÃO DE LITERATURA}

\subsection{Concentração e relação de nutrientes na folha}

É de conhecimento geral que o bom desenvolvimento das plantas depende, dentre outros fatores, de teores adequados dos macro e micronutrientes na planta.

O levantamento do estado nutricional permite avaliar os teores de macro e micronutrientes e um dos métodos utilizados para a avaliação é a análise foliar. Como as folhas são consideradas o foco das atividades fisiológicas dentro da planta, alterações na nutrição mineral são de certa forma refletidas na concentração dos nutrientes nesses órgãos (DECHEN \& BATAGLIA, 1986). O método de análise foliar tem como princípio básico a lei dos fatores limitantes, segundo a qual sob baixo nível nutricional existe uma resposta ao fornecimento de nutrientes (URETA, 1981). Baseado nessa teoria, pode-se afirmar que existe um nível crítico para cada nutriente, sendo que acima deste nível, um aumento de nutriente pode ocasionar um aumento de produção e abaixo, a planta poderia estar em condições de deficiência.

Este princípio foi posto em prática inicialmente por LAGATU \& MAUMÉ (1934), citado por DELMAS (1971) que estudando videiras da espécie Vitis vinifera, estabeleceram níveis de carência de nitrogênio $(\mathrm{N})$ baseados na diagnose foliar e forneceram os seguintes índices: $3,2 \%$ na matéria seca de folhas no início do florescimento, $2,5 \%$ no início da maturação dos frutos e $1,75 \%$ na maturação dos frutos. Para o fósforo (P) os autores encontraram os seguintes níveis: $0,26 \%$ no início do florescimento, $0,12 \%$ na maturação dos frutos e $0,22 \%$ como valor médio durante o crescimento das plantas.

KANNENBERG (1990), em estudo na Alemanha com vinhedos de uva cultivar "Gütedel", analisando pecíolos coletados no florescimento, amolecimento dos frutos e 10 dias antes da colheita, definiu o teor foliar ótimo de $\mathrm{N}$ como estando entre 2,25 e $2,55 \%$.

ATALAY (1988), estudando plantas de videira cultivar "Thompson Seedless" em solução nutritiva, com níveis de $\mathrm{P}$ variando de 0 a 150 ppm observou que, quando o teor de $\mathrm{P}$ no pecíolo era inferior a $0,23 \%$ durante 0 estágio de frutificação, as plantas apresentavam sintomas de deficiência do elemento.

DEPARDON et al. (1954) obteve maiores produções de frutos quando o teor foliar de $\mathrm{K}$ correspondeu a $0,78 \%$. 
COUTINHO et al. (1984) revelaram que, sintomas de deficiência de magnésio em solos ácidos de Portugual, ocorreram quando o teor foliar de $\mathrm{Mg}$ foi inferior a $0,25 \%$ e o teor foliar de $\mathrm{K}$ foi maior que $1,8 \%$.

BEATTIE (1955) determinou que sintomas visuais de dificiência de $\mathrm{Mn}$ e $\mathrm{K}$ ocorreram quando teores peciolares foram menores que $30 \mathrm{ppm}$ e $1,5 \%$ do peso da matéria seca, respectivamente.

SAUER (1958) verificou os teores de B em videiras cv. Sultana e concluiu que a toxicidade ocorreu em folhas contendo $300 \mathrm{ppm}$ de B ou mais, sendo que em solos argilosos os teores de B nas folhas foram maiores do que em solos arenosos.

COOK et al.(1960) obteve teores foliares de B variando de 7 a 9 ppm em folhas cloróticas deficientes das variedades Langnave e Thompson Seedless, sendo que pecíolos de folhas opostas aos cachos, no florescimento, tinham 20 a 30 ppm de B.

GÄRTEL (1961), considerando o teor de 20-30 ppm de B como normal, observou que folhas com teor foliar de $700 \mathrm{ppm}$ apresentavam deformação e necrose.

CIFFERRI (1961) observou que a média do teor foliar de B em videiras com sintomas de deficiência do elemento foi de $9,8 \mathrm{ppm}$, enquanto que 0 teor foliar de $\mathrm{B}$ de plantas sem sintomas visíveis de deficiência do elemento esteve entre 11 e 12 ppm.

VALENZUELA \& SEPÚLVEDA (1977), em um estudo com dois cultivares de uva, em três diferentes locais, através das análises de folha, concluiu que níveis de $B$ acima de 300 ppm causaram anormalidades nas folhas, sendo que o cultivar Moscatel da Áustria foi mais afetado do que o cultivar Moscatel Rosada.

Examinando alguns vinhedos do cultivar Niagara Rosada nas regiões de Indaiatuba e Jundiaí, KUNIYUKI et al. (1982) encontraram uma anomalia denominada "chocolate" pelos viticultores. Inicialmente julgaram que esta anomalia estivesse associada à infecção por vírus, porém, amostras de folhas dessas videiras foram coletadas para análise e concluiram que tratava-se de sintomas de deficiência de boro. Os teores médios das plantas normais continham $24 \mathrm{ppm}$ de $\mathrm{B}$ no limbo enquanto que as plantas afetadas continham $18 \mathrm{ppm}$ de $\mathrm{B}$ no limbo.

VALENZUELA \& NARVAEZ (1983) encontraram teores de 135 a 376 ppm de $B$ nas folhas de videiras como sendo nível crítico para excesso de boro.

SAROSI (1965), em estudos de controle de nutrição da videira através de análises foliares, dando maior atenção aos micronutrientes $\mathrm{Fe}$ e $\mathrm{Mn}$ observou que, em solos calcários, os sintomas de falta de Fe ocorreram quando o teor foliar de Fe estava abaixo de $100 \mathrm{ppm}$ ou quando o teor foliar de $\mathrm{Fe}$ era superior à $100 \mathrm{ppm}$ mas, consideravelmente menor que o teor de $\mathrm{Mn}$. 
Análises dos nutrientes dos pecíolos de videiras altamente produtivas, realizadas por JUNG et al.(1971), determinaram os seguintes intervalos de níveis de nutrientes como ótimos: $0,73-1,23 \%$ de $\mathrm{N} ; 0,144-0,398 \%$ de $\mathrm{P}$; 1,78-2,98\% de K; 0,341-0,721\% de Mg ; 824 - 2596 ppm de Mn; 46 - 97 ppm de Fe e $21-35$ ppm de B.

VERMA \& NIJJAR (1978) aplicaram cinco doses de N, P e K em diferentes combinações, em plantas de uva cultivar Perlette, com sete anos de idade, e determinaram que quando a combinação calculada foi máxima os teores no pecíolo de $\mathrm{N}, \mathrm{P}$ e K foram $0,90 \%, 0,38 \%$ e $3,46 \%$ respectivamente.

SHANGAVI \& NIJJAR (1978) concluiram, através de ensaios de fertilização com diferentes combinações, que os teores peciolares das videiras quando as produções foram máximas correspoderam a 1,06\%, 0,27\% e $1,74 \%$ para N,P e K, respectivamente.

Sendo a concentração de nutrientes dentro da planta um valor integral de fatores como época de amostragem, orgão de amostragem, porta-enxerto, condução, e outros, que interagem para afetá-la, diversos autores estudaram a influência desses fatores nos níveis adequados de macro e micronutrientes.

GALLO \& RIBAS (1962) estudando o efeito de diferentes combinações variedade-porta-enxerto, obtiveram as seguintes conclusões: (a) os mais altos valores foliares de $\mathrm{N}$ e $\mathrm{P}$ foram encontrados em variedades enxertadas sobre Ruprestfis du Lot ; (b) o maior teor foliar de Ca foi associado com o porta-enxerto Riparia x Rupestris 101-14; ( c ) o teor foliar de K foi mais dependente da variedade, sendo mais alto em Diamante Negro, ltália e Moscatel de Hamburgo; (d) o cultivar Itália sobre porta-cnxerto Rupestris du Lot teve teores foliares elevados de $\mathrm{P}$ e $\mathrm{Mg}$; (e) o teor de $\mathrm{B}$ foi o que variou mais com relação às combinações variedade-portaenxerto e pareceu não ser dependente de nenhuma das duas variáveis.

SARIC et al. (1977) enxertaram quatro cultivares de uva em três diferentes porta-enxertos e desenvolveram-no em solução nutritiva completa ou com um nutriente deficiente para $\mathrm{N}, \mathrm{P}, \mathrm{K}, \mathrm{Ca}$ ou $\mathrm{Mg}$ sendo que ambos afetaram o conteúdo de nutrientes das folhas e ramos. Segundo os autores, os enxertos tiveram maior influência no conteúdo foliar de N,P e $\mathrm{Mg}$. Os conteúdos de $\mathrm{Ca}$ e $\mathrm{K}$ foram mais afetados pelo porta-enxertos.

KOSMA et al. (1969), em estudo do efeito do método de condução no conteúdo de NPK das folhas, concluiu que, no geral, não houve efeitos significativos no conteúdo de NPK das folhas de videiras sob diferentes sistemas de condução. Além disso, os autores confirmaram que com o envelhecimento das folhas, os teores de $\mathrm{N}$ e $\mathrm{P}$ da matéria seca sempre declinaram e que com o teor de $\mathrm{K}$ a queda foi freqüente. Os autores também concluiram que os teores foliares de NPK diferiram nas variedades estudadas sendo que os teores de $\mathrm{N}$ e $\mathrm{P}$ foram elevados na variedade ltalian Rielting e o teor de $\mathrm{K}$ foi mais baixo do que na variedade Cirfandli. 
Análises dos nutrientes dos pecíolos de videiras altamente produtivas, realizadas por JUNG et al.(1971), determinaram os seguintes intervalos de níveis de nutrientes como ótimos: $0,73-1,23 \%$ de $\mathrm{N} ; 0,144-0,398 \%$ de $\mathrm{P}$; 1,78-2,98\% de K; 0,341-0,721\% de Mg ; 824 - 2596 ppm de $\mathrm{Mn} ; 46$ - 97 ppm de Fe e $21-35$ ppm de $B$.

VERMA \& NIJJAR (1978) aplicaram cinco doses de N, P e K em diferentes combinações, em plantas de uva cultivar Perlette, com sete anos de idade, e determinaram que quando a combinação calculada foi máxima os teores no pecíolo de $\mathrm{N}, \mathrm{P}$ e $\mathrm{K}$ foram $0,90 \%, 0,38 \%$ e $3,46 \%$ respectivamente.

SHANGAVI \& NIJJAR (1978) concluiram, através de ensaios de fertilização com diferentes combinações, que os teores peciolares das videiras quando as produções foram máximas correspoderam a 1,06\%, 0,27\% e 1,74\% para $\mathrm{N}, \mathrm{P}$ e K, respectivamente.

Sendo a concentração de nutrientes dentro da planta um valor integral de fatores como época de amostragem, orgão de amostragem, porta-enxerto, condução, e outros, que interagem para afetá-la, diversos autores estudaram a influência desses fatores nos níveis adequados de macro e micronutrientes.

GALLO \& RIBAS (1962) estudando o efeito de diferentes combinações variedade-porta-enxerto, obtiveram as seguintes conclusões: (a) os mais altos valores foliares de $\mathrm{N}$ e $\mathrm{P}$ foram encontrados em variedades enxertadas sobre Ruprestfis du Lot ; (b) o maior teor foliar de Ca foi associado com o porta-enxerto Riparia x Rupestris 101-14; ( c ) o teor foliar de $\mathrm{K}$ foi mais dependente da variedade, sendo mais alto em Diamante Negro, ltália e Moscatel de Hamburgo; (d) o cultivar Itália sobre porta-cnxerto Rupestris du Lot teve teores foliares elevados de $\mathrm{P}$ e $\mathrm{Mg}$; (e) o teor de $\mathrm{B}$ foi o que variou mais com relação às combinações variedade-portaenxerto e pareceu não ser dependente de nenhuma das duas variáveis.

SARIC et al. (1977) enxertaram quatro cultivares de uva em três diferentes porta-enxertos e desenvolveram-no em solução nutritiva completa ou com um nutriente deficiente para $\mathrm{N}, \mathrm{P}, \mathrm{K}, \mathrm{Ca}$ ou $\mathrm{Mg}$ sendo que ambos afetaram o conteúdo de nutrientes das folhas e ramos. Segundo os autores, os enxertos tiveram maior influência no conteúdo foliar de N,P e Mg. Os conteúdos de $\mathrm{Ca}$ e $\mathrm{K}$ foram mais afetados pelo porta-enxertos.

KOSMA et al. (1969), em estudo do efeito do método de condução no conteúdo de NPK das folhas, concluiu que, no geral, não houve efeitos significativos no conteúdo de NPK das folhas de videiras sob diferentes sistemas de condução. Além disso, os autores confirmaram que com o envelhecimento das folhas, os teores de $\mathrm{N}$ e $\mathrm{P}$ da matéria seca sempre declinaram e que com o teor de $\mathrm{K}$ a queda foi freqüente. Os autores também concluiram que os teores foliares de NPK diferiram nas variedades estudadas sendo que os teores de $\mathrm{N}$ e $\mathrm{P}$ foram elevados na variedade ltalian Rielting e o teor de $\mathrm{K}$ foi mais baixo do que na variedade Cirfandli. 
ULRICH (1942) estudou o conteúdo de potássio nos limbos e pecíolos de videiras e concluiu que o nível desse elemento no pecíolo refletiu melhor do que no limbo.

Levy (1965), citado por DELMAS (1971), estabeleceu o limite crítico do teor de $\mathrm{K}$ em $1,25 \%$ no pecíolo para as quatro épocas de coleta clássicas de amostragem (início de florescimento, florescimento, início de maturaçâo de frutos e maturação). Este valor de $\mathrm{K}$ corresponde ao teor de $0,75 \%$ no limbo. O nível crítico de $\mathrm{Mg}$ foi estabelecido em 0,20\%.

GROMAKOVSKIJ (1962), em um estudo de diagnose do nível de nutrientes em uva, através da análise foliar, concluiu que folhas retiradas acima da gema floral tiveram teores menores de $\mathrm{N}$ e $\mathrm{P}$ do que as folhas amostradas abaixo das inflorescências, sendo que, nos dois casos, os níveis no pecíolo foram maiores que os níveis obtidos no limbo foliar. O pico máximo dos teores peciolares ocorreu no florescimento e o mínimo ocorreu na colheita.

DULAC (1965) relatou que uma análise detalhada dos resultados de um ensaio de 15 anos de adubação, indicou que pecíolos foliares e pedúnculos dos cachos foram mais sensíveis do que os limbos foliares em apontar mudanças no teor de potássio no solo.

VANEK et al. (1967), através dos estudos em vinhedos com deficiência de magnésio, determinaram que o limbo foliar foi mais indicado que o pecíolo para detectar deficiência de $\mathrm{Mg}$ através de análise foliar.

ALEXANDER \& WOODHAM (1970) realizaram um estudo de escolha dos tecidos de uva para amostragem, com finalidade de diagnóstico nutricional, e determinaram que o tecido mais satisfatório para diagnóstico das deficiências de fósforo, potássio, cálcio ou magnésio é o pecíolo das folhas basais, sendo que concentrações de $0,1 \%$ de $\mathrm{P}, 0,8 \%$ de $\mathrm{K}, 0,5 \%$ de $\mathrm{Ca}$ e $0,2 \%$ de $\mathrm{Mg}$ nesse tecido estão associadas com o começo dos sintomas de deficiência ou com o crescimento dos ramos.

SHIKHAMANY \& SATYANARAYANA (1971) obtiveram correlações positivas para $\mathrm{N}, \mathrm{Mg}, \mathrm{P}$ e Ca em estudo sobre relações entre teores de limbo e pecíolo sendo que, quando os níveis de $\mathrm{P}, \mathrm{K}, \mathrm{Ca}$ e $\mathrm{Mg}$ do limbo atingiram 0,$19 ; 0,65 ; 0,8$ e $0,323 \%$, respectivamente, outras quantidades desses nutrientes se acumularam desproporcionalmente nos pecíolos.

CUMMINGS (1977) analisou amostras de margem, nervura central e pecíolo de folhas jovens e maduras, coletadas com seis intervalos de seis semanas, e concluiu que as concentrações de $\mathrm{P}, \mathrm{K}, \mathrm{Ca}, \mathrm{Mg}, \mathrm{Cu}$ e $\mathrm{Zn}$ foram maiores no pecíolo do que no limbo foliar, sugerindo que o pecíolo indica melhor o nível nutricional desses elementos. 
FREGONI (1977) observou, em diversos trabalhos, que os níveis ótimos de B foram: $20-25 \mathrm{ppm}$ para folhas, $30 \mathrm{ppm}$ para pecíolos, $20 \mathrm{ppm}$ para 0 ápice dos ramos e 1 ppm para o mosto.

ATALAY (1978), em estudo de relações entre pecíolo e limbo para determinação do nível de fósforo e zinco de vinhedos, encontrou correlações significativas entre teor de $\mathrm{P}$ no pecíolo e limbo. Segundo o autor, em vinhedos com alto teor de $\mathrm{P}$ no solo, conteúdo peciolar de $\mathrm{P}$ foi maior do que no limbo e em vinhedos com alto teor de $\mathrm{Zn}$ no solo, o conteúdo no limbo é que foi maior ocorrendo o contrário quando as reservas de $\mathrm{P}$ e $\mathrm{Zn}$ no solo eram baixas.

BERTONI \& MORARD (1982), em estudo com o cultivar Chasselas, determinaram que o conteúdo de $\mathrm{N}$ dos limbos foliares foi duas vezes maior que o dos pecíolos, enquanto que para $\mathrm{P}, \mathrm{K}, \mathrm{Mg}$ e $\mathrm{Ca}$, os valores para limbo e pecíolo foram similares. Segundo os autores os efeitos da localidade e época de amostragem no teor de $\mathrm{P}$ e $\mathrm{K}$ foram, porém, melhor refletidas pela análise do pecíolo do que do limbo, de forma que as análises de pecíolo e limbo poderiam ser usadas para complementarem uma a outra.

Os mesmos autores, em um outro trabalho no mesmo ano, examinaram a folha oposta ao $1^{\circ}$ cacho de uva, no florescimento e na maturação de plantas cultivar "Chasselas", em vinhedos do sudoeste da França, com grande variação na produção e qualidade, obtendo os seguintes teores médios de nutrientes, conforme o órgão da planta:

\begin{tabular}{cccccc}
\hline & $\mathrm{N} \%$ & $\mathrm{P} \%$ & $\mathrm{~K} \%$ & $\mathrm{Ca} \%$ & $\mathrm{Mg} \%$ \\
\hline \multirow{5}{*}{ FLORESCIMENTO } \\
Folha Inteira & $2,4-4,6$ & $0,15-0,43$ & $0,69-1,67$ & $0,8-2,5$ & $0,13-0,38$ \\
Limbo & $2,7-5,3$ & $0,16-0,27$ & $0,06-1,43$ & $0,9-2,7$ & $0,10-0,36$ \\
Pecíolo & $0,8-2,2$ & $0,13-0,35$ & $0,65-3,44$ & $0,7-1,7$ & $0,23-0,76$ \\
& \multicolumn{5}{c}{ AMADURECIMENTO } \\
Folha Inteira & $1,3-2,6$ & $0,12-0,32$ & $0,38-1,78$ & $1,3-3,5$ & $0,16-0,63$ \\
Limbo & $1,4-2,9$ & $0,13-0,27$ & $0,42-1,35$ & $1,3-3,5$ & $0,11-0,43$ \\
Pecíolo & $0,6-1,5$ & $0,08-0,56$ & $0,20-2,96$ & $1,2-3,1$ & $0,55-1,71$ \\
\hline
\end{tabular}

Os autores concluiram que em condições homogêneas (mesmo cultivar e clima), flutuações consideráveis foram devido ao tipo de solo, período de amostragem e época, de modo que, níveis de referência não poderiam ser recomendados, mas ambas as análises, de pecíolo e limbo, poderiam ser usadas para complementar à outra.

HIROCE \& TERRA (1983) determinaram os teores médios de macronutrientes no pecíolo e limbo da $6 \mathrm{a}$. folha, a partir do ápice dos ramos da 
videira "Niagara Rosada" e observaram a existência de variações nos teores existentes:

\begin{tabular}{ccc}
\hline Nutrientes & Pecíolo (\%) & Limbo (\%) \\
\hline $\mathrm{N}$ & 1,71 & 4,87 \\
$\mathrm{P}$ & 0,63 & 0,62 \\
$\mathrm{~K}$ & 7,12 & 3,29 \\
$\mathrm{Ca}$ & 1,24 & 1,65 \\
$\mathrm{Mg}$ & 0,45 & 0,32 \\
$\mathrm{~S}$ & 0,16 & 0,29 \\
\hline
\end{tabular}

KOVANCI \& ATALAY (1987) utilizaram o teor $0,23 \%$ como referência para $\mathrm{P}$ no pecíolo, em estudo com mudas de uva crescendo em níveis de $\mathrm{P}$ que variavam de 0 a $300 \mathrm{ppm}$. Os autores observaram que, em plantas pobres em nutrientes, o pecíolo tinha menos $\mathrm{P}$ do que no limbo, ocorrendo o contrário em plantes com nutrientes adequados ou em excesso.

AHMED (1989), em estudo comparativo de análise de pecíolo e limbo em uva cultivar "Anab-e-Shahi"(Vitis vinifera L.) observou que os pecíolos continham mais $\mathrm{P}, \mathrm{K}, \mathrm{Ca}, \mathrm{Mg}, \mathrm{Zn}$ e $\mathrm{Fe}$, enquanto que os limbos continham mais $\mathrm{N}$, sendo que, os teores peciolares de todos os macro e micronutrientes estudados foram positivamente correlacionados com os teores no limbo desses nutrientes.

HERNANDO \& MENDIOLA (1965) estudaram a absorção dos diferentes macronutrientes em uma mesma variedade. As variações dos conteúdos de nitrogênio, fósforo e potássio nas folhas, estudadas separadamente, seguiram aproximadamente um rítmo semelhante, diminuindo claramente à medida que transcorreu o ciclo vegetativo, e os conteúdos máximos coincidem aos mesmos períodos. A explicação deste comportamento poderia estar na tendência destes nutrientes a emigrar aos tecidos em formação. Ao contrário, os conteúdos de cálcio e magnésio aumentam, já que o cálcio, pelo seu caráter de elemento estrutural, tende a acumular-se nas folhas e o magnésio é indispensável à síntese de carboidratos, proteínas e lipídeos que formarão o fruto. Baseado nesses resultados, os autores sugerem que para o estudo de nutrição da videira, a época mais conveniente para a amostragem de folhas, com o fim de relacionar os dados analíticos obtidos e as produções, parece ser a formação do fruto, já que nos fornece uma maior dispersão destes valores, o que permite uma melhor classificação dos mesmos.

GUILLËN et al. (1965) analisaram folhas de Vifis vinifera em três épocas distintas, a fim de estudar a evolução dos nutrientes $\mathrm{N}, \mathrm{P}, \mathrm{K}, \mathrm{Ca}$ e $\mathrm{Mg}$ ao longo do ciclo da videira, através de equações de regressão e representações gráficas correspondentes. Segundo os autores, os conteúdos foliares de $\mathrm{N}$ e $\mathrm{P}$ diminuiram no começo e fim do período de florescimento, e começo e fim de maturação dos frutos durante o ciclo vegetativo, variando de 4,97 a $1,65 \%$ para o $\mathrm{N}$ e de 0,40 a $0,11 \%$ 
para o $\mathrm{P}$, e mostrando que existe uma correlação entre ambos. Os conteúdos foliares de potássio apresentaram um ligeiro aumento na primeira etapa e decresceram a um valor inferior ao inicial, posteriormente, variando de 1,45 a $0,32 \%$. Os conteúdos foliares de $\mathrm{Ca}$ e $\mathrm{Mg}$ aumentaram quase linearmente com o amadurecimento, variando de 1,0 a $5,5 \%$ para $\mathrm{Ca}$ e de 0,3 a $1,0 \%$ para o $\mathrm{Mg}$.

GONZALO et al. (1973), com o objetivo de estudar as variações estacionais normais do teor de nutrientes minerais nos limbos e pecíolos de folhas opostas ao cachos da videira cultivar Semillon (Vitis vinifera L.) nos vinhedos de Macul, em Santiago do Chile, encontraram as seguintes variações em diferentes épocas de coleta de amostras $1,4-3,4 \%$ de $\mathrm{N} ; 0,09-0,25 \%$ de $\mathrm{P} ; 0,56-1,14 \%$ de $\mathrm{K}$ ;0,5 - 1,0\% de $\mathrm{Mg} ; 1,0-3,3 \%$ de $\mathrm{Ca} ; 45-98$ ppm de $\mathrm{Mn} ; 12 \mathrm{ppm}$ de $\mathrm{Cu}$ e $20 \mathrm{ppm}$ de $\mathrm{Zn}$ para os limbos, e $0,04-0,23 \%$ de $\mathrm{P} ; 0,6-2,0 \%$ de $\mathrm{K} ; 0,33-1,2 \%$ de $\mathrm{Mg}$; $1,0-3,0 \%$ de $\mathrm{Ca} ; 24-48 \mathrm{ppm}$ de $\mathrm{Mn} ; 5-12 \mathrm{ppm}$ de $\mathrm{Zn}$ para os pecíolos.

MERINO et al. (1974) recomendaram fazer a amostragem de folhas de videira para análise foliar de B durante o florescimento ou logo após o mesmo, já que o pico do teor total do elemento nas folhas se deu nesse período do ciclo da cultura.

LAVIN \& VALENZUELA (1986) consideraram no estudo em questão que o teor de $\mathrm{N}$ no pecíolo de $0,75 \%$ no florescimento e $0,5 \%$ no fruto maduro foram adequados para videiras. Os teores de $\mathrm{P}$ no pecíolo encontrados foram de 0,1 e $0,06 \%$ no florescimento e no fruto maduro, respectivamente, em todos os tratamentos. O teor de $\mathrm{K}$ no pecíolo foi considerado alto, muitas vezes superando $3 \%$.

TERRA et al.(1993), através de uma revisão de trabalhos sobre teores considerados adequados para a videira na folha (limbo + pecíolo), no limbo e no pecíolo, separadamente, e em duas épocas (florescimento e início do amolecimento das bagas) relatou os seguintes teores:

\begin{tabular}{clccc}
\hline Época & \multicolumn{1}{c}{ Nutriente } & Folha & Pecíolo & Limbo \\
\hline Florescimento & $\mathrm{N} \%$ & 3,20 & 1,50 & 3,00 \\
& $\mathrm{P} \%$ & 0,27 & 0,26 & 0,27 \\
& $\mathrm{~K} \%$ & 1,80 & 2,50 & 0,85 \\
& $\mathrm{Ca} \%$ & 1,60 & 1,24 & 1,45 \\
& $\mathrm{Mg} \%$ & 0,50 & 0,45 & 0,32 \\
& $\mathrm{~S} \%$ & 0,35 & 0,16 & 0,29 \\
& $\mathrm{~B}$ ppm & 50 & 40 & 40 \\
& $\mathrm{Cu} \mathrm{ppm}$ & 20 & 15 & 15 \\
& Fe ppm & 100 & 100 & - \\
& Mn ppm & 30 & 20 & 30 \\
& Zn ppm & 20 & 20 & 20 \\
\hline
\end{tabular}


continuação...

\begin{tabular}{llccc}
\hline \multicolumn{1}{c}{ Época } & \multicolumn{1}{c}{ Nutriente } & Folha & Pecíolo & Limbo \\
\hline Início do & $\mathrm{N} \%$ & 1,95 & 1,10 & 2,20 \\
amolecimento & $\mathrm{P} \%$ & 0,22 & 0,22 & 0,20 \\
das bagas & $\mathrm{K} \%$ & 1,10 & 2,00 & 0,80 \\
& $\mathrm{Ca} \%$ & 1,30 & 1,30 & 1,45 \\
& $\mathrm{Mg} \%$ & 0,40 & 0,35 & 0,27 \\
& $\mathrm{~S} \%$ & 0,22 & 0,13 & 0,20 \\
& $\mathrm{~B} \mathrm{ppm}$ & 30 & 30 & 30 \\
& $\mathrm{Cu} \mathrm{ppm}$ & 14 & 10 & 20 \\
& Fe ppm & 60 & 60 & 60 \\
& $\mathrm{Mn} \mathrm{ppm}$ & 30 & 20 & 30 \\
& Zn ppm & 20 & 20 & 20 \\
\hline
\end{tabular}

Um outro fator importante na nutrição mineral adequada da cultura da videira, bem como em outras diversas culturas, é a relação entre os nutrientes, que têm sido bastante utilizadas em muitos trabalhos, ajudando nos estudos de desbalanço nutricional das culturas (BATAGLIA \& DECHEN, 1986).

DIETRICH et al. (1965), através de análises foliares de videiras cultivar Chasselas, observou que quando a relação $\mathrm{K} / \mathrm{Mg}$ foi superior à 10 , houve demonstração de sintomas de deficiências de magnésio.

VANEK et al. (1967), através dos estudos em vinhedos com deficiência de magnésio determinou que a relação $\mathrm{K} / \mathrm{Mg}$ expressou a deficiência do elemento com mais exatidão do que o teor de $\mathrm{Mg}$ nas folhas, sendo que nas folhas sem sintomas a relação $\mathrm{K} / \mathrm{Mg}$ foi de 1,73 enquanto que nas folhas deficientes foi de 8,33 .

RODRIGUEZ \& GONZÁLEZ-GARCIA (1965) estudando o equilibrio nutricional em vinhedos de Andalucia Ocidenta Espanha, concluíram que, para a região de EI Condado, a relação média $\mathrm{N}, \mathrm{P}_{2} \mathrm{O}_{5}, \mathrm{~K}_{2} \mathrm{O}$ que esteve associada com as maiores produções foi de 59,8:11,0:29,2, respectivamente. Para a região de Jerez, os autores concluíram que a relação média correspondente foi de $59,6: 17,1$ : 23,2 .

GÄRTEL (1965) realizou trabalho sobre o valor diagnóstico de análise de folhas para identificar desordens nutricionais em videiras. Uma das conclusões a que o autor chegou, nesse trabalho, foi a de que a deficiência secundária de $\mathrm{Fe}$, produzida por uma obstrução ao $\mathrm{Fe}$ nos tecidos, poderia ser identificada por uma elevação da relação $\mathrm{P} / \mathrm{Fe}$ e excesso de potássio, sendo que essa elevação da relação $\mathrm{P} / \mathrm{Fe}$ pode ser causada também por virose. Outra conclusão que o autor obteve é a de que a relação $\mathrm{K} / \mathrm{Mg}$ inferior a 1,0 caracteriza a deficiência de potássio e acima de 1,5 caracteriza a deficiência de magnésio. Injúrias nas plantas, 
induzidas por solos muito ácidos, produzem relações $\mathrm{K} / \mathrm{Mg}$ acima de 20 , teor muito alto de Mn e pequena elevação de $\mathrm{Al}$. Finalmente, o autor concluiu que deficiência e toxidez de B podem ser identificadas pelo teor de B nas folhas, mas deficiências de $\mathrm{Zn}$ causadas pelo excesso de adubação fosfatada não podem ser diagnosticadas com exatidão pelo teor do elemento nas folhas.

LAVY (1968) observou que o teor de $\mathrm{K}$ usado como padrão e considerado como ótimo na relação $\mathrm{N}: \mathrm{P}_{2} \mathrm{O}_{5}: \mathrm{K} 2 \mathrm{O}$ de 2,3:0,5:2,5 deve ser menor, e que as relações $\mathrm{N}: \mathrm{K}$ e $\mathrm{K}: \mathrm{Mg}$ são mais importantes que a relação NPK. O autor sugere também que as folhas para análise foliar devam ser coletadas duas vezes ao ano: no início da frutificação e na maturação dos frutos.

STANIMIROVIC (1968) estudou o uso da diagnose foliar na determinação da necessidade de nutrientes em videira e concluiu que a relação ótima para NPK foi de $1,0: 0,5-1,0: 2,5-3,0$, respectivamente, com uma dose extra de N quando em solo arenoso. Segundo o autor, os valores médios nas folhas foram 2,89$3,17 \%$ de $\mathrm{N} ; 0,245-0,27 \%$ de $\mathrm{P}$ e $0,70-0,88 \%$ de $\mathrm{K}$, sendo que durante $\mathrm{o}$ crescimento das videiras, os valores de NPK nas folhas decresceram mais ou menos $50 \%$.

Para BIBLINA (1968) as relações NPK $1: 1: 1$ ou $2: 1: 2$ é que proporcionaram as mais altas produções e boa qualidade de uvas, sendo que a maior necessidade de nutrientes ocorreu durante o florescimento, e a absorção de $\mathrm{K}$ aumentou até a maturação dos frutos.

BRECHBULER et al. (1968) observaram que plantas com deficiência de $\mathrm{Mg}$ geralmente apresentavam $\mathrm{K} / \mathrm{Mg}$ maior que 10 embora algumas variedades menos sensíveis em solos ácidos tolerarem relação superior a $15 \mathrm{sem}$ apresentarem sintomas externos de deficiência.

COUTINHO et al. (1984) reveleram que, sintomas de deficiência de magnésio em solos ácidos de Portugual, ocorreram quando a relação $\mathrm{K} / \mathrm{Mg}$ na folha foi 6 a 10 , sendo que quando a mesma foi superior a 10 a deficiência de magnésio não ocorreu.

BALO et al. (1988), em estudo com cultivar 'Gruner Veltlener' desenvolvida em vasos, demonstraram que a produção decresceu quando a relação $\mathrm{N} / \mathrm{K}$ na folha foi maior que $1,9-2,4$. Os mesmos autores concluiram que os níveis ótimos de $\mathrm{P}$ e $\mathrm{K}$ nas folhas foram $0,22 \%$ e $1,2 \%$, respectivamente.

\subsection{Sistema Integrado de Diagnose e Recomendação (DRIS)}

Esta técnica foi desenvolvida por BEAUFILS, primeiramente com o nome de Diagnose Fisiológica e através do estudo de aspectos nutricionais de seringueiras (Hevea brasiliensis), cultivadas no Vietnã e Camboja. 
Em 1956, BEAUFILS propôs o estudo através das relações N/P, $\mathrm{N} / \mathrm{K}$ e K/P e também o diagrama para a interpretação do balanço nutricional de N,P e $\mathrm{K}$ em seringueiras.

BATAGLIA \& DECHEN (1986) relataram que as relações de nutrientes em tecidos vegetais tem sido bastante utilizadas em muitos trabalhos, ajudando nos estudos de desbalanço nutricional em culturas. Segundo os mesmos autores, enquanto alguns trabalhos têm boa correlação entre a relação de nutrientes e a produção, outros têm tido pouco sucesso, sendo que o DRIS procura esclarecer esta controvérsia. As relações entre nutrientes não são muito usadas rotineiramente na diagnose foliar mas se constituem no mecanismo básico para o estabelecimento dos critérios de interpretação pelo DRIS.

BEAUFILS (1973) formulou uma revisão sobre sua técnica e anunciou o Sistema Integrado de Diagnose e Recomendação(DRIS) em substituição à Diagnose Fisiológica. Nesta revisão o autor considerou que a produtividade e a qualidade de uma cultura particular constituem a resposta da planta a vários estímulos do ambiente e não só diretamente do estímulo provocado, conforme representação esquemática a seguir:

PROPRIEDADE DO SOLO

$+$

TRATAMENTOS

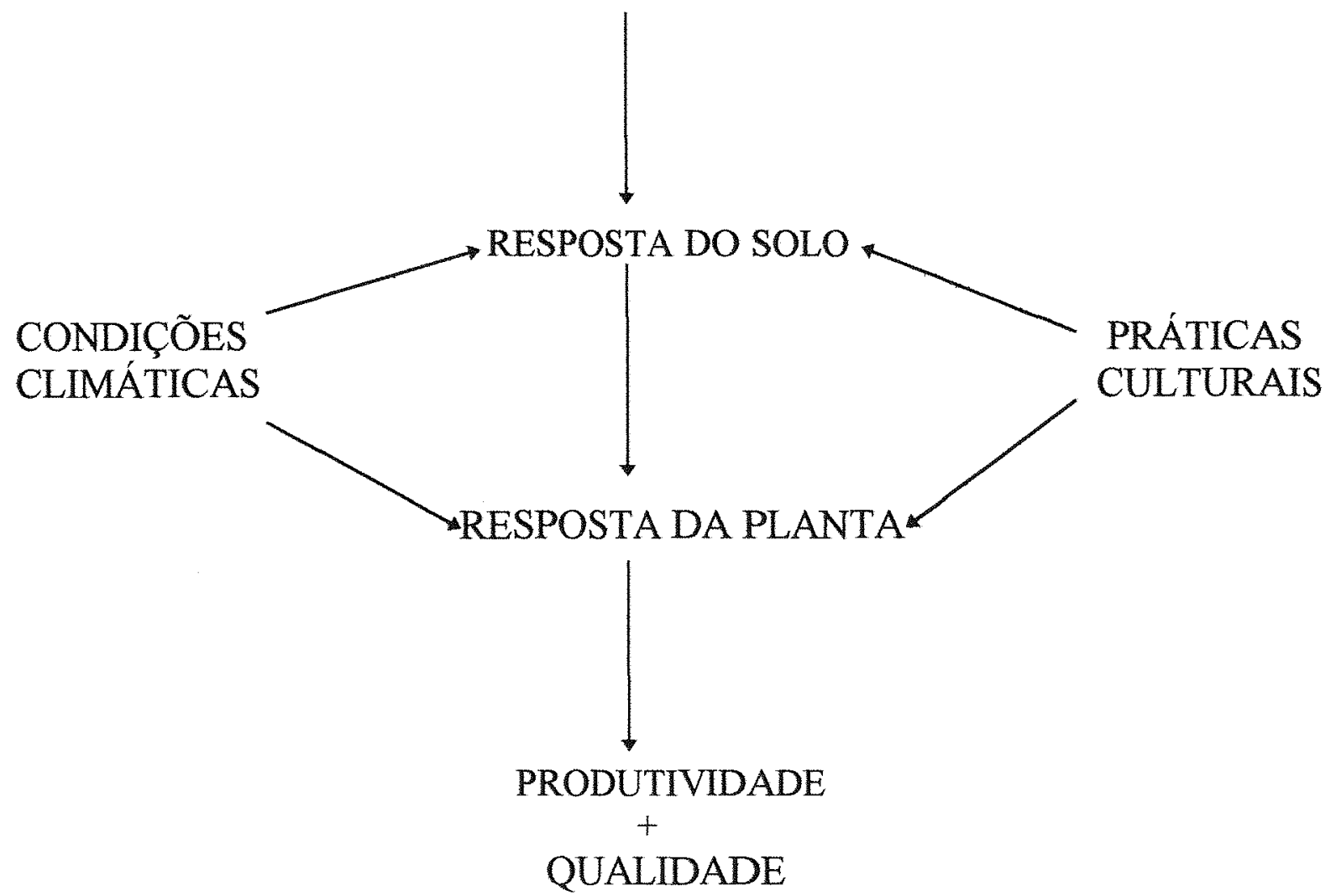


O mesmo autor relata ainda que a aplicação desse sistema inclui a seleção da população normal (população B), que passa pela classificação das plantas observadas em, não anormais e anormais, sendo que:

condições adversas.

- plantas não anormais são aquelas que não foram afetadas por adversas.

- planta anormais são aquelas que foram afetadas por condições

Ainda, BEAULFILS (1973) afirma que a seleção da população não anormal é baseada em condições vegetativas e produção, sendo o princípio usado na seleção, ilustrado esquematicamente a seguir:

Primeixa Seleção em condições vegetativas

Segunda Seleção com produtividade

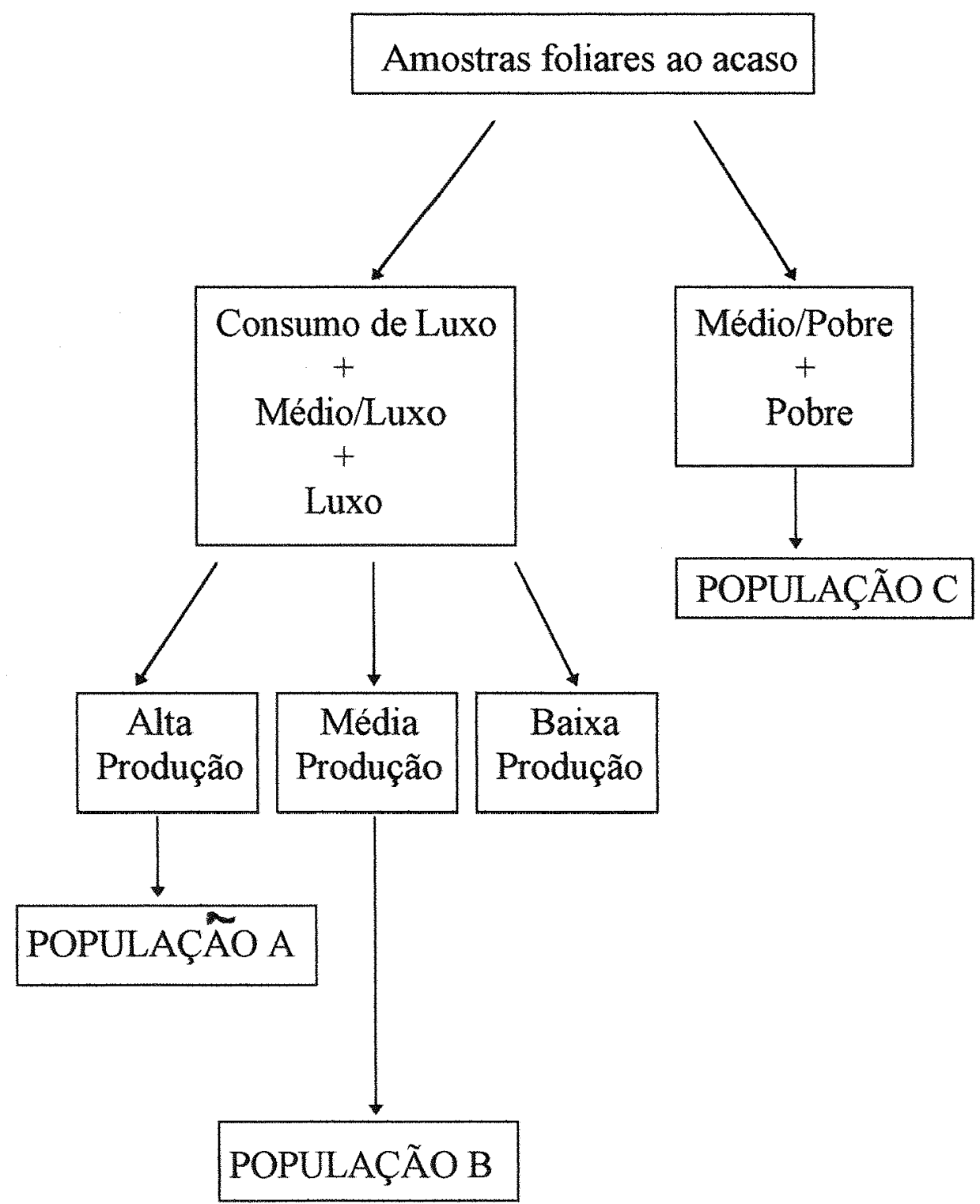


Dessa maneira, o DRIS estuda os fatores contribuintes que afetam a produção, resultando numa calibração da composição do solo e da planta em relação a produtividade. Esta calibração é feita através de índices que avaliam quanto o índice de um determinado nutriente dista do seu ótimo, e, assim, são ordenados os nutrientes segundo sua limitação para a produtividade. Esses índices também indicam o grau em que o solo ou a planta necessitam de um determinado nutriente, considerando automaticamente $\mathrm{o}$ equilibrio de nutrientes na planta (SUMNER, 1978).

MEYER (1975) trabalhando com cana-de-açucar na África do Sul observou efeito significativo da posição da folha na planta, da idade e da época de coleta das amostras e efetivo efeito varietal sobre o DRIS. Por outro lado, encontrou melhor diagnóstico da deficiência de $\mathrm{P}$ quando analisou, através das relações N/P, $\mathrm{K} / \mathrm{P}$ e dos índices de Beaufils, do que simplesmente pelo teor de $\mathrm{P}$ na matéria seca.

SUMNER \& BEAUFILS (1975), em ensaios desenvolvidos na África do Sul com cana-de-açúcar, observaram que o DRIS poderia ser aplicado independentemente da idade da cultura, da flutuação sazonal e do regime interno de umidade, já que a ordem da necessidade em nutrientes do $1^{\circ}$ ao $10^{\circ}$ mês de idade permaneceu inalterada e foi a seguinte: $\mathrm{P}>\mathrm{K}>\mathrm{N}$. No mesmo trabalho, os autores encontraram certa independência do DRIS com relação à variedade.

SUMNER (1977a) aplicou o DRIS para a cultura do trigo e observou a validade de sua interpretação independente da veriedade utilizada e da idade da planta na época da amostragem foliar. Ainda, SUMNER (1977) estudando o DRIS para a cultura do milho, apresentou conclusões onde esta técnica poderia ser aplicada em qualquer estádio de desenvolvimento e sob quaisquer condições. Mais tarde, SUMNER (1978) observou o DRIS na cultura da soja e sua independência da variedade, idade da planta na época da amostragem e posição da folha da mesma.

ZAMBELLO JR. \& ORLANDO FILHO (1979) aplicaram pela primeira vez no Brasil a metodologia do DRIS para a cultura da cana-de-açúcar e verificaram o efeito verietal, sobre os índices.

ZAMBELLO JR. \& ORLANDO FILHO (1980) concluiram que o DRIS poderia ser aplicado independente do estado de umidade em que se encontrava a cana-planta, pois esta técnica adaptou-se tanto para a cultura sob regime de irrigação como quando sob as condições nornais de precipitação.

ZAMBELLO JR. \& ORLANDO FILHO (1980 a) estudaram o DRIS em cana-de-açúcar, utilizando folhas e intenódios, e constataram que a metodologia apresentou-se bastante promissora, embora tenha sido observado que a sensibilidade da técnica reside em parte no elevado número de dados e na vasta experiência e perspicácia do indivíduo que irá executar as interpretações, principalmente na seleção da população não normal; pois é esta que proporcionará o diagrama interpretativo do balanço nutricional e dos indíces primários. 
Diversos trabalhos verificaram vantagens do DRIS sobre o nível crítico foliar e o nível crítico de solos para se fazerem diagnoses com o propósito de recomendação de adubação (ESCANO et al., 1981; JONES, 1981; JONES \& BOWEN, 1981; HANSON, 1981; JONES et al. 1986; WALWORTH \& SUMNER, 1987), com as seguintes observações: (a) para se fazer diagnose considerasse o equi librio nutricional com base em padrões nutrícionais de referência ou normas. Isto é particularmente importante em altos níveis de produção, em que o equilibrio nutricional é muitas vezes o fator mais importante e crítico na determinação da produtividade vegetal; (b) as normaìs, ou composição de referência para o equilibrio nutricional de uma determinada cultura podem ser extrapoladas para diversas regiões de país; (c) pode-se fazer diagnoses em diferentes fases de desenvolvimento vegetal independente do cultivar; (d) os nutrientes limitantes da produção, tanto por deficiência quanto por excesso, podem ser prontamente identificados e ordenados em função de sua importância na limitação da produtividade.

SCHALLER (1988) verificou a superioridade do Sistema Integrado de Diagnose e Recomendação (DRIS) para análise de folha de videiras. 
O cultivar de uva fina de mesa Itália (Piróvano) era o cultivar plantado nas propriedades amostradas para o levantamento nutrícional. Este cultivar originou-se do cruzamento entre as variedades Bicane e Moscatel de Hamburgo (SOUSA, 1969). As videiras desse cultivar são plantas muito vigorosas, de ciclo longo (mais ou menos 150 dias na região noroeste de São Paulo) e com produtividade média de 30t/ha. Os cachos têm a forma cilíndrico-cônica, grandes (400 a $800 \mathrm{~g}$ ), um tanto alongados e naturalmente muito compactos. As bagas são grandes ( 8 a $12 \mathrm{~g}$ ), de cor esverdeada a levemente amarelada quando bem maduras, ovaladas, com textura trincante e sabor neutro levemente moscatel quando bem maduras (TERRA et al., 1993).

O levantamento foi realizado em 20 propriedades da região noroeste do Estado de São Paulo, compreendendo os municípios de Jales, Palmeira D'Oeste, São Francisco e Urânia, situados a $20^{\circ} 16^{\prime}$ de latitude Sul, $50^{\circ} 33^{\prime}$ de longitude oeste e $483 \mathrm{~m}$ de altitude média. As temperaturas médias são sempre maiores que $12,5^{\circ} \mathrm{C}$ e as máximas médias raramente atingem $33^{\circ} \mathrm{C}$, com precipitação anual de $1280 \mathrm{~mm}$.

Os solos predominantes nas propriedades onde foi realizado o levantamento nutricional são solos Podzólicos Vermelho-Amarelos, anteriormente denominados Podzolizados de Lins e Marília, variação Lins e variação Marília. Esses solos, em geral, têm baixa capacidade de troca de cátions, caráter eutrófico, isto é, saturação em bases igual ou superior a $50 \%$ e, geralmente, valores de $\mathrm{pH}$ em água superiores a 5,6. Encontram-se, contudo, solos com caráter distrófico, ou seja, tanto a saturação por bases quanto a saturação por alumínio são inferiores a $50 \%$ e, em geral, valores de $\mathrm{pH}$ em água entre 5,0 e 5,6, e outros com caráter álico, isto é, com saturação em bases inferior a $50 \%$ e saturação em alumínio igual ou superior a $50 \%$ e, normalmente, apresentam valores de $\mathrm{pH}$ em água inferiores a 5,0\% (TERRA, 1993).

Para a realização do levantamento do estado nutricional da videira cultivar Itália na região noroeste do Estado de São Paulo, foram selecionadas 20 propriedades, no ano de 1991. De cada propriedade foi escolhido um talhão de vinhedo em produção com práticas culturais semelhantes, sendo essas práticas as preconizadas por TERRA (1993). Os talhões amostrados apresentavam área média de 0,35 ha, com uma média de 230 pés de videira em produção enxertadas sobre 0 porta-enxerto $420 \mathrm{~A}$, originado do cruzamento entre as espécies Vitis berlandieri e Vitis ripária, espaçadas de $5 \times 3 \mathrm{~m}$ e com idade média de 5 anos. Segundo SOUSA 
(1969), o cultivar Itália da espécie Vitis vinifera apresenta satisfatória produtividade quando enxertada sobre 42O-A.

Para a obtenção de dados preliminares necessários à região do levantamento, foi aplicado um questionário com perguntas sobre as propriedades e talhões amostrados a respeito de porta-enxerto utilizado, espaçamento, calagem, adubação e produção estimada.

De cada talhão foram coletadas amostras de solo em 20 pontos, nas entrelinhas das videiras, distantes cerca de $2 \mathrm{~m}$ das plantas, formando uma amostra composta e, com o auxílio de um trado do tipo Sondaterra ${ }^{*}$. As coletas das amostras de solo foram realizadas antes da poda, no mês de abril, e nas profundidades de $0-20$ e $20-40 \mathrm{~cm}$. As amostras foram enviadas ao Laboratório do Departamento de Ciência do Solo da Escola Superior de Agricultura "Luiz de Queiróz", da Universidade de São Paulo, onde foram submetidas à análise granulométrica e às determinações de $\mathrm{pH}$ em cloreto de cálcio, matéria orgânica, fósforo $(\mathrm{P})$ por resina, potássio $(\mathrm{K})$, cálcio $(\mathrm{Ca})$, magnésio $(\mathrm{Mg})$, acidez potencial $(\mathrm{H}+\mathrm{AI})$, capacidade de troca de cátions $(\mathrm{T})$ e saturação de bases $(\mathrm{V} \%)$. As determinações químicas das amostras de terra, para os macronutrientes, dos diferentes talhões foram realizadas segundo os métodos de análise para fins de fertilidade descritos por RAIJ (1987). Para o micronutriente boro (B) ultilizou-se o método citado por CRUZ \& FERREIRA (1984) e para os demais micronutrientes foi utilizado os métodos citados por LINDSAY \& NORWELL (1978).

Foram realizadas também análises de folhas para cada talhão amostrado, com coleta em três épocas distintas: florescimento (1 1 coleta), onde ocorre um pico de concentração da maioria dos nutrientes nos tecidos; quando as bagas estavam na fase entre ena e meia baga ( $2^{\text {a }}$ coleta) e no início da troca de cor das bagas "veraison" ( 3 a coleta), quando há maior estabilidade nos teores de nutrientes, permitindo assim maior amplitude na época da coleta (DAL BO, 1989). No levantamento, essas três épocas corresponderam aos seguintes períodos: $1^{\text {a }}$ coleta- 03/04 a 30/05/1991; 2a coleta- 17/05 a 04/07/1991 e 3a coleta- 07/06 a 09/08/1991. Coletou-se de cada talhão amostrado, em 20 plantas ao acaso, 5 folhas por planta, totalizando 100 folhas por talhão que formaram uma amostra. As folhas colhidas foram as recém-maduras de cada ramo produtivo, separando-se imediatamente seus pecíolos e limbos, formando assim amostras distintas. As amostras de limbo e pecíolo foram enviadas ao Laboratório do Departamento de Ciência do Solo da ESALQ/USP, onde após o seu devido preparo, foram submetidas às determinações de nitrogênio $(\mathrm{N})$, fósforo $(\mathrm{P})$, potássio $(\mathrm{K})$, cálcio $(\mathrm{Ca})$, magnésio $(\mathrm{Mg})$, enxofre $(\mathrm{S})$, Boro $(\mathrm{B})$, ferro $(\mathrm{Fe})$, cobre $(\mathrm{Cu})$, manganês $(\mathrm{Mn})$ e Zinco $(\mathrm{Zn})$.

\footnotetext{
"Trado do tipo sonda fabricado pela BRAVIFER-Indústria de Equipamento e Assessoria Agronômica -ME
} 
As determinações químicas realizadas nos limbos e pecíolos amostrados dos diferentes talhões seguiram os métodos descritos em MALAVOLTA et al., (1989).

Os dados da produção, para cada talhão amostrado foram obtidos através de imformações criteriosas do produtor e embasada em uma avaliação estimada da produção, realizada anteriormente à colheita.

A interpretação dos resultados de análise foliar (limbo e pecíolo) foi feita aplicando-se o método DRIS- Sistema Integrado de Diagnose e Recomendação (BEAUFILS, 1973; BATAGLIA \& DECHEN, 1986; ZAMBELLO JR. 1979 e LEITE, 1993).

Para o estabelecimento das normas (M,V,SD e CV das relações das amostras provenientes dos vinhedos de alta produtividade), necessárias ao cálculo dos índices do DRIS , separou-se os vinhedos em duas classes: 1) População A-alta produtividade (27,3 t ou mais de uva $/$ ha) e 2) População B- baixa produtividade ( menos de $27,3 \mathrm{t}$ de uva /ha), onde o valor $27,3 \mathrm{t}$ de uva /ha é a média de produção encontrada entre os vinhedos amostrados e considerada alta para a cultura da videira.

Para a população de alta produtividade ( População A), calculouse as relações, entre todos os nutrientes analisados, dois a dois, e para cada relação calculou-se a média $(\mathrm{M})$, variação $(\mathrm{V})$, desvio padrão $(\mathrm{SD})$ e coeficiente de variação (CV).

Com as normas assim estabelecidas, calculou-se os índices DRIS e os índices de balanço nutricional (IBN) de acordo com a metodologia descrita por BATAGLIA \& DECHEN (1986) desenvolvida por BEAUFILS (1973),utilizando-se as seguintes fórmulas:

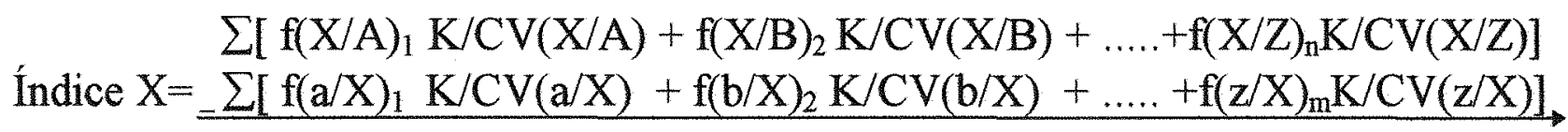
$\mathrm{n}+\mathrm{m}$

$\mathrm{IBN}=\sum[$ índice $\mathrm{X}]$ em valores absolutos

Onde

$A, B, \ldots Z$ e $a, b, \ldots z$ representam qualquer concentração de nutrientes possíveis de diagnose

CV é o coeficiente de variação da relação na população não anormal

$\mathrm{K}$ é o coeficiente de sensibilidade, de valor arbitrário $(1,10,20 \ldots)$

$\mathrm{X} / \mathrm{A}, \mathrm{X} / \mathrm{B}, \ldots \mathrm{X} / \mathrm{Z}$ são as relações dos nutrientes na amostra 


\section{RESULTADOS E DISCUSSÃO}

\subsection{Solos}

\subsubsection{Análise Granulométrica}

Considerando-se as análises granulométricas para as profundidades de $0-20 \mathrm{~cm}$ e $20-40 \mathrm{~cm}$ (Quadros 1 e 2) podemos afirmar que os solos estudados são médio arenosos a arenosos segundo a interpretação do Departamento de Ciência do Solo da Escola Superior de Agricultura "Luiz de Queiroz", da Universidade de São Paulo, sendo que $80 \%$ dos vinhedos amostrados apresentaram a camada subsuperficial $(20-40 \mathrm{~cm})$ classificada como arenosa. Essa interpretação define as classes de textura baseada no teor de argila, de modo que quando a porcentagem de argila for menor que $14 \%$ a amostra de solo é considerada arenosa; de 15 a $24 \%$, médio arenosa; de 25 a $34 \%$ médio argilosa de 35 a $39 \%$, argilosa e muito argilosa quando a porcentagem for igual ou maior que $60 \%$.

Desagregação, aeração e drenagem boas, assim como fácil subsolagem são características de solos arenosos. Por outro lado, tais solos, são em geral muito desagregados, não possuindo capacidade adequada de adsorção e de manutenção de umidade e de nutrientes. Portanto, são comumente secos, insuficientemente férteis e carentes de granulação (BRADY, 1989). Segundo este autor, apenas a adição de matéria orgânica, prática que é realizada na região de Jales, é considerada um método prático para melhorar a estrutura desses solos, onde a mesma funcionará como agente aglutinador de partículas e também aumentará a capacidade de retenção de água. 
Quadro 1. Resultados das análises granulométricas de solo para os vinhedos amostrados, profundidade de $0-20 \mathrm{~cm}$, em levantamento nutricional na região de Jales, em 1991.

\begin{tabular}{|c|c|c|c|c|c|c|c|}
\hline $\begin{array}{c}\text { Vinhedos } \\
\text { Profundidade }\end{array}$ & \multicolumn{3}{|c|}{ Areia (\%)* } & Silte & Arg. & Classe** & Produção \\
\cline { 2 - 7 } (0-20cm) & G & F & G+F & $\%$ & $\%$ & de & Textura \\
\hline JAL 01 & 08 & 69 & 77 & 08 & 15 & md.ar. & 24 \\
JAL 02 & 05 & 69 & 74 & 11 & 15 & md.ar. & 27 \\
JAL 03 & 08 & 67 & 75 & 12 & 13 & ar. & 25 \\
JAL 04 & 06 & 67 & 73 & 12 & 15 & md.ar. & 24 \\
JAL 05 & 06 & 66 & 72 & 16 & 12 & ar. & 25 \\
JAL 06 & 07 & 68 & 75 & 11 & 14 & ar. & 33 \\
JAL 07 & 13 & 62 & 75 & 09 & 16 & md.ar. & 24 \\
JAL 08 & 07 & 69 & 76 & 09 & 15 & md.ar. & 25 \\
JAL 09 & 10 & 63 & 73 & 08 & 19 & md.ar. & 26 \\
JAL 10 & 11 & 67 & 78 & 06 & 16 & md.ar. & 26 \\
JAL 11 & 10 & 71 & 81 & 05 & 14 & ar. & 26 \\
JAL 12 & 12 & 65 & 77 & 07 & 16 & md.ar. & 30 \\
JAL 13 & 07 & 72 & 79 & 10 & 11 & ar. & 36 \\
JAL 14 & 03 & 50 & 53 & 18 & 29 & md.ar. & 30 \\
JAL 15 & 05 & 68 & 73 & 15 & 12 & ar. & 31 \\
JAL 16 & 04 & 77 & 81 & 09 & 10 & ar. & 24 \\
JAL 17 & 04 & 73 & 77 & 14 & 09 & ar. & 24 \\
JAL 18 & 04 & 73 & 77 & 11 & 12 & ar. & 24 \\
JAL 19 & 03 & 66 & 69 & 16 & 15 & md.ar. & 26 \\
JAL 20 & 03 & 66 & 69 & 16 & 15 & md.ar. & 26 \\
\hline
\end{tabular}

* Areia: $\mathrm{G}=$ grossa $\mathrm{F}=$ fina

** Textura: ar.= arenosa md.ar.= média arenosa 
Quadro 2. Resultados das análises granulométricas de solo para os vinhedos amostrados, profundidade de $20-40 \mathrm{~cm}$, em levantamento nutricional na região de Jales, ano de 1991.

\begin{tabular}{|c|c|c|c|c|c|c|c|}
\hline $\begin{array}{c}\text { Vinhedos } \\
\text { Profundidad }\end{array}$ & \multicolumn{2}{|c|}{ Areia (\%) } & Silte & Arg. & Classe** & Produção \\
\cline { 2 - 8 }$(20-40 \mathrm{~cm})$ & $\mathrm{G}$ & $\mathrm{F}$ & $\mathrm{G}+\mathrm{F}$ & $\%$ & & de & \\
\hline JAL 01 & 07 & 69 & 76 & 07 & 17 & md.ar. & 24 \\
JAL 02 & 05 & 65 & 70 & 10 & 20 & md.ar. & 27 \\
JAL 03 & 06 & 63 & 69 & 12 & 19 & md.ar. & 25 \\
JAL 04 & 05 & 64 & 69 & 12 & 19 & md.ar. & 24 \\
JAL 05 & 04 & 62 & 66 & 15 & 19 & md.ar. & 25 \\
JAL 06 & 07 & 66 & 73 & 11 & 16 & md.ar. & 33 \\
JAL 07 & 13 & 60 & 73 & 07 & 20 & md.ar. & 24 \\
JAL 08 & 07 & 64 & 71 & 10 & 19 & md.ar. & 25 \\
JAL 09 & 09 & 60 & 69 & 07 & 24 & md.ar. & 26 \\
JAL 10 & 10 & 65 & 75 & 07 & 18 & md.ar. & 26 \\
JAL 11 & 10 & 69 & 79 & 06 & 15 & md.ar. & 26 \\
JAL 12 & 11 & 62 & 73 & 06 & 21 & md.ar. & 30 \\
JAL13 & 05 & 72 & 77 & 09 & 14 & ar. & 36 \\
JAL 14 & 05 & 38 & 43 & 20 & 37 & arg. & 30 \\
JAL 15 & 04 & 67 & 71 & 09 & 20 & md.ar. & 31 \\
JAL 16 & 04 & 71 & 75 & 11 & 14 & ar. & 24 \\
JAL 17 & 04 & 73 & 77 & 12 & 11 & ar. & 24 \\
JAL 18 & 03 & 61 & 64 & 13 & 23 & md.ar. & 24 \\
JAL 19 & 02 & 61 & 63 & 15 & 22 & md.ar. & 26 \\
JAL 20 & 05 & 69 & 74 & 09 & 17 & md.ar. & 36 \\
\hline
\end{tabular}

*Areia: $\mathrm{G}=$ grossa $\mathrm{F}=$ fina

** Textura: ar $=$ arenosa md.ar. $=$ média arenosa $\arg .=$ argilosa 


\subsubsection{Macronutrientes}

A interpretação dos resultados analíticos para macronutrientes no solo (Apêndices 1 e 2), apresentada através do Quadro 3 e baseada nos valores de interpretação de TRANI \& DRUGOWICH, 1989 (Tabela 1) mostra que a problemática dos vinhedos estudados quanto à situação de bases é mínima $(10 \%)$.

Quanto à acidez, o problema é maior na subsuperficie $(20-40 \mathrm{~cm})$ onde $50 \%$ dos vinhedos amostrados apresentaram acidez na faixa de média a muito alta. Este parâmetro é importante pois a videira é uma cultura exigente em calagem, a saturação de bases ideal é de $80 \%$, além de se tratar de uma cultura perene, que tende a explorar a camada subsuperficial quando a mesma estiver em condições adequadas de $\mathrm{pH}$, promovendo maior crescimento das raízes e melhor aproveitamento dos nutrientes e da água. Além disso o $\mathrm{pH}$ controla o solubilidade dos nutrientes no solo exercendo por isso, considerável influência sobre a absorção dos mesmos pelas plantas. Para o fósforo a solubilidade é máxíma com o $\mathrm{pH}$ do solo está variando de 6,0 a 7,0 .

Quando a acidez é intensa, o íon fosfato pode ser fortemente fixado por óxidos hidratados dos mesmos (MELLO et al. 1983). Com relação ao potássio o grande problema é a lixiviação a que o nutriente está sujeito em solos muito ácidos, fator que se agrava pelo fato dos solos da região estudada tenderem a arenosos e também pela prática de irrigação frequentemente utilizada para a cultura da videira na região. O problema do fósforo pode ser mais grave, em vinhedos com teores baixos do nutriente na camada subsuperficial, o que ocorreu com cerca de $25 \%$ dos vinhedos amostrados. 
Tabela 1. Interpretação para macronutrientes no solo

\begin{tabular}{|l|c|c|c|c|c|c|}
\hline \multicolumn{2}{|c|}{ Parâmetro Expressão } & \multicolumn{5}{|c|}{ Classificação } \\
\cline { 3 - 7 } & & muito baixo & baixo & médio & alto & muito alto \\
\hline Acidez & $\mathrm{pH} \mathrm{em} \mathrm{CaCl}$ & $>6,0$ & $5,6-6,0$ & $5,1-5,5$ & $4,4-5,0$ & $\leq 4,3$ \\
\hline $\begin{array}{l}\text { Matéria } \\
\text { Orgânica }\end{array}$ & $\%$ & & $<1,5$ & $1,5-2,5$ & $>2,5$ & \\
\hline Fósforo (P) & $\mu \mathrm{g} / \mathrm{cm}^{3}$ & 0,6 & $7-15$ & $16-40$ & $41-80$ & $>80$ \\
\hline Enxofre (S-S0 $\left.\mathrm{C}_{4}\right)$ & $\mu \mathrm{g} / \mathrm{cm}^{3}$ & $0-5,0$ & $5,1-10,0$ & $10,1-15,0$ & $>15$ & \\
\hline Potássio (K) & $\mathrm{meq} / 100 \mathrm{~cm}^{3}$ & $0-0,07$ & $0,08-0,15$ & $0,16-0,30$ & $0,31-0,60$ & $>0,60$ \\
\hline Cálcio(Ca) & $\mathrm{meq} / 100 \mathrm{~cm}^{3}$ & & $<2,0$ & $2,0-4,0$ & $>4,0$ & \\
\hline Magnésio (Mg) & $\mathrm{meq} / 100 \mathrm{~cm}^{3}$ & & $0-0,4$ & $0,5-0,8$ & $>0,8$ & \\
\hline Ac. Potencial & $\mathrm{meq} / 100 \mathrm{~cm}^{3}$ & & $<2,5$ & $2,5-5,0$ & $>5,0$ & \\
\hline Soma de Bases & $\mathrm{meq} / 100 \mathrm{~cm}^{3}$ & & $<2,5$ & $2,5-5,5$ & $>5,5$ & \\
\hline CTC (T) & $\mathrm{meq} / 100 \mathrm{~cm}^{3}$ & & $<5,0$ & $5,0-8,0$ & $>8,0$ & \\
\hline Saturação em Bases & $(\%)$ & $0-25$ & $26-50$ & $51-70$ & $71-90$ & $>90$ \\
\hline
\end{tabular}

Fonte: TRANI \& DRUGOWICH, 1989, compilado 
Quadro 3. Interpretação dos resultados de análise de solo para os macronutrientes, nas profundidades de $0-20 \mathrm{~cm}$ e $20-40 \mathrm{~cm}$, para os vinhedos amostrados, em um levantamento nutricional na região de Jales, ano de 1991.

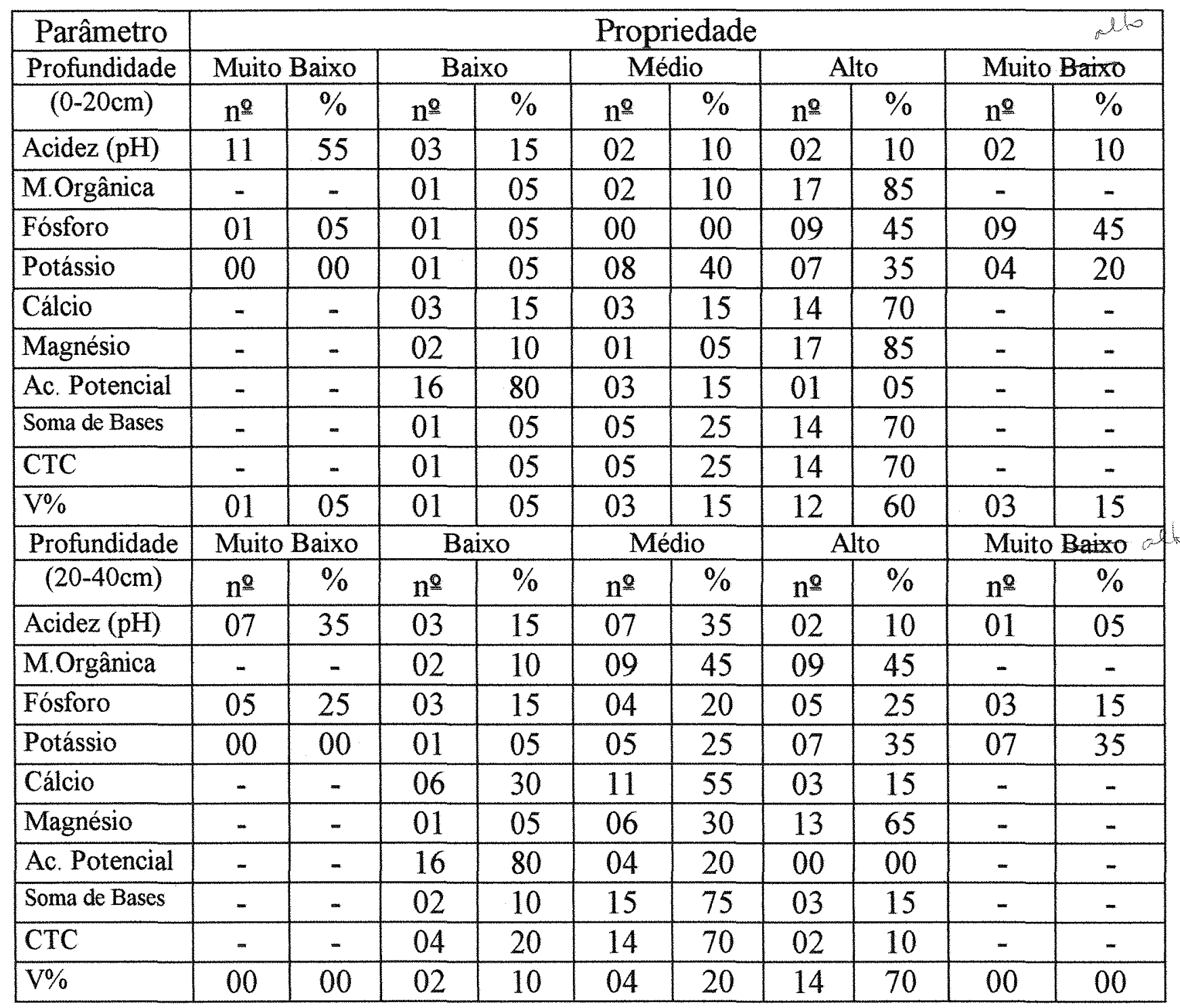




\subsubsection{Micronutrientes}

A interpretação dos resultados analíticos para micronutrientes no solo (Apêndices 1 e 2), apresentada através do Quadro 4 e baseada nos valores de interpretação de DECHEN \& CARMELLO (1985), apresentada na tabela 2, mostra que os vinhedos amostrados apresentaram pelo excesso dos micronutrientes, devido provavelmente, à presença desses elementos nos produtos químicos frequentemente utilizados na cultura da videira, como defensivos agrícolas.

Quadro 4. Interpretação dos resultados de análise de solo, para os micronutrientes, nas profundidades de $0-20 \mathrm{~cm}$ e $20-40 \mathrm{~cm}$, para os vinhedos amostrados, em um levantamento nutricional na região de Jales, ano de 1991.

\begin{tabular}{|c|c|c|c|c|c|c|c|c|}
\hline Parâmetro & \multicolumn{8}{|c|}{ Propriedade } \\
\hline Profundidade & \multicolumn{2}{|c|}{ Muito Baixo } & \multicolumn{2}{|c|}{ Baixo } & \multicolumn{2}{|c|}{ Médio } & \multicolumn{2}{|c|}{ Alto } \\
\hline$(0-20 \mathrm{~cm})$ & $\mathrm{n}^{\underline{Q}}$ & $\%$ & $n^{0}$ & $\%$ & $n^{2}$ & $\%$ & $\mathrm{n}^{2}$ & $\%$ \\
\hline Boro & 00 & 00 & 00 & 00 & 01 & 05 & 19 & 95 \\
\hline Cobre & 00 & 00 & 00 & 00 & 15 & 75 & 05 & 25 \\
\hline Ferro & 00 & 00 & 00 & 00 & 00 & 00 & 20 & 100 \\
\hline Manganês & 00 & 00 & $\overline{00}$ & 00 & 12 & 60 & 08 & 40 \\
\hline Zinco & 00 & 00 & 00 & 00 & 00 & 00 & 20 & 100 \\
\hline Profundidade & \multicolumn{2}{|c|}{ Muito Baixo } & \multicolumn{2}{|c|}{ Baixo } & \multicolumn{2}{|c|}{ Médio } & \multicolumn{2}{|c|}{ Alto } \\
\hline$(20-40 \mathrm{~cm})$ & $n^{2}$ & $\%$ & $n^{2}$ & $\%$ & $\mathrm{n}^{\mathrm{Q}}$ & $\%$ & $n^{2}$ & $\%$ \\
\hline Boro & 00 & 00 & 00 & 00 & 01 & 05 & 19 & 95 \\
\hline Cobre & 00 & 00 & 02 & 10 & 19 & 95 & 00 & 00 \\
\hline Ferro & 00 & 00 & 00 & 00 & 00 & 00 & 20 & 100 \\
\hline Manganês & 00 & 00 & 00 & 00 & 20 & 100 & 00 & 00 \\
\hline Zinco & 00 & 00 & 00 & 00 & 11 & 55 & 09 & 45 \\
\hline
\end{tabular}


Tabela 2. Interpretação para micronutrientes no solo

\begin{tabular}{|c|c|c|c|c|c|}
\hline \multirow[t]{2}{*}{ ELEMENTO } & \multicolumn{5}{|c|}{ CLASSIFICAÇÃO (ppm)* } \\
\hline & $\begin{array}{l}\text { Muito } \\
\text { Baixo }\end{array}$ & Baixo & Médio & Alto & Referência Bibliográfica \\
\hline Cobre $(\mathrm{Cu})^{*}$ & $<0,5$ & $0,5-1,5$ & $1,5-2,0$ & $>2,0$ & \multirow{4}{*}{$\begin{array}{l}\text { DECHEN,A.R.\& CARMELLO,Q.A. } \\
\text { (ESALQ, DEP.QUÍMICA,1985) }\end{array}$} \\
\hline Ferro $(\mathrm{Fe})^{*}$ & $<2,5$ & $2,5-4,5$ & $4,5-9,0$ & $>9,0$ & \\
\hline Manganês $(\mathrm{Mn})^{*}$ & $<5,0$ & $5,0-10$ & $10-130$ & $>130$ & \\
\hline Zinco $(\mathrm{Zn})^{*}$ & $<0,5$ & $0,5-1,0$ & $1,0-2,5$ & $>2,5$ & \\
\hline Boro (B) & $<0,5$ & $0,5-1,0$ & $1,0-1,5$ & $>1,5$ & DECHEN,A.R.(ESALQ, COM.VERBAL) \\
\hline
\end{tabular}

* Extração pelo D.T. P.A (Ácido Dietileno Triamino Pentacético) (Rel. Solo: Solução 1:2).

\subsection{Folhas}

A partir dos resultados das análises químicas das amostras de limbo e pecíolo dos vinhedos selecionados, correspondentes às três coletas (Apêndices 3 a 8), calculou-se a média e o coeficiente de variação para todos os nutrientes (macro e micronutrientes), para limbo e pecíolo, nas três épocas de amostragem (Quadros 5 a 10).

Quadro 5. Média e coeficiente de variação dos nutrientes no limbo para $1^{\text {a }}$ coleta (florescimento).

\begin{tabular}{|l|llllll|lllll|}
\hline Nutrientes & $\mathrm{N}$ & $\mathrm{P}$ & $\mathrm{K}$ & $\mathrm{Ca}$ & $\mathrm{Mg}$ & $\mathrm{S}$ & $\mathrm{B}$ & $\mathrm{Cu}$ & $\mathrm{Fe}$ & $\mathrm{Mn}$ & $\mathrm{Zn}$ \\
\cline { 2 - 10 } & \multicolumn{9}{|c}{$\%$} & & \multicolumn{4}{c|}{$\ln \mathrm{ppm}$} \\
Média & 4,39 & 0,60 & 2,27 & 2,56 & 0,49 & 0,75 & 3,81 & 3,55 & 6,04 & 7,32 & 5,43 \\
C.V.(\%) & 12,43 & 27,69 & 13,39 & 15,43 & 22,69 & 15,54 & 5,72 & 19,24 & 5,04 & 10,58 & 9,39 \\
\hline
\end{tabular}

Quadro 6. Média e coeficiente de variação dos nutrientes no limbo para 2 coleta (frutos entre ervilha e meia-baga).

\begin{tabular}{|l|llllll|lllll|}
\hline Nutrientes & $\mathrm{N}$ & $\mathrm{P}$ & $\mathrm{K}$ & $\mathrm{Ca}$ & $\mathrm{Mg}$ & $\mathrm{S}$ & $\mathrm{B}$ & $\mathrm{Cu}$ & $\mathrm{Fe}$ & $\mathrm{Mn}$ & $\mathrm{Zn}$ \\
\cline { 2 - 10 } & \multicolumn{9}{|c|}{$\%$} & \multicolumn{4}{c|}{$\ln \mathrm{ppm}$} \\
Média & 3,82 & 0,60 & 2,27 & 2,18 & 0,44 & 0,71 & 3,76 & 3,79 & 6,76 & 7,21 & 5,30 \\
C.V.(\%) & 9,83 & 34,74 & 15,10 & 15,01 & 19,73 & 28,57 & 4,08 & 50,61 & 12,48 & 8,46 & 12,52 \\
\hline
\end{tabular}


Quadro 7. Média e coeficiente de variação dos nutrientes no limbo para 3 coleta (inicio de maturação das bagas).

\begin{tabular}{|l|llllll|lllll|}
\hline Nutrientes & $\mathrm{N}$ & $\mathrm{P}$ & $\mathrm{K}$ & $\mathrm{Ca}$ & $\mathrm{Mg}$ & $\mathrm{S}$ & $\mathrm{B}$ & $\mathrm{Cu}$ & $\mathrm{Fe}$ & $\mathrm{Mn}$ & $\mathrm{Zn}$ \\
\cline { 2 - 10 } & \multicolumn{9}{|c|}{$\%$} & \multicolumn{5}{c|}{$\ln \mathrm{ppm}$} \\
Média & $\mathbf{3}, 14$ & 0,62 & 2,24 & 2,96 & 0,73 & 0,42 & 3,41 & 4,19 & 6,75 & 6,94 & 4,89 \\
C.V.(\%) & 10,70 & 49,27 & 83,68 & 23,03 & 59,96 & 51,84 & 8,51 & 59,34 & 17,69 & 8,26 & 2,17 \\
\hline
\end{tabular}

Quadro 8. Média e coeficiente de variação dos nutrientes no pecíolo para $1^{\mathrm{a}}$ coleta (florescimento).

\begin{tabular}{|l|llllll|lllll|}
\hline Nutrientes & $\mathrm{N}$ & $\mathrm{P}$ & $\mathrm{K}$ & $\mathrm{Ca}$ & $\mathrm{Mg}$ & $\mathrm{S}$ & $\mathrm{B}$ & $\mathrm{Cu}$ & $\mathrm{Fe}$ & $\mathrm{Mn}$ & $\mathrm{Zn}$ \\
\cline { 2 - 11 } & \multicolumn{9}{|c|}{$\%$} & & \multicolumn{4}{c|}{$\ln \mathrm{ppm}$} \\
\cline { 2 - 10 } \\
\cline { 2 - 10 } \\
C.V.(\%) & 1,53 & 0,70 & 5,86 & 1,81 & 0,48 & 0,23 & 3,67 & 2,68 & 4,15 & 6,22 & 4,23 \\
\hline
\end{tabular}

Quadro 9. Média e coeficiente de variação dos nutrientes no peciolo para 2 a coleta (frutos entre ervilha e meia-baga).

\begin{tabular}{|l|llllll|lllll|}
\hline Nutrientes & $\mathrm{N}$ & $\mathrm{P}$ & $\mathrm{K}$ & $\mathrm{Ca}$ & $\mathrm{Mg}$ & $\mathrm{S}$ & $\mathrm{B}$ & $\mathrm{Cu}$ & $\mathrm{Fe}$ & $\mathrm{Mn}$ & $\mathrm{Zn}$ \\
\cline { 2 - 10 } & \multicolumn{6}{|c|}{$\%$} & \multicolumn{5}{c|}{$\ln \mathrm{ppm}$} \\
\cline { 2 - 10 } Média & 1,23 & 0,71 & 6,03 & 1,64 & 0,52 & 0,25 & 3,76 & 3,04 & 4,19 & 6,49 & 4,22 \\
C.V.(\%) & 20,55 & 18,59 & 23,84 & 19,46 & 16,61 & 21,50 & 4,88 & 33,20 & 10,51 & 5,29 & 5,90 \\
\hline
\end{tabular}

Quadro 10. Média e coeficiente de variação dos nutrientes no pecíolo para 3 a coleta (inicio de maturação das bagas).

\begin{tabular}{|l|llllll|lllll|}
\hline Nutrientes & $\mathrm{N}$ & $\mathrm{P}$ & $\mathrm{K}$ & $\mathrm{Ca}$ & $\mathrm{Mg}$ & $\mathrm{S}$ & $\mathrm{B}$ & $\mathrm{Cu}$ & $\mathrm{Fe}$ & $\mathrm{Mn}$ & $\mathrm{Zn}$ \\
\cline { 2 - 11 } & \multicolumn{9}{|c|}{$\%$} & & \multicolumn{4}{c|}{$\ln \mathrm{ppm}$} \\
Média & 1,04 & 0,81 & 3,70 & 3,19 & 1,23 & 0,18 & 2,96 & 3,27 & 5,49 & 7,26 & 4,25 \\
C.V.(\%) & 15,12 & 36,38 & 36,45 & 18,02 & 41,14 & 48,11 & 10,94 & 52,25 & 15,04 & 10,58 & 15,75 \\
\hline
\end{tabular}

Observando-se os valores dos coeficientes de variação para os macronutrientes no limbo, considerando-se as três coletas (Quadros 5 a 7 ), 
verificou-se que todos os macronutrientes apresentaram valores abaixo de 50 , com exceção para o fósforo, potássio, magnésio e enxofre que apresentaram valores de 50 ou acima como ocorreu com o potássio ( $\cong 84 \%$ )e o magnésio ( $\cong 60 \%)$, na época de maturação das bagas. Com relação aos micronutrientes, nas três coletas os valores foram baixos para a maioria dos nutrientes, com excessão do cobre na 2 e 3 a coletas que foi de $\cong 50 \mathrm{e} \cong 60$, respectivamente. Analisando os dados de pecíolo, observase que, entre os macronutrientes, a maioria dos nutrientes apresentaram valores abaixo de 50, sendo que apenas o magnésio e o enxofre, na 3 a coleta, apresentaram valores próximos de 50 . Quanto aos micronutrientes, o cobre foi o único que apresentou valor de coeficiente de variação acima de 50 e apenas na época de início de maturação das bagas. Os demais micronutrientes, nas três épocas de coleta, apresentaram valores abaixo de $34 \%$.

Levando-se em consideração que quanto maior o coeficiente de variação, ou seja, maior a amplitude de variação dos valores dos nutrientes, que em parte pode ser explicada por fatores nutricionais, maior os dequilibrios nutricionais, que quando os valores de coeficiente de variação estão em torno de 50 ou acima esses desequilíbrios tornam-se preocupantes pois limitam seriamente a produção, é de se esperar que os vinhedos amostrados apresentem problemas nutricionais com relação aos macronutrientes na época de início de maturação das bagas, com excessão do cálcio e nitrogênio. Problemas nutricionais poderão ser esperados com relação ao micronutriente cobre, na 2 e 3 a coletas (frutos entre ervilha e meia-baga e início de maturação das bagas, respectivamente).

Para melhor entendimento a respeito de problemas nutricionais que poderão ocorrer na região estudada, elaborou-se os quadros de sequência de coeficientes de variação, apresentados abaixo.

Quadro 11. Sequência decrescente de coeficiente de variação para macro e micronutrientes no limbo, para as três coletas (florescimento, frutos entre ervilha e meia-baga e início da maturação das bagas).

\begin{tabular}{|c|c|c|}
\hline \multirow{2}{*}{ Coletas } & \multicolumn{2}{|c|}{ Sequência Decrescente } \\
\cline { 2 - 3 } & Macronutrientes & Micronutrientes \\
\hline Primeira & $\mathrm{P}>\mathrm{Mg}>\mathrm{Ca} \cong \mathrm{S}>\mathrm{K}>\mathrm{N}$ & $\mathrm{Cu}>>\mathrm{Mn}>\mathrm{Zn}>\mathrm{B}>\mathrm{Fe}$ \\
\hline Segunda & $\mathrm{P}>\mathrm{S}>\mathrm{Mg}>\mathrm{K}>\mathrm{Ca}>\mathrm{N}$ & $\mathrm{Cu}>>\mathrm{Fe} \cong \mathrm{Zn}>\mathrm{Mn}>\mathrm{B}$ \\
\hline Terceira & $\mathrm{K}>>\mathrm{Mg}>\mathrm{S}>\mathrm{P}>\mathrm{Ca}>\mathrm{N}$ & $\mathrm{Cu}>>\mathrm{Zn}>\mathrm{Fe}>\mathrm{B}>\mathrm{Mn}$ \\
\hline
\end{tabular}


Quadro 12. Sequência decrescente de coeficiente de variação para macro e micronutrientes no pecíolo, para as três coletas (florescimento, frutos entre ervilha e meia-baga e início da maturação das bagas).

\begin{tabular}{|c|c|c|}
\hline \multirow{2}{*}{ Coletas } & \multicolumn{2}{|c|}{ Sequência Decrescente } \\
\cline { 2 - 3 } & Macronutrientes & Micronutrientes \\
\hline Primeira & $\mathrm{S}>\mathrm{Mg}>\mathrm{K}>\mathrm{N}>\mathrm{P} \cong \mathrm{Ca}$ & $\mathrm{Cu}>>\mathrm{Zn}>\mathrm{Fe}>\mathrm{B}>\mathrm{Zn}$ \\
\hline Segunda & $\mathrm{K}>\mathrm{S}>\mathrm{N}>\mathrm{Ca} \cong \mathrm{P}>\mathrm{Mg}$ & $\mathrm{Cu}>>\mathrm{Fe}>\mathrm{Zn}>\mathrm{Mn}>\mathrm{B}$ \\
\hline Terceira & $\mathrm{S}>\mathrm{Mg}>\mathrm{K} \cong \mathrm{P}>\mathrm{Ca}>\mathrm{N}$ & $\mathrm{Cu}>>\mathrm{Fe} \cong \mathrm{Zn}>\mathrm{B} \cong \mathrm{Mn}$ \\
\hline
\end{tabular}

A partir dos quadros 11 e 12 observou-se que as sequências variaram bastante em função do orgão de amostragem e da época de coleta. Este fato pode ser justificado pela variação dos níveis dos nutrientes na planta durante 0 ciclo da cultura e da concentração diferenciada nos diferentes orgãos da videira. Em decorrência da análise desses dados pode-se confirmar que problemas de ordem nutricional poderão ocorrer com os macronutrientes enxofre, potássio, magnésio e fósforo e com o micronutriente cobre, devido provavelmente às aplicações de produtos químicos contendo o micronutriente.

Para o estudo mais aprofundado e mais preciso da diagnose do estado nutricional da região de Jales, utilizou-se Sistema Integrado de Diagnose e Recomendação (DRIS), que é feita para cada vinhedo individualmente. Para o estabelecimento das normas para metodologia do DRIS, foram utilizados os resultados de análise foliar dos vinhedos com produtividade acima de 27,3 tha (JAL 06, JAL 12, JAL 13, JAL 14, JAL 15 e JAL 20), que corresponde à média de produtividade entre os vinhedos amostrados e considerada adequada para a cultura da videira. Essas normas correspondem à média, ao desvio padrão e ao coeficiente de variação para os nutrientes e para a relação dos mesmos dois a dois (Quadros 13 a 18). 
Quadro 13. Média, Desvio Padrão e Coeficiente de Variação (Normas) para os nutrientes e para suas Relações Dois a Dois, considerando limbo - $1^{\mathrm{a}}$ coleta (florescimento).

\begin{tabular}{|c|c|c|c|}
\hline NUTRIENTES & MÉDIA & DESVIO PADRÃO & COEF. VARIAÇÃO $(\%)$ \\
\hline$N(\%)$ & 4,3960 & 0,5496 & 12,4332 \\
\hline $\mathrm{P}(\%)$ & 0,6040 & 0,1673 & 27,6941 \\
\hline $\mathrm{K}(\%)$ & 2,2740 & 0,3047 & 13,3984 \\
\hline $\mathrm{Ca}(\%)$ & 2,5620 & 0,3955 & 15,4371 \\
\hline $\mathrm{Mg}(\%)$ & 0,4920 & 0,1117 & 22,6970 \\
\hline $\mathrm{S}(\%)$ & 0,7540 & 0,1172 & 15,5405 \\
\hline $\mathrm{B} \ln (\mathrm{ppm})$ & 3,8128 & 0,2183 & 5,7251 \\
\hline $\mathrm{Cu} \ln (\mathrm{ppm})$ & 3,5513 & 0,6835 & 19,2466 \\
\hline $\mathrm{Fe} \ln (\mathrm{ppm})$ & 6,0468 & 0,3053 & 5,0496 \\
\hline $\mathrm{Mn} \ln (\mathrm{ppm})$ & 7,3225 & 0,7750 & 10,5838 \\
\hline $\mathrm{Zn} \ln (\mathrm{ppm})$ & 5,4320 & 0,5105 & 9,3977 \\
\hline RELAÇÃO & MÉDIA & DESVIO PADRÃO & COEF. VARIAÇÃO $(\%)$ \\
\hline $\mathrm{N} / \mathrm{P}$ & 7,6221 & 1,6335 & 21,4307 \\
\hline $\mathrm{N} / \mathrm{K}$ & 1.9358 & 0,0490 & 2,5340 \\
\hline $\mathrm{N} / \mathrm{Ca}$ & 1,7576 & 0,4064 & 23,1247 \\
\hline $\mathrm{N} / \mathrm{Mg}$ & 9,1678 & 0,5245 & 16,6289 \\
\hline $\mathrm{N} / \mathrm{S}$ & 5,9420 & 1,1425 & 19,2276 \\
\hline $\mathrm{N} / \mathrm{B}$ & 1,1511 & 0,1075 & 9,3438 \\
\hline $\mathrm{N} / \mathrm{Cu}$ & 1,2680 & 0,2398 & 18,2198 \\
\hline $\mathrm{N} / \mathrm{Fe}$ & 0,7256 & 0,0673 & 9,2766 \\
\hline N/Mn & 0,6098 & 0,1271 & 20,8371 \\
\hline $\mathrm{N} / \mathrm{Zn}$ & 0,8191 & 0,1569 & 9,1583 \\
\hline $\mathrm{P} / \mathrm{N}$ & 0,1353 & 0,0242 & 17,8967 \\
\hline $\mathrm{P} / \mathrm{K}$ & 0,2613 & 0,0436 & 16,7001 \\
\hline $\mathrm{P} / \mathrm{Ca}$ & 0,2443 & 0,0913 & 37,4104 \\
\hline $\mathrm{P} / \mathrm{Mg}$ & 1,2458 & 0,3295 & 26,4474 \\
\hline
\end{tabular}


continuação...

\begin{tabular}{|c|c|c|c|}
\hline RELAČ̃̃O & MÉDIA & DESVIO PADRÃO & COEF. VARIAÇÃO $(\%)$ \\
\hline $\mathrm{P} / \mathrm{S}$ & 0,8240 & $\begin{array}{r}0,2769 \\
\end{array}$ & 33,6109 \\
\hline $\mathrm{P} / \mathrm{B}$ & 0,1574 & 0,0391 & 24,8399 \\
\hline $\mathrm{P} / \mathrm{Cu}$ & 0,1717 & 0,0480 & 27,9760 \\
\hline $\mathrm{P} / \mathrm{Fe}$ & 0,0990 & 0,0240 & 24,1816 \\
\hline $\mathrm{P} / \mathrm{Mn}$ & 0,0846 & 0,0297 & 35,1478 \\
\hline $\mathrm{P} / \mathrm{Zn}$ & 0,1135 & 0,0381 & 33,5541 \\
\hline $\mathrm{K} / \mathrm{N}$ & 0,5168 & 0,0132 & 2,5464 \\
\hline $\mathrm{K} / \mathrm{P}$ & 0,9282 & 0,7668 & 19,5218 \\
\hline $\mathrm{K} / \mathrm{Ca}$ & 0,9092 & 0,2123 & 23,3558 \\
\hline $\mathrm{K} / \mathrm{Mg}$ & 4,7515 & 0,8953 & 18,8431 \\
\hline $\mathrm{K} / \mathrm{S}$ & 3,0812 & 0,6531 & 21,1967 \\
\hline $\mathrm{K} / \mathrm{B}$ & 0,5950 & 0,0572 & 9,6151 \\
\hline $\mathrm{K} / \mathrm{Cu}$ & 0,6550 & 0,1261 & 19,2501 \\
\hline $\mathrm{K} / \mathrm{Fe}$ & 0,3751 & 0,0366 & 9,7692 \\
\hline $\mathrm{K} / \mathrm{Mn}$ & 0,3161 & 0,0715 & 22,6189 \\
\hline $\mathrm{K} / \mathrm{Zn}$ & 0,4245 & 0,0891 & 20,9820 \\
\hline $\mathrm{Ca} / \mathrm{N}$ & 0,5922 & 0,1287 & 21,7284 \\
\hline $\mathrm{Ca} / \mathrm{P}$ & 4,6615 & 2,0378 & 43,7144 \\
\hline $\mathrm{Ca} / \mathrm{K}$ & 1,1481 & 0,2651 & 23,0880 \\
\hline $\mathrm{Ca} / \mathrm{Mg}$ & 5,4324 & 1,4196 & 26,1327 \\
\hline $\mathrm{Ca} / \mathrm{S}$ & 5,4311 & 0,5484 & 15,9826 \\
\hline $\mathrm{Ca} / \mathrm{B}$ & 0,6724 & 0,1012 & 15,0534 \\
\hline $\mathrm{Ca} / \mathrm{Cu}$ & 0,7557 & 0,2354 & 31,1548 \\
\hline $\mathrm{Ca} / \mathrm{Fe}$ & 0,4260 & 0,0785 & 18,4191 \\
\hline $\mathrm{Ca} / \mathrm{Mn}$ & 0,3534 & 0,0726 & 20,5534 \\
\hline $\mathrm{Ca} / \mathrm{Zn}$ & 0,4755 & 0,0928 & 19,5081 \\
\hline $\mathrm{Mg} / \mathrm{N}$ & 0,1115 & 0,0182 & 16,3329 \\
\hline $\mathrm{Mg} / \mathrm{P}$ & 0,8530 & 0,2400 & 28,1345 \\
\hline $\mathrm{Mg} / \mathrm{K}$ & 0,2164 & 0,0395 & 18,2551 \\
\hline $\mathrm{Mg} / \mathrm{Ca}$ & 0,1967 & 0,0613 & 31,1491 \\
\hline $\mathrm{Mg} / \mathrm{S}$ & 0,6534 & 0,1175 & 17,9804 \\
\hline $\mathrm{Mg} / \mathrm{B}$ & 0,1291 & 0,0291 & 22,5424 \\
\hline $\mathrm{Mg} / \mathrm{Cu}$ & 0,1425 & 0,0371 & 25,9924 \\
\hline $\mathrm{Mg} / \mathrm{Fe}$ & 0,0814 & 0,0180 & 22,1021 \\
\hline $\mathrm{Mg} / \mathrm{Mn}$ & 0,0676 & 0,0155 & 22,9025 \\
\hline
\end{tabular}


continuação...

\begin{tabular}{|c|c|c|c|}
\hline RELAÇÃO & MÉDIA & DESVIO PADRÃO & COEF. VARIAÇÃO $(\%)$ \\
\hline $\mathrm{Mg} / \mathrm{Zn}$ & 0,0908 & 0,0198 & 21,8072 \\
\hline $\mathrm{S} / \mathrm{N}$ & 0,1739 & 0,0363 & 20,8815 \\
\hline $\mathrm{S} / \mathrm{P}$ & 1,3676 & 0,5863 & 42,8761 \\
\hline $\mathrm{S} / \mathrm{K}$ & 0,3378 & 0,0781 & 23,1265 \\
\hline $\mathrm{S} / \mathrm{Ca}$ & 0,2975 & 0,0472 & 15,8863 \\
\hline $\mathrm{S} / \mathrm{Mg}$ & 1,5706 & 0,2833 & 18,0400 \\
\hline $\mathrm{S} / \mathrm{B}$ & 0,1986 & 0,0353 & 17,7590 \\
\hline $\mathrm{S} / \mathrm{Cu}$ & 0,2211 & 0,0623 & 28,1919 \\
\hline $\mathrm{S} / \mathrm{Fe}$ & 0,1254 & 0,0240 & 19,0936 \\
\hline $\mathrm{S} / \mathrm{Mn}$ & 0,1030 & 0,0115 & 11,1313 \\
\hline $\mathrm{S} / \mathrm{Zn}$ & 0,1387 & 0,0150 & 10,8416 \\
\hline $\mathrm{B} / \mathrm{N}$ & 0,8749 & 0,0821 & 9,3808 \\
\hline $\mathrm{B} / \mathrm{P}$ & 6,7531 & 2,0567 & 30,4550 \\
\hline $\mathrm{B} / \mathrm{K}$ & 1,6939 & 0,1706 & 10,0723 \\
\hline $\mathrm{B} / \mathrm{Ca}$ & 1,5161 & 0,2401 & 15,8389 \\
\hline $\mathrm{B} / \mathrm{Mg}$ & 8,0660 & 1,7875 & 22,1612 \\
\hline $\mathrm{B} / \mathrm{S}$ & 5,1624 & 0,8971 & 17,3771 \\
\hline $\mathrm{B} / \mathrm{Cu}$ & 1,1050 & 0,2127 & 19,2477 \\
\hline $\mathrm{B} / \mathrm{Fe}$ & 0,6309 & 0,0282 & 4,4665 \\
\hline $\mathrm{B} / \mathrm{Mn}$ & 0,5280 & 0,0891 & 16,8714 \\
\hline $\mathrm{B} / \mathrm{Zn}$ & 0,7099 & 0,1092 & 15,3835 \\
\hline $\mathrm{Cu} / \mathrm{N}$ & 0,8158 & 0,1825 & 22,3700 \\
\hline $\mathrm{Cu} / \mathrm{P}$ & 6,1989 & 1,7053 & 27,5094 \\
\hline $\mathrm{Cu} / \mathrm{K}$ & 1,5772 & 0,3351 & 21,2486 \\
\hline $\mathrm{Cu} / \mathrm{Ca}$ & 1,4419 & 0,4810 & 33,3540 \\
\hline $\mathrm{Cu} / \mathrm{Mg}$ & 7,6014 & 2,8507 & 37,5029 \\
\hline $\mathrm{Cu} / \mathrm{S}$ & 4,8759 & 1,6077 & 32,9731 \\
\hline $\mathrm{Cu} / \mathrm{B}$ & 0,9342 & 0,1913 & 20,4780 \\
\hline $\mathrm{Cu} / \mathrm{Fe}$ & 0,5854 & 0,0959 & 16,3838 \\
\hline $\mathrm{Cu} / \mathrm{Mn}$ & 0,4905 & 0,1108 & 22,5977 \\
\hline $\mathrm{Cu} / \mathrm{Zn}$ & 0,6606 & 0,1514 & 22,9193 \\
\hline $\mathrm{Fe} / \mathrm{N}$ & 1,3879 & 0,1330 & 9,5804 \\
\hline $\mathrm{Fe} / \mathrm{P}$ & 10,6881 & 9,7175 & 29,1630 \\
\hline $\mathrm{Fe} / \mathrm{K}$ & 2,6871 & 0,2699 & 10,0450 \\
\hline $\mathrm{Fe} / \mathrm{Ca}$ & 2,4178 & 0,4783 & 19,7810 \\
\hline
\end{tabular}


continuação...

\begin{tabular}{|l|r|r|r|}
\hline \multicolumn{1}{|c|}{ RELAÇÃO } & MÉDIA & DESVIO PADRÃO & COEF. VARIAČÃO (\%) \\
\hline $\mathrm{Fe} / \mathrm{Mg}$ & 12,8072 & 2,9832 & 23,2935 \\
\hline $\mathrm{Fe} / \mathrm{S}$ & 8,2056 & 1,5420 & 18,7917 \\
\hline $\mathrm{Fe} / \mathrm{B}$ & 1,5875 & 0,0708 & 4,4609 \\
\hline $\mathrm{Fe} / \mathrm{Cu}$ & 1,7429 & 0,2676 & 15,3554 \\
\hline $\mathrm{Fe} / \mathrm{Mn}$ & 0,8363 & 0,1264 & 15,1128 \\
\hline $\mathrm{Fe} / \mathrm{Zn}$ & 1,1247 & 0,1555 & 13,8256 \\
\hline $\mathrm{Mn} / \mathrm{N}$ & 1,6979 & 0,3531 & 20,7988 \\
\hline $\mathrm{Mn} / \mathrm{P}$ & 13,3618 & 5,7655 & 43,1494 \\
\hline $\mathrm{Mn} / \mathrm{K}$ & 3,2962 & 0,7457 & 22,6234 \\
\hline $\mathrm{Mn} / \mathrm{Ca}$ & 2,9149 & 0,5277 & 18,1032 \\
\hline $\mathrm{Mn} / \mathrm{Mg}$ & 15,4931 & 3,8178 & 24,6419 \\
\hline $\mathrm{Mn} / \mathrm{S}$ & 9,8126 & 1,1634 & 11,8561 \\
\hline $\mathrm{Mn} / \mathrm{B}$ & 1,9329 & 0,2910 & 15,0536 \\
\hline $\mathrm{Mn} / \mathrm{Cu}$ & 2,1286 & 0,5072 & 23,8294 \\
\hline $\mathrm{Mn} / \mathrm{Fe}$ & 1,2176 & 0,1825 & 14,9910 \\
\hline $\mathrm{Mn} / \mathrm{Zn}$ & 1,3469 & 0,0290 & 2,1500 \\
\hline $\mathrm{Zn} / \mathrm{N}$ & 1,2581 & 0,2475 & 19,6739 \\
\hline $\mathrm{Zn} / \mathrm{P}$ & 9,8897 & 4,2031 & 42,4996 \\
\hline $\mathrm{Zn} / \mathrm{K}$ & 2,4422 & 0,5270 & 21,5802 \\
\hline $\mathrm{Zn} / \mathrm{Ca}$ & 2,1635 & 0,2936 & 18,1476 \\
\hline $\mathrm{Zn} / \mathrm{Mg}$ & 11,4797 & 2,6981 & 23,5036 \\
\hline $\mathrm{Zn} / \mathrm{S}$ & 7,2829 & 0,8132 & 11,1655 \\
\hline $\mathrm{Zn} / \mathrm{B}$ & 1,4332 & 0,2000 & 13,9566 \\
\hline $\mathrm{Zn} / \mathrm{Cu}$ & 1,5801 & 0,3711 & 23,4820 \\
\hline $\mathrm{Zn} / \mathrm{Fe}$ & 0,9029 & 0,1256 & 13,9039 \\
\hline $\mathrm{Zn} / \mathrm{Mn}$ & 0,7427 & 0,0160 & 2,1560 \\
\hline & & & \\
\hline & & & \\
\hline
\end{tabular}


Quadro 14. Média, Desvio Padrão e Coeficiente de Variação (Normas) para os nutrientes e para suas Relações Dois a Dois, considerando limbo - 2 coleta (fruto entre ervilha e meia-baga).

\begin{tabular}{|c|c|c|c|}
\hline NUTRIENTES & MÉDIA & DESVIO PADRÃO & COEF. VARIAÇÃO (\%) \\
\hline $\mathrm{N}(\%)$ & 3,8280 & 0,3766 & 9,8378 \\
\hline $\mathrm{P}(\%)$ & 0,6080 & 0,2112 & 34,7425 \\
\hline $\mathrm{K}(\%)$ & 2,2760 & 0,3437 & 15,1011 \\
\hline $\mathrm{Ca}(\%)$ & 2,1800 & 0,3274 & 15,0190 \\
\hline $\operatorname{Mg}(\%)$ & 0,4440 & 0,0876 & 19,7378 \\
\hline$S(\%)$ & 0,7140 & 0,2040 & 28,5762 \\
\hline $\mathrm{B} \ln (\mathrm{ppm})$ & 3,7611 & 0,1536 & 4,0831 \\
\hline $\mathrm{Cu} \ln (\mathrm{ppm})$ & 3,7915 & 1,9191 & 50,6160 \\
\hline $\mathrm{Fe} \ln (\mathrm{ppm})$ & 6,7605 & 0,8442 & 12,4874 \\
\hline $\mathrm{Mn} \ln (\mathrm{ppm})$ & 7,2150 & 0,6105 & 8,4613 \\
\hline $\mathrm{Zn} \ln (\mathrm{ppm})$ & 5,3028 & 0,6589 & 12,4259 \\
\hline RELAÇÃO & MÉDIA & DESVIO PADRÃO & COEF. VARIAÇÃO (\%) \\
\hline $\mathrm{N} / \mathrm{P}$ & 7,0663 & 2,9440 & 41,6624 \\
\hline $\mathrm{N} / \mathrm{K}$ & 1,7006 & 0,2017 & 11,8633 \\
\hline $\mathrm{N} / \mathrm{Ca}$ & 1,7744 & 0,1923 & 10,8373 \\
\hline $\mathrm{N} / \mathrm{Mg}$ & 8,9234 & 2,0100 & 22,5246 \\
\hline $\mathrm{N} / \mathrm{S}$ & 5,7642 & 1,8227 & 31,6213 \\
\hline $\mathrm{N} / \mathrm{B}$ & 1,0204 & 0,0147 & 11,8977 \\
\hline $\mathrm{N} / \mathrm{Cu}$ & 1,1887 & 0,4924 & 41,4282 \\
\hline $\mathrm{N} / \mathrm{Fe}$ & 0,5798 & 0,1357 & 23,4131 \\
\hline $\mathrm{N} / \mathrm{Mn}$ & 0,5334 & 0,0665 & 12,4609 \\
\hline $\mathrm{N} / \mathrm{Zn}$ & 0,7335 & 0,1380 & 18,8111 \\
\hline $\mathrm{P} / \mathrm{N}$ & 0,1626 & 0,0672 & 41,3509 \\
\hline $\mathrm{P} / \mathrm{K}$ & 0,2719 & 0,0968 & 35,6134 \\
\hline $\mathrm{P} / \mathrm{Ca}$ & 0,2945 & 0,1496 & 50,8021 \\
\hline $\mathrm{P} / \mathrm{Mg}$ & 1,3971 & 0,5053 & 36,1678 \\
\hline $\mathrm{P} / \mathrm{S}$ & 0,9437 & 0,4768 & 50,5261 \\
\hline $\mathrm{P} / \mathrm{B}$ & 0,1605 & 0,0509 & 31,7271 \\
\hline $\mathrm{P} / \mathrm{Cu}$ & 0,1846 & 0,0801 & 43,3900 \\
\hline $\mathrm{P} / \mathrm{Fe}$ & 0,0896 & 0,0272 & 30,3747 \\
\hline
\end{tabular}


continuação...

\begin{tabular}{|c|c|c|c|}
\hline RELAÇÃO & MÉDIA & DESVIO PADRÃO & COEF. VARIAÇÃO (\%) \\
\hline $\mathrm{P} / \mathrm{Mn}$ & 0,0857 & 0,0327 & 38,1226 \\
\hline $\mathrm{P} / \mathrm{Zn}$ & 0,1171 & 0,0446 & 38,1288 \\
\hline $\mathrm{K} / \mathrm{N}$ & 0,5940 & 0,0634 & 10,6704 \\
\hline $\mathrm{K} / \mathrm{P}$ & 4,1627 & 1,7977 & 43,1867 \\
\hline $\mathrm{K} / \mathrm{Ca}$ & 1,0631 & 0,2181 & 20,5174 \\
\hline $\mathrm{K} / \mathrm{Mg}$ & 5,3147 & 1,3675 & 25,7302 \\
\hline $\mathrm{K} / \mathrm{S}$ & 3,4517 & 1,1808 & 34,2082 \\
\hline $\mathrm{K} / \mathrm{B}$ & 0,6052 & 0,0910 & 15,0409 \\
\hline $\mathrm{K} / \mathrm{Cu}$ & 0,7202 & 0,3194 & 44,3409 \\
\hline $\mathrm{K} / \mathrm{Fe}$ & 0,3455 & 0,0937 & 27.1136 \\
\hline $\mathrm{K} / \mathrm{Mn}$ & 0,3181 & 0,0582 & 18,2872 \\
\hline $\mathrm{K} / \mathrm{Zn}$ & 0,4388 & 0,1057 & 24,0749 \\
\hline $\mathrm{Ca} / \mathrm{N}$ & 0,5689 & 0,0621 & 10,9168 \\
\hline $\mathrm{Ca} / \mathrm{P}$ & 4,0579 & 1,7244 & 42,4952 \\
\hline $\mathrm{Ca} / \mathrm{K}$ & 0,9769 & 0,2250 & 23,0389 \\
\hline $\mathrm{Ca} / \mathrm{Mg}$ & 5,0818 & 1,2195 & 23,9967 \\
\hline $\mathrm{Ca} / \mathrm{S}$ & 3,2723 & 1,0794 & 32,9862 \\
\hline $\mathrm{Ca} / \mathrm{B}$ & 0,5825 & 0,1051 & 18,0412 \\
\hline $\mathrm{Ca} / \mathrm{Cu}$ & 0,6681 & 0,2787 & 41,6881 \\
\hline $\mathrm{Ca} / \mathrm{Fe}$ & 0,3304 & 0,0859 & 25,9888 \\
\hline $\mathrm{Ca} / \mathrm{Mn}$ & 0,3031 & 0,0466 & 15,3889 \\
\hline $\mathrm{Ca} / \mathrm{Zn}$ & 0,4161 & 0,0848 & 20,3784 \\
\hline $\mathrm{Mg} / \mathrm{N}$ & 0,1173 & 0,0292 & 24,9299 \\
\hline $\mathrm{Mg} / \mathrm{P}$ & 0,7968 & 0,2867 & 35,9862 \\
\hline $\mathrm{Mg} / \mathrm{K}$ & 0,2002 & 0,0588 & 29,3758 \\
\hline $\mathrm{Mg} / \mathrm{Ca}$ & 0,2092 & 0,0655 & 31,3032 \\
\hline $\mathrm{Mg} / \mathrm{S}$ & 0,6438 & 0,1205 & 18,7180 \\
\hline $\mathrm{Mg} / \mathrm{B}$ & 0,1184 & 0,0248 & 20,9025 \\
\hline $\mathrm{Mg} / \mathrm{Cu}$ & 0,1308 & 0,0396 & 30,2565 \\
\hline $\mathrm{Mg} / \mathrm{Fe}$ & 0,0661 & 0,0124 & 18,7407 \\
\hline $\mathrm{Mg} / \mathrm{Mn}$ & 0,0613 & 0,0099 & 16,0800 \\
\hline $\mathrm{Mg} / \mathrm{Zn}$ & 0,0839 & 0,0148 & 17,6183 \\
\hline $\mathrm{S} / \mathrm{N}$ & 0,1880 & 0,0584 & 31,0699 \\
\hline $\mathrm{S} / \mathrm{P}$ & 1,3474 & 0,7379 & 54,7651 \\
\hline $\mathrm{S} / \mathrm{K}$ & 0,3245 & 0,1329 & 40,9435 \\
\hline
\end{tabular}


continuação...

\begin{tabular}{|c|c|c|c|}
\hline RELAÇÃO & MÉDIA & DESVIO PADRÃO & COEF. VARIAÇÃO (\%) \\
\hline $\mathrm{S} / \mathrm{Ca}$ & 0,3324 & 0,1026 & 30,8796 \\
\hline $\mathrm{S} / \mathrm{Mg}$ & 1,6015 & 0,3218 & 20,0940 \\
\hline $\mathrm{S} / \mathrm{B}$ & 0,1915 & 0,0608 & 31,7330 \\
\hline $\mathrm{S} / \mathrm{Cu}$ & 0,2060 & 0,0679 & 32,9745 \\
\hline $\mathrm{S} / \mathrm{Fe}$ & 0,1064 & 0,0294 & 27,5930 \\
\hline $\mathrm{S} / \mathrm{Mn}$ & 0,0976 & 0,0205 & 21,0279 \\
\hline $\mathrm{S} / \mathrm{Zn}$ & 0,1332 & 0,0266 & 19,9890 \\
\hline $\mathrm{B} / \mathrm{N}$ & 0,9913 & 0,1190 & 12,0032 \\
\hline $\mathrm{B} / \mathrm{P}$ & 6,7828 & 2,2637 & 33,3642 \\
\hline $\mathrm{B} / \mathrm{K}$ & 1,6825 & 0,2524 & 15,0046 \\
\hline $\mathrm{B} / \mathrm{Ca}$ & 1,7663 & 0,3458 & 19,5761 \\
\hline $\mathrm{B} / \mathrm{Mg}$ & 8,7753 & 2,0127 & 22,9361 \\
\hline $\mathrm{B} / \mathrm{S}$ & 5,7203 & 2,0381 & 35,6288 \\
\hline $\mathrm{B} / \mathrm{Cu}$ & 1,1532 & 0,4055 & 35,1664 \\
\hline $\mathrm{B} / \mathrm{Fe}$ & 0,5631 & 0,0715 & 12,6953 \\
\hline $\mathrm{B} / \mathrm{Mn}$ & 0,5255 & 0,0634 & 12,0665 \\
\hline $\mathrm{B} / \mathrm{Zn}$ & 0,7191 & 0,1010 & 14,0448 \\
\hline $\mathrm{Cu} / \mathrm{N}$ & 1,0144 & 0,5548 & 54,6953 \\
\hline $\mathrm{Cu} / \mathrm{P}$ & 6,9894 & 4,7460 & 67,9033 \\
\hline $\mathrm{Cu} / \mathrm{K}$ & 1,7984 & 1,2461 & 69,2880 \\
\hline $\mathrm{Cu} / \mathrm{Ca}$ & 1,7573 & 0,8135 & 46,2961 \\
\hline $\mathrm{Cu} / \mathrm{Mg}$ & 8,4221 & 3,2899 & 39,0627 \\
\hline $\mathrm{Cu} / \mathrm{S}$ & 5,2883 & 1,6863 & 31,8863 \\
\hline $\mathrm{Cu} / \mathrm{B}$ & 1,0200 & 0,5594 & 54,8500 \\
\hline $\mathrm{Cu} / \mathrm{Fe}$ & 0,5518 & 0,2406 & 43,6012 \\
\hline $\mathrm{Cu} / \mathrm{Mn}$ & 0,5160 & 0,2188 & 42,4031 \\
\hline $\mathrm{Cu} / \mathrm{Zn}$ & 0,6928 & 0,2510 & 36,2340 \\
\hline $\mathrm{Fe} / \mathrm{N}$ & 1,7961 & 0,3823 & 21,2821 \\
\hline $\mathrm{Fe} / \mathrm{P}$ & 12,0985 & 3,9107 & 32,3239 \\
\hline $\mathrm{Fe} / \mathrm{K}$ & 3,0643 & 0,7939 & 25,9091 \\
\hline $\mathrm{Fe} / \mathrm{Ca}$ & 3,1974 & 0,8411 & 26,3062 \\
\hline $\mathrm{Fe} / \mathrm{Mg}$ & 15,6699 & 3,6841 & 23,5108 \\
\hline $\mathrm{Fe} / \mathrm{S}$ & 10,1945 & 3,7070 & 36,3631 \\
\hline $\mathrm{Fe} / \mathrm{B}$ & 1,7978 & 0,2180 & 12,1233 \\
\hline $\mathrm{Fe} / \mathrm{Cu}$ & 2,0121 & 0,5804 & 28,8463 \\
\hline
\end{tabular}


continuação...

\begin{tabular}{|l|r|r|r|}
\hline \multicolumn{1}{|c|}{ RELAÇÃO } & MÉDIA & DESVIO PADRÃO & COEF. VARIAÇÃO (\%) \\
\hline $\mathrm{Fe} / \mathrm{Mn}$ & 0,9420 & 0,1425 & 15,1240 \\
\hline $\mathrm{Fe} / \mathrm{Zn}$ & 1,2811 & 0,1511 & 11,7961 \\
\hline $\mathrm{Mn} / \mathrm{N}$ & 1,8982 & 0,2345 & 12,3525 \\
\hline $\mathrm{Mn} / \mathrm{P}$ & 13,2993 & 5,4935 & 1,3068 \\
\hline $\mathrm{Mn} / \mathrm{K}$ & 3,2469 & 0,7167 & 2,0736 \\
\hline $\mathrm{Mn} / \mathrm{Ca}$ & 3,3656 & 0,5449 & 6,1910 \\
\hline $\mathrm{Mn} / \mathrm{Mg}$ & 16,6274 & 2,5519 & 5,3478 \\
\hline $\mathrm{Mn} / \mathrm{S}$ & 10,6629 & 2,5163 & 3,5989 \\
\hline $\mathrm{Mn} / \mathrm{B}$ & 1,9254 & 0,2345 & 2,1803 \\
\hline $\mathrm{Mn} / \mathrm{Cu}$ & 2,1680 & 0,7030 & 2,2453 \\
\hline $\mathrm{Mn} / \mathrm{Fe}$ & 1,0805 & 0,1569 & 4,5237 \\
\hline $\mathrm{Mn} / \mathrm{Zn}$ & 1,3675 & 0,0966 & 7,0652 \\
\hline $\mathrm{Zn} / \mathrm{N}$ & 1,4010 & 0,2528 & 8,0443 \\
\hline $\mathrm{Zn} / \mathrm{P}$ & 9,7587 & 4,0589 & 1,5922 \\
\hline $\mathrm{Zn} / \mathrm{K}$ & 2,4069 & 0,6833 & 8,3891 \\
\hline $\mathrm{Zn} / \mathrm{Ca}$ & 2,4780 & 0,4671 & 8,8518 \\
\hline $\mathrm{Zn} / \mathrm{Mg}$ & 12,2142 & 1,9909 & 5,4434 \\
\hline $\mathrm{Zn} / \mathrm{S}$ & 7,8248 & 1,9909 & 5,4434 \\
\hline $\mathrm{Zn} / \mathrm{B}$ & 1,4156 & 0,2239 & 5,8162 \\
\hline $\mathrm{Zn} / \mathrm{Cu}$ & 1,5674 & 0,4378 & 7,9305 \\
\hline $\mathrm{Zn} / \mathrm{Fe}$ & 0,7891 & 0,0901 & 1,4169 \\
\hline $\mathrm{Zn} / \mathrm{Mn}$ & 0,7342 & 0,0511 & 6,9588 \\
\hline & & & \\
\hline
\end{tabular}


Quadro 15. Média, Desvio Padrão e Coeficiente de Variação (Normas) para os nutrientes e para suas Relações Dois a Dois, considerando limbo - 3 a coleta (inicio de maturação das bagas).

\begin{tabular}{|c|c|c|c|}
\hline NUTRIENTES & MÉDIA & DESVIO PADRÃO & COEF. VARIAÇÃO (\%) \\
\hline $\mathrm{N}(\%)$ & 3,1460 & 0,3369 & 10,7078 \\
\hline $\mathrm{P}(\%)$ & 0,6200 & 0,3055 & 49,2794 \\
\hline $\mathrm{K}(\%)$ & 2,2420 & 1,8762 & 83,6835 \\
\hline $\mathrm{Ca}(\%)$ & 2,9680 & 0,6838 & 20,0388 \\
\hline $\mathrm{Mg}(\%)$ & 0,7300 & 0,4378 & 59,9697 \\
\hline$S(\%)$ & 0,4220 & 0,2188 & 51,8465 \\
\hline $\mathrm{B} \ln (\mathrm{ppm})$ & 3,4126 & 0,2907 & 8,5194 \\
\hline $\mathrm{Cu} \ln (\mathrm{ppm})$ & 4,1921 & 2,4878 & 59,3444 \\
\hline Fe $\ln (\mathrm{ppm})$ & 6,7567 & 1,1958 & 17,6974 \\
\hline $\mathrm{Mn} \ln (\mathrm{ppm})$ & 6,9442 & 0,5754 & 8,2862 \\
\hline $\mathrm{Zn} \ln (\mathrm{ppm})$ & 4,8926 & 1,0851 & 22,1789 \\
\hline RELAÇÃO & MÉDIA & DESVIO PADRÃO & COEF. VARIAÇÃO $(\%)$ \\
\hline $\mathrm{N} / \mathrm{P}$ & 6,0712 & 2,6541 & 43,7158 \\
\hline $\mathrm{N} / \mathrm{K}$ & 1,9013 & 0,8031 & 42,2391 \\
\hline $\mathrm{N} / \mathrm{Ca}$ & 1,1261 & 0,3749 & 33,2973 \\
\hline $\mathrm{N} / \mathrm{Mg}$ & 5,2353 & 2,1780 & 41,6021 \\
\hline $\mathrm{N} / \mathrm{S}$ & 10,7837 & 8,8490 & 82,0587 \\
\hline $\mathrm{N} / \mathrm{B}$ & 0,9225 & 0,0716 & 7,7587 \\
\hline $\mathrm{N} / \mathrm{Cu}$ & 1,0568 & 0,7042 & 66,6385 \\
\hline $\mathrm{N} / \mathrm{Fe}$ & 0,4846 & 0,1413 & 29,1496 \\
\hline $\mathrm{N} / \mathrm{Mn}$ & 0,4554 & 0,0599 & 13,1442 \\
\hline $\mathrm{N} / \mathrm{Zn}$ & 0,6704 & 0,1666 & 24,8509 \\
\hline $\mathrm{P} / \mathrm{N}$ & 0,1913 & 0,0801 & 41,8828 \\
\hline $\mathrm{P} / \mathrm{K}$ & 0,3370 & 0,1735 & 51,4868 \\
\hline $\mathrm{P} / \mathrm{Ca}$ & 0,2361 & 0,1701 & 72,0303 \\
\hline $\mathrm{P} / \mathrm{Mg}$ & 0,9758 & 0,5893 & 60,3870 \\
\hline $\mathrm{P} / \mathrm{S}$ & 2,5719 & 2,9793 & 115,8424 \\
\hline $\mathrm{P} / \mathrm{B}$ & 0,1782 & 0,0801 & 44,9163 \\
\hline $\mathrm{P} / \mathrm{Cu}$ & 0,2304 & 0,2275 & 98,7474 \\
\hline $\mathrm{P} / \mathrm{Fe}$ & 0,1009 & 0,0707 & 70,1123 \\
\hline
\end{tabular}


continuação...

\begin{tabular}{|c|c|c|c|}
\hline RELAÇÃO & MÉDIA & DESVIO PADRÃO & COEF. VARIAÇÃO (\%) \\
\hline $\mathrm{P} / \mathrm{Mn}$ & 0,0896 & 0,0437 & 48,8134 \\
\hline $\mathrm{P} / \mathrm{Zn}$ & 0,1375 & 0,0836 & 60,8061 \\
\hline $\mathrm{K} / \mathrm{N}$ & 0,7014 & 0,5452 & 77,7291 \\
\hline $\mathrm{K} / \mathrm{P}$ & 3,6987 & 1,8508 & 50,0392 \\
\hline $\mathrm{K} / \mathrm{Ca}$ & 0,9289 & 1,1003 & 118,4500 \\
\hline $\mathrm{K} / \mathrm{Mg}$ & 2,9238 & 0,7780 & 26,6087 \\
\hline $\mathrm{K} / \mathrm{S}$ & 11,1414 & 17,8510 & 160,2218 \\
\hline $\mathrm{K} / \mathrm{B}$ & 0,6551 & 0,5377 & 82,0770 \\
\hline $\mathrm{K} / \mathrm{Cu}$ & 0,9920 & 1,4015 & 141,2903 \\
\hline $\mathrm{K} / \mathrm{Fe}$ & 0,3961 & 0,4547 & 114,7913 \\
\hline $\mathrm{K} / \mathrm{Mn}$ & 0,3284 & 0,2872 & 87,4730 \\
\hline $\mathrm{K} / \mathrm{Zn}$ & 0,5098 & 0,5060 & 99,2421 \\
\hline $\mathrm{Ca} / \mathrm{N}$ & 0,9622 & 0,2933 & 30,4773 \\
\hline $\mathrm{Ca} / \mathrm{P}$ & 6,4097 & 4,6474 & 72,5053 \\
\hline $\mathrm{Ca} / \mathrm{K}$ & 1,9082 & 0,8877 & 46,5223 \\
\hline $\mathrm{Ca} / \mathrm{Mg}$ & 5,1853 & 2,4242 & 46,7513 \\
\hline $\mathrm{Ca} / \mathrm{S}$ & 8,6919 & 4,1793 & 48,0825 \\
\hline $\mathrm{Ca} / \mathrm{B}$ & 0,8793 & 0,2449 & 27,8554 \\
\hline $\mathrm{Ca} / \mathrm{Cu}$ & 0,9047 & 0,4376 & 48,3703 \\
\hline $\mathrm{Ca} / \mathrm{Fe}$ & 0,4378 & 0,0515 & 11,7654 \\
\hline $\mathrm{Ca} / \mathrm{Mn}$ & 0,4257 & 0,0823 & 19,3361 \\
\hline $\mathrm{Ca} / \mathrm{Zn}$ & 0,6150 & 0,1290 & 20,9694 \\
\hline $\mathrm{Mg} / \mathrm{N}$ & 0,2306 & 0,1272 & 55,1507 \\
\hline $\mathrm{Mg} / \mathrm{P}$ & 1,3218 & 0,7055 & 53,3772 \\
\hline $\mathrm{Mg} / \mathrm{K}$ & 0,3652 & 0,1103 & 30,2027 \\
\hline $\mathrm{Mg} / \mathrm{Ca}$ & 0,2888 & 0,2721 & 94,2115 \\
\hline $\mathrm{Mg} / \mathrm{S}$ & 3,2036 & 4,6210 & 144,2429 \\
\hline $\mathrm{Mg} / \mathrm{B}$ & 0,2157 & 0,1273 & 59,0201 \\
\hline $\mathrm{Mg} / \mathrm{Cu}$ & 0,2896 & 0,3592 & 124,0345 \\
\hline $\mathrm{Mg} / \mathrm{Fe}$ & 0,1236 & 0,1118 & 90,5161 \\
\hline $\mathrm{Mg} / \mathrm{Mn}$ & 0,1069 & 0,0679 & 63,5052 \\
\hline $\mathrm{Mg} / \mathrm{Zn}$ & 0,1593 & 0,1208 & 75,8330 \\
\hline $\mathrm{S} / \mathrm{N}$ & 0,1390 & 0,0795 & 57,2161 \\
\hline $\mathrm{S} / \mathrm{P}$ & 1,0008 & 0,8934 & 89,2646 \\
\hline $\mathrm{S} / \mathrm{K}$ & 0,2922 & 0,1927 & 65,9447 \\
\hline
\end{tabular}


continuação...

\begin{tabular}{|c|c|c|c|}
\hline RELAÇÃO & MÉDIA & DESVIO PADRÃO & COEF. VARIAÇÃO (\%) \\
\hline $\mathrm{S} / \mathrm{Ca}$ & 0,1367 & 0,0589 & 43,0593 \\
\hline $\mathrm{S} / \mathrm{Mg}$ & 0,7398 & 0,3896 & 52,6659 \\
\hline $\mathrm{S} / \mathrm{B}$ & 0,1276 & 0,0741 & 58,0406 \\
\hline $\mathrm{S} / \mathrm{Cu}$ & 0,1122 & 0,0583 & 51,9467 \\
\hline $\mathrm{S} / \mathrm{Fe}$ & 0,0598 & 0,0261 & 43,7354 \\
\hline $\mathrm{S} / \mathrm{Mn}$ & 0,0612 & 0,0326 & 53,5857 \\
\hline $\mathrm{S} / \mathrm{Zn}$ & 0,0829 & 0,0325 & 39,2114 \\
\hline $\mathrm{B} / \mathrm{N}$ & 1,0894 & 0,0856 & 7,8603 \\
\hline $\mathrm{B} / \mathrm{P}$ & 6,6826 & 3,1442 & 47,0514 \\
\hline $\mathrm{B} / \mathrm{K}$ & 2,0733 & 0,8530 & 41,1427 \\
\hline $\mathrm{B} / \mathrm{Ca}$ & 1,2140 & 0,3605 & 29,6984 \\
\hline $\mathrm{B} / \mathrm{Mg}$ & 5,7721 & 2,6057 & 45,1428 \\
\hline $\mathrm{B} / \mathrm{S}$ & 11,5627 & 9,0295 & 78,0916 \\
\hline $\mathrm{B} / \mathrm{Cu}$ & 1,1592 & 0,5871 & 66,1002 \\
\hline $\mathrm{B} / \mathrm{Fe}$ & 0,5233 & 0,1341 & 25,6222 \\
\hline $\mathrm{B} / \mathrm{Mn}$ & 0,4932 & 0,0467 & 9,4580 \\
\hline $\mathrm{B} / \mathrm{Zn}$ & 0,7313 & 0,1933 & 26,4302 \\
\hline $\mathrm{Cu} / \mathrm{N}$ & 1,3420 & 0,7949 & 54,2343 \\
\hline $\mathrm{Cu} / \mathrm{P}$ & 9,0818 & 7,7225 & 85,0326 \\
\hline $\mathrm{Cu} / \mathrm{K}$ & 2,8856 & 2,2771 & 78,9125 \\
\hline $\mathrm{Cu} / \mathrm{Ca}$ & 1,3730 & 0,7553 & 55,0091 \\
\hline $\mathrm{Cu} / \mathrm{Mg}$ & 7,1355 & 4,2857 & 60,0617 \\
\hline $\mathrm{Cu} / \mathrm{S}$ & 10,4711 & 3,9176 & 37,4133 \\
\hline $\mathrm{Cu} / \mathrm{B}$ & 1,2568 & 0,7976 & 63,4595 \\
\hline $\mathrm{Cu} / \mathrm{Fe}$ & 0,5982 & 0,3037 & 50,7713 \\
\hline $\mathrm{Cu} / \mathrm{Mn}$ & 0,6061 & 0,3827 & 63,1474 \\
\hline $\mathrm{Cu} / \mathrm{Zn}$ & 0,8066 & 0,3494 & 43,3241 \\
\hline $\mathrm{Fe} / \mathrm{N}$ & 2,1805 & 0,5109 & 23,4291 \\
\hline $\mathrm{Fe} / \mathrm{P}$ & 14,1841 & 8,7123 & 61,4228 \\
\hline $\mathrm{Fe} / \mathrm{K}$ & 4,3584 & 2,0547 & 47,1437 \\
\hline $\mathrm{Fe} / \mathrm{Ca}$ & 2,3081 & 0,2534 & 10,9810 \\
\hline $\mathrm{Fe} / \mathrm{Mg}$ & 11,8271 & 5,5299 & 46,7559 \\
\hline $\mathrm{Fe} / \mathrm{S}$ & 20,0751 & 10,0502 & 50,0633 \\
\hline $\mathrm{Fe} / \mathrm{B}$ & 1,9961 & 0,4212 & 21,1011 \\
\hline $\mathrm{Fe} / \mathrm{Cu}$ & 2,1097 & 1,1441 & 54,2325 \\
\hline
\end{tabular}


continuação...

\begin{tabular}{|l|r|r|r|}
\hline \multicolumn{1}{|c|}{ RELAÇÃO } & MÉDIA & DESVIO PADRÃO & COEF. VARIAÇÃO (\%) \\
\hline $\mathrm{Fe} / \mathrm{Mn}$ & 0,9756 & 0,1805 & 18,5039 \\
\hline $\mathrm{Fe} / \mathrm{Zn}$ & 1,4110 & 0,3014 & 21,3613 \\
\hline $\mathrm{Mn} / \mathrm{N}$ & 2,2285 & 0,3129 & 14,0402 \\
\hline $\mathrm{Mn} / \mathrm{P}$ & 14,0708 & 8,1614 & 58,0021 \\
\hline $\mathrm{Mn} / \mathrm{K}$ & 4,2431 & 1,7166 & 40,4571 \\
\hline $\mathrm{Mn} / \mathrm{Ca}$ & 2,4375 & 0,5795 & 23,7755 \\
\hline $\mathrm{Mn} / \mathrm{Mg}$ & 11,7303 & 5,0366 & 42,9368 \\
\hline $\mathrm{Mn} / \mathrm{S}$ & 22,9086 & 16,8804 & 73,6858 \\
\hline $\mathrm{Mn} / \mathrm{B}$ & 2,0439 & 0,2177 & 10,6511 \\
\hline $\mathrm{Mn} / \mathrm{Cu}$ & 2,2949 & 1,3991 & 60,9682 \\
\hline $\mathrm{Mn} / \mathrm{Fe}$ & 1,0582 & 0,2270 & 21,4476 \\
\hline $\mathrm{Mn} / \mathrm{Zn}$ & 1,4722 & 0,3135 & 21,2980 \\
\hline $\mathrm{Zn} / \mathrm{N}$ & 1,5779 & 0,4378 & 27,7448 \\
\hline $\mathrm{Zn} / \mathrm{P}$ & 10,3978 & 7,2966 & 70,1748 \\
\hline $\mathrm{Zn} / \mathrm{K}$ & 3,1005 & 1,6030 & 51,7025 \\
\hline $\mathrm{Zn} / \mathrm{Ca}$ & 1,6870 & 0,3645 & 21,6065 \\
\hline $\mathrm{Zn} / \mathrm{Mg}$ & 8,1375 & 3,0704 & 37,7316 \\
\hline $\mathrm{Zn} / \mathrm{S}$ & 14,8120 & 9,0939 & 61,3955 \\
\hline $\mathrm{Zn} / \mathrm{B}$ & 1,4578 & 0,4276 & 29,3307 \\
\hline $\mathrm{Zn} / \mathrm{Cu}$ & 1,4812 & 0,7186 & 48,5130 \\
\hline $\mathrm{Zn} / \mathrm{Fe}$ & 0,7328 & 0,1415 & 19,3156 \\
\hline $\mathrm{Zn} / \mathrm{Mn}$ & 0,7080 & 0,1694 & 23,9237 \\
\hline & & & \\
\hline
\end{tabular}


Quadro 16. Média, Desvio Padrão e Coeficiente de Variação (Normas) para os nutrientes e para suas Relações Dois a Dois, considerando Pecíolo - 1 a coleta (florescimento).

\begin{tabular}{|c|c|c|c|}
\hline NUTRIENTES & MÉDIA & DESVIO PADRÃO & COEF. VARIAÇÃO (\%) \\
\hline $\mathrm{N}(\%)$ & 1,5380 & 0,3178 & 20,6656 \\
\hline $\mathrm{P}(\%)$ & 0,7000 & 0,1300 & 18,5714 \\
\hline $\mathrm{K}(\%)$ & 5,8680 & 1,2250 & 20,8763 \\
\hline $\mathrm{Ca}(\%)$ & 1,8100 & 0,3241 & 17,9069 \\
\hline $\operatorname{Mg}(\%)$ & 0,4840 & 0,1167 & 24,1214 \\
\hline S(\%) & 0,2300 & 0,0731 & 31,8016 \\
\hline $\mathrm{B} \ln (\mathrm{ppm})$ & 3,6736 & 0,1569 & 4,2715 \\
\hline $\mathrm{Cu} \ln (\mathrm{ppm})$ & 2,6806 & 0,5511 & 20,5592 \\
\hline $\mathrm{Fe} \ln (\mathrm{ppm})$ & 4,1569 & 0,2483 & 5,9726 \\
\hline $\mathrm{Mn} \ln (\mathrm{ppm})$ & 6,2214 & 0,2306 & 3,7069 \\
\hline $\mathrm{Zn} \ln (\mathrm{ppm})$ & 4,2385 & 0,2747 & 6,4818 \\
\hline RELAÇÃO & MÉDIA & DESVIO PADRÃO & COEF. VARIAÇÃO $(\%)$ \\
\hline $\mathrm{N} / \mathrm{P}$ & 2,2122 & 0,3179 & 14,3703 \\
\hline $\mathrm{N} / \mathrm{K}$ & 0,2701 & 0,0715 & 26,4498 \\
\hline $\mathrm{N} / \mathrm{Ca}$ & 0,8715 & 0,2300 & 26,3972 \\
\hline $\mathrm{N} / \mathrm{Mg}$ & 3,3200 & 1,0542 & 31,7531 \\
\hline $\mathrm{N} / \mathrm{S}$ & 7,3128 & 2,6625 & 36,4088 \\
\hline $\mathrm{N} / \mathrm{B}$ & 0,4177 & 0,0769 & 18,4182 \\
\hline $\mathrm{N} / \mathrm{Cu}$ & 0,5925 & 0,1617 & 27,2874 \\
\hline $\mathrm{N} / \mathrm{Fe}$ & 0,3688 & 0,0638 & 17,2997 \\
\hline $\mathrm{N} / \mathrm{Mn}$ & 0,2469 & 0,0486 & 19,6864 \\
\hline $\mathrm{N} / \mathrm{Zn}$ & 0,3619 & 0,0637 & 17,05859 \\
\hline $\mathrm{P} / \mathrm{N}$ & 0,4598 & 0,0678 & 14,7387 \\
\hline $\mathrm{P} / \mathrm{K}$ & 0,1239 & 0,0359 & 28,9623 \\
\hline $\mathrm{P} / \mathrm{Ca}$ & 0,4025 & 0,1234 & 30,6638 \\
\hline $\mathrm{P} / \mathrm{Mg}$ & 1,5132 & 0,4493 & 29,6928 \\
\hline $\mathrm{P} / \mathrm{S}$ & 3,4497 & 1,7056 & 49,4407 \\
\hline $\mathrm{P} / \mathrm{B}$ & 0,1909 & 0,0366 & 19,1538 \\
\hline $\mathrm{P} / \mathrm{Cu}$ & 0,2725 & 0,0757 & 27,7957 \\
\hline $\mathrm{P} / \mathrm{Fe}$ & 0,1676 & 0,0241 & 14,3761 \\
\hline
\end{tabular}


continuação...

\begin{tabular}{|c|c|c|c|}
\hline RELAÇÃO & MÉDIA & DESVIO PADRÃO & COEF. VARIAÇÃO (\%) \\
\hline $\mathrm{P} / \mathrm{Mn}$ & 0,1127 & 0,0216 & 19,1340 \\
\hline $\mathrm{P} / \mathrm{Zn}$ & 0,1657 & 0,0317 & 19,1002 \\
\hline $\mathrm{K} / \mathrm{N}$ & 3,8933 & 0,9212 & 23,6606 \\
\hline $\mathrm{K} / \mathrm{P}$ & 8,6055 & 2,4227 & 28,1526 \\
\hline $\mathrm{K} / \mathrm{Ca}$ & 3,2874 & 0,7979 & 24,2700 \\
\hline $\mathrm{K} / \mathrm{Mg}$ & 12,9195 & 4,4552 & 34,4848 \\
\hline $\mathrm{K} / \mathrm{S}$ & 29,2186 & 14,6000 & 49,9680 \\
\hline $\mathrm{K} / \mathrm{B}$ & 1,5967 & 0,3111 & 19,5210 \\
\hline $\mathrm{K} / \mathrm{Cu}$ & 2,2429 & 0,5827 & 25,9794 \\
\hline $\mathrm{K} / \mathrm{Fe}$ & 1,4080 & 0,2673 & 18,9817 \\
\hline $\mathrm{K} / \mathrm{Mn}$ & 0,9471 & 0,2098 & 22,1537 \\
\hline $\mathrm{K} / \mathrm{Zn}$ & 1,3858 & 0,2803 & 20,2291 \\
\hline $\mathrm{Ca} / \mathrm{N}$ & 1,2189 & 0,3470 & 28,4661 \\
\hline $\mathrm{Ca} / \mathrm{P}$ & 2,7201 & 1,0041 & 36,9144 \\
\hline $\mathrm{Ca} / \mathrm{K}$ & 0,3175 & 0,0701 & 22,0724 \\
\hline $\mathrm{Ca} / \mathrm{Mg}$ & 3,9817 & 1,3475 & 33,8419 \\
\hline $\mathrm{Ca} / \mathrm{S}$ & 8,8411 & 4,0005 & 45,2489 \\
\hline $\mathrm{Ca} / \mathrm{B}$ & 0,4910 & 0,0725 & 14,7625 \\
\hline $\mathrm{Ca} / \mathrm{Cu}$ & 0,6910 & 0,1515 & 21,9255 \\
\hline $\mathrm{Ca} / \mathrm{Fe}$ & 0,4379 & 0,0920 & 21,0131 \\
\hline $\mathrm{Ca} / \mathrm{Mn}$ & 0,2911 & 0,0517 & 17,7739 \\
\hline $\mathrm{Ca} / \mathrm{Zn}$ & 0,4271 & 0,0693 & 16,2289 \\
\hline $\mathrm{Mg} / \mathrm{N}$ & 0,3229 & 0,0877 & 27,1554 \\
\hline $\mathrm{Mg} / \mathrm{P}$ & 0,7109 & 0,2129 & 29,9492 \\
\hline $\mathrm{Mg} / \mathrm{K}$ & 0,0887 & 0,0427 & 48,1569 \\
\hline $\mathrm{Mg} / \mathrm{Ca}$ & 0,2794 & 0,1048 & 37,5301 \\
\hline $\mathrm{Mg} / \mathrm{S}$ & 2,2287 & 0,6033 & 27,0690 \\
\hline $\mathrm{Mg} / \mathrm{B}$ & 0,1325 & 0,0352 & 26,5531 \\
\hline $\mathrm{Mg} / \mathrm{Cu}$ & 0,1829 & 0,0428 & 23,4136 \\
\hline $\mathrm{Mg} / \mathrm{Fe}$ & 0,1173 & 0,0314 & 26,7441 \\
\hline $\mathrm{Mg} / \mathrm{Mn}$ & 0,0776 & 0,0174 & 22,3828 \\
\hline $\mathrm{Mg} / \mathrm{Zn}$ & 0,1138 & 0,0249 & 21,8587 \\
\hline $\mathrm{S} / \mathrm{N}$ & 0,1515 & 0,0523 & 34,5208 \\
\hline $\mathrm{S} / \mathrm{P}$ & 0,3405 & 0,1363 & 40,0137 \\
\hline $\mathrm{S} / \mathrm{K}$ & 0,0423 & 0,0232 & 54,8291 \\
\hline
\end{tabular}


continuação...

\begin{tabular}{|c|c|c|c|}
\hline RELAÇÃO & MÉDIA & DESVIO PADRÃO & COEF. VARIAÇÃO (\%) \\
\hline $\mathrm{S} / \mathrm{Ca}$ & 0,1305 & 0,0513 & 39,3449 \\
\hline $\mathrm{S} / \mathrm{Mg}$ & 0,4729 & 0,1140 & 24,1091 \\
\hline $\mathrm{S} / \mathrm{B}$ & 0,0626 & 0,0204 & 32,5827 \\
\hline $\mathrm{S} / \mathrm{Cu}$ & 0,0861 & 0,0275 & 31,9278 \\
\hline $\mathrm{S} / \mathrm{Fe}$ & 0,0559 & 0,0195 & 34,8405 \\
\hline $\mathrm{S} / \mathrm{Mn}$ & 0,0367 & 0,0108 & 29,4116 \\
\hline $\mathrm{S} / \mathrm{Zn}$ & 0,0537 & 0,0156 & 29,1638 \\
\hline $\mathrm{B} / \mathrm{N}$ & 2,4606 & 0,4524 & 18,3847 \\
\hline $\mathrm{B} / \mathrm{P}$ & 5,4191 & 1,1937 & 22,0276 \\
\hline $\mathrm{B} / \mathrm{K}$ & 0,6522 & 0,1598 & 24,5088 \\
\hline $\mathrm{B} / \mathrm{Ca}$ & 2,0709 & 0,2928 & 14,1399 \\
\hline $\mathrm{B} / \mathrm{Mg}$ & 7,9940 & 2,1133 & 26,4365 \\
\hline $\mathrm{B} / \mathrm{S}$ & 18,0429 & 8,3228 & 46,1279 \\
\hline $\mathrm{B} / \mathrm{Cu}$ & 1,4146 & 0,2782 & 19,6649 \\
\hline $\mathrm{B} / \mathrm{Fe}$ & 0,8860 & 0,0602 & 6,7921 \\
\hline $\mathrm{B} / \mathrm{Mn}$ & 0,5909 & 0,0282 & 4,7746 \\
\hline $\mathrm{B} / \mathrm{Zn}$ & 0,8690 & 0,0546 & 6,2814 \\
\hline $\mathrm{Cu} / \mathrm{N}$ & 1,8082 & 0,5758 & 31,8434 \\
\hline $\mathrm{Cu} / \mathrm{P}$ & 4,0372 & 1,6699 & 41,3637 \\
\hline $\mathrm{Cu} / \mathrm{K}$ & 0,4729 & 0,1315 & 27,8122 \\
\hline $\mathrm{Cu} / \mathrm{Ca}$ & 1,5045 & 0,3308 & 21,9873 \\
\hline $\mathrm{Cu} / \mathrm{Mg}$ & 5,6917 & 1,2269 & 21,5557 \\
\hline $\mathrm{Cu} / \mathrm{S}$ & 12,6331 & 4,1709 & 33,0158 \\
\hline $\mathrm{Cu} / \mathrm{B}$ & 0,7305 & 0,1508 & 20,6452 \\
\hline $\mathrm{Cu} / \mathrm{Fe}$ & 0,6506 & 0,1642 & 25,2381 \\
\hline $\mathrm{Cu} / \mathrm{Mn}$ & 0,4311 & 0,0893 & 20,7062 \\
\hline $\mathrm{Cu} / \mathrm{Zn}$ & 0,6297 & 0,1037 & 16,4707 \\
\hline $\mathrm{Fe} / \mathrm{N}$ & 2,7787 & 0,4922 & 17,7141 \\
\hline $\mathrm{Fe} / \mathrm{P}$ & 6,0777 & 0,9671 & 15,9124 \\
\hline $\mathrm{Fe} / \mathrm{K}$ & 0,7364 & 0,1734 & 23,5518 \\
\hline $\mathrm{Fe} / \mathrm{Ca}$ & 2,3599 & 0,4588 & 19,4414 \\
\hline $\mathrm{Fe} / \mathrm{Mg}$ & 9,0592 & 2,5293 & 27,9201 \\
\hline $\mathrm{Fe} / \mathrm{S}$ & 20,6881 & 10,5488 & 50,9896 \\
\hline $\mathrm{Fe} / \mathrm{B}$ & 1,1328 & 0,0761 & 6,7165 \\
\hline $\mathrm{Fe} / \mathrm{Cu}$ & 1,6092 & 0,3656 & 22,7194 \\
\hline
\end{tabular}


continuação...

\begin{tabular}{|l|r|r|r|}
\hline \multicolumn{1}{|c|}{ RELAÇÃO } & MÉDIA & DESVIO PADRÃO & COEF. VARIAÇÃO $\%$ (\%) \\
\hline $\mathrm{Fe} / \mathrm{Mn}$ & 0,6694 & 0,0552 & 8,2536 \\
\hline $\mathrm{Fe} / \mathrm{Zn}$ & 0,9853 & 0,1032 & 10,4770 \\
\hline $\mathrm{Mn} / \mathrm{N}$ & 4,1712 & 0,7732 & 18,5371 \\
\hline $\mathrm{Mn} / \mathrm{P}$ & 9,1749 & 1,9784 & 21,5635 \\
\hline $\mathrm{Mn} / \mathrm{K}$ & 1,1149 & 0,3353 & 30,0733 \\
\hline $\mathrm{Mn} / \mathrm{Ca}$ & 3,5229 & 0,6190 & 17,5706 \\
\hline $\mathrm{Mn} / \mathrm{Mg}$ & 13,4349 & 3,0542 & 22,7337 \\
\hline $\mathrm{Mn} / \mathrm{S}$ & 30,3152 & 13,2792 & 43,8040 \\
\hline $\mathrm{Mn} / \mathrm{B}$ & 1,6955 & 0,0843 & 4,9706 \\
\hline $\mathrm{Mn} / \mathrm{Cu}$ & 2,3939 & 0,4492 & 18,7662 \\
\hline $\mathrm{Mn} / \mathrm{Fe}$ & 1,5022 & 0,1261 & 8,3925 \\
\hline $\mathrm{Mn} / \mathrm{Zn}$ & 1,4713 & 0,0788 & 5,3568 \\
\hline $\mathrm{Zn} / \mathrm{N}$ & 2,8322 & 0,4956 & 17,4972 \\
\hline $\mathrm{Zn} / \mathrm{P}$ & 6,2587 & 1,4890 & 23,7907 \\
\hline $\mathrm{Zn} / \mathrm{K}$ & 0,7542 & 0,2025 & 26,8516 \\
\hline $\mathrm{Zn} / \mathrm{Ca}$ & 2,3942 & 0,4073 & 17,0122 \\
\hline $\mathrm{Zn} / \mathrm{Mg}$ & 9,1212 & 1,9316 & 21,1769 \\
\hline $\mathrm{Zn} / \mathrm{S}$ & 20,4178 & 7,9320 & 38,8485 \\
\hline $\mathrm{Zn} / \mathrm{B}$ & 1,1543 & 0,0697 & 6,0422 \\
\hline $\mathrm{Zn} / \mathrm{Cu}$ & 1,6198 & 0,2420 & 14,9412 \\
\hline $\mathrm{Zn} / \mathrm{Fe}$ & 1,0236 & 0,1033 & 10,0939 \\
\hline $\mathrm{Zn} / \mathrm{Mn}$ & 0,6812 & 0,0359 & 5,2739 \\
\hline & & & \\
\hline
\end{tabular}


Quadro 17. Média, Desvio Padrão e Coeficiente de Variação (Normas) para os nutrientes e para suas Relações Dois a Dois, considerando pecíolo- $2^{\mathrm{a}}$ coleta (fruto entre ervilha e meia-baga).

\begin{tabular}{|c|c|c|c|}
\hline NUTRIENTES & MEDIA & DESVIO PADRÃO & COEF. VARIAÇÃO (\%) \\
\hline $\mathrm{N}(\%)$ & 1,2340 & 0,2536 & 20,5538 \\
\hline $\mathrm{P}(\%)$ & 0,7160 & 0,1332 & 18,5969 \\
\hline $\mathrm{K}(\%)$ & 6,0320 & 1,4380 & 23,8402 \\
\hline $\mathrm{Ca}(\%)$ & 1,6460 & 0,3204 & 19,4676 \\
\hline $\mathrm{Mg}(\%)$ & 0,5220 & 0,0867 & 16,6126 \\
\hline $\mathrm{S}(\%)$ & 0,2560 & 0,0550 & 21,5021 \\
\hline $\mathrm{B} \ln (\mathrm{ppm})$ & 3,7662 & 0,1839 & 4,8844 \\
\hline $\mathrm{Cu} \ln (\mathrm{ppm})$ & 3,0422 & 1,0102 & 33,2060 \\
\hline $\mathrm{Fe} \ln (\mathrm{ppm})$ & 4,1998 & 0,4417 & 10,5172 \\
\hline $\mathrm{Mn} \ln (\mathrm{ppm})$ & 6,4943 & 0,3436 & 5,2910 \\
\hline $\mathrm{Zn} \ln (\mathrm{ppm})$ & 4,2249 & 0,2495 & 5,9049 \\
\hline RELAÇÃO & MÉDIA & DESVIO PADRÃO & COEF. VARIAÇÃO (\%) \\
\hline $\mathrm{N} / \mathrm{P}$ & 1,8348 & 0,7948 & 43,3168 \\
\hline $\mathrm{N} / \mathrm{K}$ & 0,2114 & 0,0543 & 25,6719 \\
\hline $\mathrm{N} / \mathrm{Ca}$ & 0,7695 & 0,1808 & 23,4914 \\
\hline $\mathrm{N} / \mathrm{Mg}$ & 2,4337 & 0,7369 & 30,2802 \\
\hline $\mathrm{N} / \mathrm{S}$ & 4,8326 & 0,2936 & 6,0743 \\
\hline $\mathrm{N} / \mathrm{B}$ & 0,3291 & 0,0740 & 22,4754 \\
\hline $\mathrm{N} / \mathrm{Cu}$ & 0,4439 & 0,1781 & 40,1153 \\
\hline $\mathrm{N} / \mathrm{Fe}$ & 0,2986 & 0,0791 & 26,4971 \\
\hline $\mathrm{N} / \mathrm{Mn}$ & 0,1903 & 0,0395 & 20,7372 \\
\hline $\mathrm{N} / \mathrm{Zn}$ & 0,2912 & 0,0493 & 16,9345 \\
\hline $\mathrm{P} / \mathrm{N}$ & 0,6117 & 0,2010 & 32,8593 \\
\hline $\mathrm{P} / \mathrm{K}$ & 0,1262 & 0,0419 & 33,2333 \\
\hline $\mathrm{P} / \mathrm{Ca}$ & 0,4629 & 0,1955 & 42,2463 \\
\hline $\mathrm{P} / \mathrm{Mg}$ & 1,3844 & 0,2455 & 17,7343 \\
\hline $\mathrm{P} / \mathrm{S}$ & 2,9510 & 0,9504 & 32,2056 \\
\hline $\mathrm{P} / \mathrm{B}$ & 0,1904 & 0,0365 & 19,1785 \\
\hline $\mathrm{P} / \mathrm{Cu}$ & 0,2525 & 0,0808 & 32,0048 \\
\hline $\mathrm{P} / \mathrm{Fe}$ & 0,1708 & 0,0295 & 17,2607 \\
\hline
\end{tabular}


continuação...

\begin{tabular}{|c|c|c|c|}
\hline RELAÇÃO & MÉDIA & DESVIO PADRÃO & COEF. VARIAÇÃO $(\%)$ \\
\hline $\mathrm{P} / \mathrm{Mn}$ & 01107 & 00233 & 209968 \\
\hline $\mathrm{P} / \mathrm{Zn}$ & 01712 & 00410 & 239257 \\
\hline $\mathrm{K} / \mathrm{N}$ & 49525 & 10992 & 221941 \\
\hline $\mathrm{K} / \mathrm{P}$ & 88670 & 36393 & 410432 \\
\hline $\mathrm{K} / \mathrm{Ca}$ & 37935 & 11682 & 307943 \\
\hline $\mathrm{K} / \mathrm{Mg}$ & 120868 & 44092 & 364794 \\
\hline $\mathrm{K} / \mathrm{S}$ & 240614 & 63737 & 264893 \\
\hline $\mathrm{K} / \mathrm{B}$ & 15970 & 03549 & 222200 \\
\hline $\mathrm{K} / \mathrm{Cu}$ & 22657 & 11397 & 503013 \\
\hline $\mathrm{K} / \mathrm{Fe}$ & 14695 & 04766 & 324343 \\
\hline $\mathrm{K} / \mathrm{Mn}$ & 09373 & 02540 & 270943 \\
\hline $\mathrm{K} / \mathrm{Zn}$ & 14330 & 03495 & 243871 \\
\hline $\mathrm{Ca} / \mathrm{N}$ & 13640 & 03483 & 255329 \\
\hline $\mathrm{Ca} / \mathrm{P}$ & 24054 & 07582 & 315191 \\
\hline $\mathrm{Ca} / \mathrm{K}$ & 02865 & 00941 & 328389 \\
\hline $\mathrm{Ca} / \mathrm{Mg}$ & 32628 & 09771 & 298980 \\
\hline $\mathrm{Ca} / \mathrm{S}$ & 65795 & 16175 & 245834 \\
\hline $\mathrm{Ca} / \mathrm{B}$ & 04365 & 00793 & 181600 \\
\hline $\mathrm{Ca} / \mathrm{Cu}$ & 05918 & 02303 & 389127 \\
\hline $\mathrm{Ca} / \mathrm{Fe}$ & 03955 & 00859 & 217181 \\
\hline $\mathrm{Ca} / \mathrm{Mn}$ & 02528 & 00448 & 176977 \\
\hline $\mathrm{Ca} / \mathrm{Zn}$ & 03877 & 00622 & 160555 \\
\hline $\mathrm{Mg} / \mathrm{N}$ & 04380 & 01145 & 261383 \\
\hline $\mathrm{Mg} / \mathrm{P}$ & 07420 & 01388 & 187046 \\
\hline $\mathrm{Mg} / \mathrm{K}$ & 00933 & 00377 & 403651 \\
\hline $\mathrm{Mg} / \mathrm{Ca}$ & 03357 & 01266 & 377016 \\
\hline $\mathrm{Mg} / \mathrm{S}$ & 21103 & 05303 & 251285 \\
\hline $\mathrm{Mg} / \mathrm{B}$ & 01396 & 00293 & 210018 \\
\hline $\mathrm{Mg} / \mathrm{Cu}$ & 01797 & 00347 & 193095 \\
\hline $\mathrm{Mg} / \mathrm{Fe}$ & 01246 & 00186 & 149525 \\
\hline $\mathrm{Mg} / \mathrm{Mn}$ & 00804 & 00128 & 159284 \\
\hline $\mathrm{Mg} / \mathrm{Zn}$ & 01242 & 00239 & 192683 \\
\hline $\mathrm{S} / \mathrm{N}$ & 02075 & 00121 & 58072 \\
\hline $\mathrm{S} / \mathrm{P}$ & 03808 & 01692 & 444271 \\
\hline $\mathrm{S} / \mathrm{K}$ & 00440 & 00120 & 273121 \\
\hline
\end{tabular}


continuação...

\begin{tabular}{|c|c|c|c|}
\hline RELAÇÃO & MÉDIA & DESVIO PADRÃO & COEF. VARIAÇÃO $(\%)$ \\
\hline $\mathrm{S} / \mathrm{Ca}$ & 01596 & 0,0388 & 24,3235 \\
\hline $\mathrm{S} / \mathrm{Mg}$ & 05039 & 0,1531 & 30,3927 \\
\hline $\mathrm{S} / \mathrm{B}$ & 00683 & 0,0161 & 23,6072 \\
\hline $\mathrm{S} / \mathrm{Cu}$ & 00913 & 0,0347 & 38,0486 \\
\hline $\mathrm{S} / \mathrm{Fe}$ & 00617 & 0,0160 & 25,8712 \\
\hline $\mathrm{S} / \mathrm{Mn}$ & 00394 & 0,0083 & 21,0675 \\
\hline $\mathrm{S} / \mathrm{Zn}$ & 00603 & 0,0105 & 17,4203 \\
\hline $\mathrm{B} / \mathrm{N}$ & 31491 & 0,6185 & 19,6422 \\
\hline $\mathrm{B} / \mathrm{P}$ & 54179 & 1,0984 & 20,2741 \\
\hline $\mathrm{B} / \mathrm{K}$ & 06519 & 0,1466 & 22,4867 \\
\hline $\mathrm{B} / \mathrm{Ca}$ & 23696 & 0,5438 & 22,9476 \\
\hline $\mathrm{B} / \mathrm{Mg}$ & 74066 & 14604 & 19,7171 \\
\hline $\mathrm{B} / \mathrm{S}$ & 152465 & 3,0780 & 20,2283 \\
\hline $\mathrm{B} / \mathrm{Cu}$ & 13558 & 0,4675 & 34,4807 \\
\hline $\mathrm{B} / \mathrm{Fe}$ & 0,9056 & 0,1177 & 12,9933 \\
\hline $\mathrm{B} / \mathrm{Mn}$ & 0,5817 & 0,0487 & 8,3638 \\
\hline $\mathrm{B} / \mathrm{Zn}$ & 0,8943 & 0,0734 & 8,2116 \\
\hline $\mathrm{Cu} / \mathrm{N}$ & 2,5494 & 0,9423 & 36,9603 \\
\hline $\mathrm{Cu} / \mathrm{P}$ & 4,3267 & 1,4899 & 34,4344 \\
\hline $\mathrm{Cu} / \mathrm{K}$ & 0,5639 & 0,3360 & 59,5869 \\
\hline $\mathrm{Cu} / \mathrm{Ca}$ & 1,9312 & 0,7924 & 41,0287 \\
\hline $\mathrm{Cu} / \mathrm{Mg}$ & 5,7382 & 1,1427 & 19,9137 \\
\hline $\mathrm{Cu} / \mathrm{S}$ & 12,2190 & 4,2964 & 35,1614 \\
\hline $\mathrm{Cu} / \mathrm{B}$ & 0,8177 & 0,3086 & 37,7435 \\
\hline $\mathrm{Cu} / \mathrm{Fe}$ & 0,7199 & 0,2169 & 30,1329 \\
\hline $\mathrm{Cu} / \mathrm{Mn}$ & 0,4646 & 0,1351 & 29,0797 \\
\hline $\mathrm{Cu} / \mathrm{Zn}$ & 0,7193 & 0,2285 & 31,7705 \\
\hline $\mathrm{Fe} / \mathrm{N}$ & 3,5307 & 0,8769 & 24,8362 \\
\hline $\mathrm{Fe} / \mathrm{P}$ & 6,0026 & 1,0912 & 18,1780 \\
\hline $\mathrm{Fe} / \mathrm{K}$ & 0,7400 & 0,2322 & 31,3847 \\
\hline $\mathrm{Fe} / \mathrm{Ca}$ & 2,6556 & 0,7426 & 27,9627 \\
\hline $\mathrm{Fe} / \mathrm{Mg}$ & 8,1717 & 1,2504 & 15,3011 \\
\hline $\mathrm{Fe} / \mathrm{S}$ & 16,9662 & 3,7363 & 22,0220 \\
\hline $\mathrm{Fe} / \mathrm{B}$ & 1,1178 & 0,1306 & 11,6825 \\
\hline $\mathrm{Fe} / \mathrm{Cu}$ & 1,4717 & 0,3488 & 23,6992 \\
\hline
\end{tabular}


continuação...

\begin{tabular}{|l|r|r|r|}
\hline \multicolumn{1}{|c|}{ RELAÇÃO } & MÉDIA & DESVIO PADRÃO & COEF. VARIAÇÃO (\%) \\
\hline $\mathrm{Fe} / \mathrm{Mn}$ & 0,6466 & 0,0581 & 8,9787 \\
\hline $\mathrm{Fe} / \mathrm{Zn}$ & 0,9966 & 0,1185 & 11,8870 \\
\hline $\mathrm{Mn} / \mathrm{N}$ & 5,4138 & 0,9675 & 17,8709 \\
\hline $\mathrm{Mn} / \mathrm{P}$ & 9,3638 & 2,0217 & 21,5901 \\
\hline $\mathrm{Mn} / \mathrm{K}$ & 1,1399 & 0,3433 & 30,1175 \\
\hline $\mathrm{Mn} / \mathrm{Ca}$ & 4,0771 & 0,8687 & 21,3066 \\
\hline $\mathrm{Mn} / \mathrm{Mg}$ & 12,6805 & 1,8919 & 14,9200 \\
\hline $\mathrm{Mn} / \mathrm{S}$ & 26,1010 & 4,3748 & 16,7609 \\
\hline $\mathrm{Mn} / \mathrm{B}$ & 1,7291 & 0,1491 & 8,6241 \\
\hline $\mathrm{Mn} / \mathrm{Cu}$ & 2,2946 & 0,6313 & 27,5125 \\
\hline $\mathrm{Mn} / \mathrm{Fe}$ & 1,5564 & 0,1368 & 8,7896 \\
\hline $\mathrm{Mn} / \mathrm{Zn}$ & 1,5386 & 0,0604 & 3,9244 \\
\hline $\mathrm{Zn} / \mathrm{N}$ & 3,5064 & 0,5368 & 15,3088 \\
\hline $\mathrm{Zn} / \mathrm{P}$ & 6,1269 & 1,5419 & 25,1656 \\
\hline $\mathrm{Zn} / \mathrm{K}$ & 0,7371 & 0,2045 & 27,7381 \\
\hline $\mathrm{Zn} / \mathrm{Ca}$ & 2,6419 & 0,4898 & 18,5407 \\
\hline $\mathrm{Zn} / \mathrm{Mg}$ & 8,2822 & 1,4864 & 17,9476 \\
\hline $\mathrm{Zn} / \mathrm{S}$ & 16,9156 & 2,4824 & 14,6751 \\
\hline $\mathrm{Zn} / \mathrm{B}$ & 1,1244 & 0,0938 & 8,3422 \\
\hline $\mathrm{Zn} / \mathrm{Cu}$ & 1,5025 & 0,4556 & 30,3221 \\
\hline $\mathrm{Zn} / \mathrm{Fe}$ & 1,0146 & 0,1184 & 11,6642 \\
\hline $\mathrm{Zn} / \mathrm{Mn}$ & 0,6508 & 0,0260 & 3,9936 \\
\hline & & & \\
\hline & & & \\
\hline & & & \\
\hline & & & \\
\hline
\end{tabular}


Quadro 18. Média, Desvio Padrão e Coeficiente de Variação (Normas) para os nutrientes e para suas Relações Dois a Dois, considerando pecíolo- 3a coleta (inicio de maturação das bagas).

\begin{tabular}{|c|c|c|c|}
\hline NUTRIENTES & MÉDIA & DESVIO PADRÃO & COEF. VARIAÇÃO (\%) \\
\hline $\mathrm{N}(\%)$ & 1,0480 & 0,1585 & 15,1234 \\
\hline $\mathrm{P}(\%)$ & 0,8100 & 0,2947 & 36,3831 \\
\hline $\mathrm{K}(\%)$ & 3,7040 & 1,3504 & 36,4584 \\
\hline $\mathrm{Ca}(\%)$ & 3,1900 & 0,5749 & 18,0230 \\
\hline $\operatorname{Mg}(\%)$ & 1,2300 & 0,5061 & 41,1434 \\
\hline $\mathrm{S}(\%)$ & 0,1800 & 0,0866 & 48,1125 \\
\hline $\mathrm{B} \ln (\mathrm{ppm})$ & 2,9635 & 0,3244 & 10,9480 \\
\hline $\mathrm{Cu} \ln (\mathrm{ppm})$ & 3,2775 & 1,7127 & 52,2557 \\
\hline $\mathrm{Fe} \ln (\mathrm{ppm})$ & 5,4964 & 0,8268 & 15,0426 \\
\hline $\mathrm{Mn} \ln (\mathrm{ppm})$ & 7,2621 & 0,7686 & 10,5839 \\
\hline $\mathrm{Zn} \ln (\mathrm{ppm})$ & 4,2534 & 0,6701 & 15,7554 \\
\hline RELAÇÃO & MÉDIA & DESVIO PADRÃO & COEF. VARIAÇÃO (\%) \\
\hline $\mathrm{N} / \mathrm{P}$ & 1,4012 & 0,4176 & 29,8018 \\
\hline $\mathrm{N} / \mathrm{K}$ & 0,3622 & 0,2827 & 78,0355 \\
\hline $\mathrm{N} / \mathrm{Ca}$ & 0,3321 & 0,0465 & 14,0103 \\
\hline $\mathrm{N} / \mathrm{Mg}$ & 0,9850 & 0,4788 & 48,6078 \\
\hline $\mathrm{N} / \mathrm{S}$ & 7,2533 & 4,2365 & 58,4086 \\
\hline $\mathrm{N} / \mathrm{B}$ & 0,3599 & 0,0806 & 22,3995 \\
\hline $\mathrm{N} / \mathrm{Cu}$ & 0,3900 & 0,1752 & 44,9267 \\
\hline $\mathrm{N} / \mathrm{Fe}$ & 0,1924 & 0,0312 & 16,2194 \\
\hline $\mathrm{N} / \mathrm{Mn}$ & 0,1461 & 0,0309 & 21,1415 \\
\hline $\mathrm{N} / \mathrm{Zn}$ & 0,2517 & 0,0582 & 23,1374 \\
\hline $\mathrm{P} / \mathrm{N}$ & 0,7591 & 0,1965 & 25,8906 \\
\hline $\mathrm{P} / \mathrm{K}$ & 0,3085 & 0,3228 & 104,6356 \\
\hline $\mathrm{P} / \mathrm{Ca}$ & 0,2530 & 0,0740 & 29,2520 \\
\hline $\mathrm{P} / \mathrm{Mg}$ & 0,7997 & 0,5848 & 73,1302 \\
\hline $\mathrm{P} / \mathrm{S}$ & 5,7238 & 3,6586 & 63,9194 \\
\hline $\mathrm{P} / \mathrm{B}$ & 0,2817 & 0,1187 & 42,1466 \\
\hline $\mathrm{P} / \mathrm{Cu}$ & 0,3067 & 0,1707 & 55,6712 \\
\hline $\mathrm{P} / \mathrm{Fe}$ & 0,1463 & 0,0440 & 30,0876 \\
\hline
\end{tabular}


continuação...

\begin{tabular}{|c|c|c|c|}
\hline RELAÇÃO & MÉDIA & DESVIO PADRÃO & COEF. VARIAÇÃO (\%) \\
\hline $\mathrm{P} / \mathrm{Mn}$ & 0,1149 & 0,0499 & 43,4785 \\
\hline $\mathrm{P} / \mathrm{Zn}$ & 0,1991 & 0,0933 & 46,8806 \\
\hline $\mathrm{K} / \mathrm{N}$ & 3,6433 & 1,4398 & 39,5187 \\
\hline $\mathrm{K} / \mathrm{P}$ & 5,3998 & 2,9389 & 54,4261 \\
\hline $\mathrm{K} / \mathrm{Ca}$ & 1,2257 & 0,5076 & 41,4141 \\
\hline $\mathrm{K} / \mathrm{Mg}$ & 3,1102 & 1,0903 & 35,0571 \\
\hline $\mathrm{K} / \mathrm{S}$ & 26,8694 & 18,8683 & 70,2223 \\
\hline $\mathrm{K} / \mathrm{B}$ & 1,2568 & 0,4815 & 38,3079 \\
\hline $\mathrm{K} / \mathrm{Cu}$ & 1,3825 & 0,8949 & 64,7304 \\
\hline $\mathrm{K} / \mathrm{Fe}$ & 0,7078 & 0,2922 & 41,2875 \\
\hline $\mathrm{K} / \mathrm{Mn}$ & 0,5059 & 0,1808 & 35,7406 \\
\hline $\mathrm{K} / \mathrm{Zn}$ & 0,8603 & 0,2936 & 34,1244 \\
\hline $\mathrm{Ca} / \mathrm{N}$ & 3,0556 & 0,3986 & 13,0447 \\
\hline $\mathrm{Ca} / \mathrm{P}$ & 4,3119 & 1,5658 & 36,3141 \\
\hline $\mathrm{Ca} / \mathrm{K}$ & 1,1493 & 1,0192 & 88,6732 \\
\hline $\mathrm{Ca} / \mathrm{Mg}$ & 3,0928 & 1,7562 & 56,7840 \\
\hline $\mathrm{Ca} / \mathrm{S}$ & 21,1181 & 10,4528 & 49,4970 \\
\hline $\mathrm{Ca} / \mathrm{B}$ & 1,0871 & 0,2309 & 21,2420 \\
\hline $\mathrm{Ca} / \mathrm{Cu}$ & 1,2102 & 0,5752 & 47,5249 \\
\hline $\mathrm{Ca} / \mathrm{Fe}$ & 0,5796 & 0,0534 & 9,2072 \\
\hline $\mathrm{Ca} / \mathrm{Mn}$ & 0,4460 & 0,1123 & 25,1747 \\
\hline $\mathrm{Ca} / \mathrm{Zn}$ & 0,7724 & 0,2299 & 29,7689 \\
\hline $\mathrm{Mg} / \mathrm{N}$ & 1,2041 & 0,5248 & 43,5813 \\
\hline $\mathrm{Mg} / \mathrm{P}$ & 1,7477 & 0,9407 & 53,8238 \\
\hline $\mathrm{Mg} / \mathrm{K}$ & 0,3573 & 0,1293 & 36,1854 \\
\hline $\mathrm{Mg} / \mathrm{Ca}$ & 0,4127 & 0,2292 & 55,5511 \\
\hline $\mathrm{Mg} / \mathrm{S}$ & 8,7829 & 6,4138 & 73,0257 \\
\hline $\mathrm{Mg} / \mathrm{B}$ & 0,4263 & 0,2149 & 50,4024 \\
\hline $\mathrm{Mg} / \mathrm{Cu}$ & 0,4111 & 0,1464 & 35,6036 \\
\hline $\mathrm{Mg} / \mathrm{Fe}$ & 0,2345 & 0,1162 & 49,5728 \\
\hline $\mathrm{Mg} / \mathrm{Mn}$ & 0,1669 & 0,0597 & 35,7740 \\
\hline $\mathrm{Mg} / \mathrm{Zn}$ & 0,2836 & 0,0903 & 31,8441 \\
\hline $\mathrm{S} / \mathrm{N}$ & 0,1775 & 0,0916 & 51,5874 \\
\hline $\mathrm{S} / \mathrm{P}$ & 0,2705 & 0,2199 & 81,2828 \\
\hline $\mathrm{S} / \mathrm{K}$ & 0,0658 & 0,0618 & 93,8581 \\
\hline
\end{tabular}


continuação...

\begin{tabular}{|c|c|c|c|}
\hline RELAÇÃO & MÉDIA & DESVIO PADRÃO & COEF. VARIAÇÃO (\%) \\
\hline $\mathrm{S} / \mathrm{Ca}$ & 0,0564 & $\begin{array}{r}0,0249 \\
\end{array}$ & 44,1375 \\
\hline $\mathrm{S} / \mathrm{Mg}$ & 0,1740 & 0,1158 & 66,5364 \\
\hline $\mathrm{S} / \mathrm{B}$ & 0,0599 & 0,0261 & 43,6222 \\
\hline $\mathrm{S} / \mathrm{Cu}$ & 0,0654 & 0,0357 & 54,5792 \\
\hline $\mathrm{S} / \mathrm{Fe}$ & 0,0325 & 0,0148 & 45,7581 \\
\hline $\mathrm{S} / \mathrm{Mn}$ & 0,0247 & 0,0109 & 44,3357 \\
\hline $\mathrm{S} / \mathrm{Zn}$ & 0,0429 & 0,0201 & 46,8571 \\
\hline $\mathrm{B} / \mathrm{N}$ & 2,9113 & 0,7481 & 25,6957 \\
\hline $\mathrm{B} / \mathrm{P}$ & 4,2163 & 2,0166 & 47,8288 \\
\hline $\mathrm{B} / \mathrm{K}$ & 0,9820 & 0,6323 & 64,3880 \\
\hline $\mathrm{B} / \mathrm{Ca}$ & 0,9532 & 0,1995 & 20,9234 \\
\hline $\mathrm{B} / \mathrm{Mg}$ & 2,7616 & 1,1108 & 40,2208 \\
\hline $\mathrm{B} / \mathrm{S}$ & 19,5307 & 8,4659 & 43,3467 \\
\hline $\mathrm{B} / \mathrm{Cu}$ & 1,1411 & 0,6267 & 54,9229 \\
\hline $\mathrm{B} / \mathrm{Fe}$ & 0,5478 & 0,0934 & 17,0488 \\
\hline $\mathrm{B} / \mathrm{Mn}$ & 0,4111 & 0,0578 & 14,0552 \\
\hline $\mathrm{B} / \mathrm{Zn}$ & 0,7117 & 0,1439 & 20,2184 \\
\hline $\mathrm{Cu} / \mathrm{N}$ & 3,1736 & 1,7226 & 54,2788 \\
\hline $\mathrm{Cu} / \mathrm{P}$ & 4,6559 & 3,2469 & 69,7379 \\
\hline $\mathrm{Cu} / \mathrm{K}$ & 1,0245 & 0,6145 & 59,9860 \\
\hline $\mathrm{Cu} / \mathrm{Ca}$ & 1,0872 & 0,7123 & 65,5200 \\
\hline $\mathrm{Cu} / \mathrm{Mg}$ & 2,6733 & 0,8640 & 32,3205 \\
\hline $\mathrm{Cu} / \mathrm{S}$ & 22,2469 & 17,6010 & 79,1167 \\
\hline $\mathrm{Cu} / \mathrm{B}$ & 1,1439 & 0,6841 & 59,8062 \\
\hline $\mathrm{Cu} / \mathrm{Fe}$ & 0,6174 & 0,3698 & 59,8886 \\
\hline $\mathrm{Cu} / \mathrm{Mn}$ & 0,4412 & 0,2021 & 45,8126 \\
\hline $\mathrm{Cu} / \mathrm{Zn}$ & 0,7483 & 0,3158 & 42,2015 \\
\hline $\mathrm{Fe} / \mathrm{N}$ & 5,3034 & 0,8155 & 15,3777 \\
\hline $\mathrm{Fe} / \mathrm{P}$ & 7,4616 & 2,6398 & 35,3779 \\
\hline $\mathrm{Fe} / \mathrm{K}$ & 1,9891 & 1,7640 & 88,6825 \\
\hline $\mathrm{Fe} / \mathrm{Ca}$ & 1,7366 & 0,1550 & 8,9262 \\
\hline $\mathrm{Fe} / \mathrm{Mg}$ & 5,3104 & 3,0072 & 566279 \\
\hline $\mathrm{Fe} / \mathrm{S}$ & 36,0303 & 15,3253 & 42,5345 \\
\hline $\mathrm{Fe} / \mathrm{B}$ & 1,8733 & 0,3547 & 18,9340 \\
\hline $\mathrm{Fe} / \mathrm{Cu}$ & 2,0827 & 1,0055 & 48,2792 \\
\hline
\end{tabular}


continuação...

\begin{tabular}{|l|r|r|r|}
\hline \multicolumn{1}{|c|}{ RELAÇÃO } & MÉDIA & DESVIO PADRÃO & COEF. VARIAÇÃO (\%) \\
\hline $\mathrm{Fe} / \mathrm{Mn}$ & 0,7685 & 0,1783 & 23,2070 \\
\hline $\mathrm{Fe} / \mathrm{Zn}$ & 1,3340 & 0,3894 & 29,1893 \\
\hline $\mathrm{Mn} / \mathrm{N}$ & 7,0859 & 1,4399 & 20,3211 \\
\hline $\mathrm{Mn} / \mathrm{P}$ & 10,3096 & 4,9184 & 47,7066 \\
\hline $\mathrm{Mn} / \mathrm{K}$ & 2,3576 & 1,3783 & 58,4609 \\
\hline $\mathrm{Mn} / \mathrm{Ca}$ & 23,4070 & 0,5287 & 22,5249 \\
\hline $\mathrm{Mn} / \mathrm{Mg}$ & 6,5590 & 2,1050 & 32,0930 \\
\hline $\mathrm{Mn} / \mathrm{S}$ & 48,5690 & 23,1223 & 47,6072 \\
\hline $\mathrm{Mn} / \mathrm{B}$ & 2,4713 & 0,3501 & 14,1688 \\
\hline $\mathrm{Mn} / \mathrm{Cu}$ & 2,6562 & 1,1326 & 42,6382 \\
\hline $\mathrm{Mn} / \mathrm{Fe}$ & 1,3489 & 0,2597 & 19,2545 \\
\hline $\mathrm{Mn} / \mathrm{Zn}$ & 1,7202 & 0,1190 & 6,9176 \\
\hline $\mathrm{Zn} / \mathrm{N}$ & 4,1379 & 0,8979 & 21,6996 \\
\hline $\mathrm{Zn} / \mathrm{P}$ & 6,0547 & 3,0332 & 50,0963 \\
\hline $\mathrm{Zn} / \mathrm{K}$ & 1,3492 & 0,7067 & 52,3778 \\
\hline $\mathrm{Zn} / \mathrm{Ca}$ & 1,3770 & 0,3549 & 25,7764 \\
\hline $\mathrm{Zn} / \mathrm{Mg}$ & 3,7791 & 1,0342 & 27,3671 \\
\hline $\mathrm{Zn} / \mathrm{S}$ & 28,7813 & 150020 & 52,1242 \\
\hline $\mathrm{Zn} / \mathrm{B}$ & 1,4505 & 0,2837 & 19,5588 \\
\hline $\mathrm{Zn} / \mathrm{Cu}$ & 1,5291 & 0,5990 & 39,1729 \\
\hline $\mathrm{Zn} / \mathrm{Fe}$ & 0,7930 & 0,1888 & 23,8065 \\
\hline $\mathrm{Zn} / \mathrm{Mn}$ & 0,5835 & 0,0394 & 6,7533 \\
\hline & & & \\
\hline & & & \\
\hline
\end{tabular}

É importante ressaltar que as normas obtidas são para a região em estudo, e correspondem a um número reduzido de observações (6 vinhedos) que apresentaram produtividade igual ou superior a 27,3 t/ha. $O$ estudo por região permite verificar se ocorrem diferenças significativas, em estudo posterior, que justifiquem separar as regiões ou então, ter um maior número de observações possíveis, reduzindo assim ao máximo o coeficiente de variação das relações dois a dois entre os nutrientes.

Pelo estudo das relações dos nutrientes no limbo (Quadros 13 a 15 ), observa-se que na época do florescimento (1 $1^{\text {a }}$ coleta) não se obteve valores maiores que 50 para nenhuma relação contendo o micronutriente cobre. Na época em que os frutos estão entre ervilha e meia-baga (2 coleta) observou-se valores acima de 50 para relações que envolvem fósforo e cobre, chegando a $\cong 69$ para 
relação $\mathrm{Cu} / \mathrm{K}$. Na época de amadurecimento dos frutos (3르 coleta) observou-se valores muito elevados de coeficiente de variações para relações que envolvem fósforo, potássio, magnésio, enxofre e cobre com diversas relações apresentando valores acima de 100\% como $\mathrm{P} / \mathrm{S}(115,84), \mathrm{K} / \mathrm{Ca}(118,45), \mathrm{K} / \mathrm{S}(16 \mathrm{O}, 22), \mathrm{K} / \mathrm{Cu}$ $(141,29), \mathrm{K} / \mathrm{Fe}(114,79), \mathrm{Mg} / \mathrm{S}(144,24)$ e $\mathrm{Mg} / \mathrm{Cu}(124,03)$. O estudo das relações dos nutrientes no pecíolo (Quadros 16 a 18), demonstraram que na época do florescimento (1 $1^{\text {a }}$ coleta) praticamente não houve valores altos de coeficientes de variação, apenas $\mathrm{S} / \mathrm{K}(54,82)$ e $\mathrm{Fe} / \mathrm{S}(50,98)$. Na época de frutos entre ervilha e meia-baga ( 2 a coleta), da mesma forma, apenas as relações $\mathrm{K} / \mathrm{Cu}$ e $\mathrm{Cu} / \mathrm{K}$ apresentaram valores acima de 50. Na época de amadurecimento dos frutos coleta) os coeficientes de variação foram elevados para as relações com magnésio, enxofre, cobre, fósforo e potássio chegando a $104,63 \%$ para $\mathrm{P} / \mathrm{K}$. Da mesma forma que no estudo dos coeficientes de variação dos nutrientes realizado anteriormente, valores próximos ou acima de $50 \%$ demonstram um desequilíbrio na relação estudada e era de se esperar que relações contendo nutrientes que apresentaram desequilíbrio nutricional no estudo anterior também apresentassem valores elevados nesse estudo. Para a cultura da videira relações de nutrientes contendo o nitrogênio, principalmente a relação $\mathrm{N} / \mathrm{K}$ que quando apresentam valores muito altos promovem o aparecimento da doença Fuçagare além de vários outros problemas nutricionais que podem ocorrer quando a excesso de nitrogênio (TERRA, 1993). No estudo em questão as relações contendo nitrogênio não apresentaram valores muito elevados de coeficiente de variação mostrando que problemas nutricionais não deverão ocorrer devido ao excesso do nutriente e sim devido relações contendo enxofre e fósforo, que apresentaram valores próximos ou acima de $50 \%$. Outro problema nutricional pode ser percebido através das relações contendo cobre que apresentaram valores altos de coeficiente de variação, devido ao excesso do nutriente através das pulverizações frequentes na videria de produtos contendo o micronutriente.

O estudo do estado nutricional através do DRIS também permite determinar a ordem pela qual os nutrientes estão limitando a produção (Quadros 19 a 24), através dos índices DRIS obtido para cada nutriente, indicando os valores negativos, a deficiência, que diminui à medida que os mesmos tendem a zero.

Segundo SUMNER (1977b), quando se têm vários nutrientes deficientes, a ordem da grandeza dos índices é que vai determinar o tratamento a ser aplicado para melhorar a produtividade dos vinhedos.

Através desse sistema, também pode-se realizar estudos pelo índice de balanço nutricional (IBN), que corresponde à soma dos valores absolutos dos índices DRIS de cada nutriente dividido pelo número de nutrientes estudados que nesse trabalho corresponde a onze (11), sendo que, quanto menor IBN ou mais próximo de zero, melhor o estado nutricional do vinhedo em questão, de forma 
semelhante às observações de SUMNER (1977c). Os vinhedos amostrados com produtividade acima de 27,3 tha ( JAL 06, JAL 12, JAL 13, JAL 14, JAL 15 e JAL 20) apresentaram uma amplitude de variação de IBN no limbo de 06 a $16 ; 09$ a 07 e 09 a 20 para a 1 $1^{\text {a }}$ e $3^{2}$ coletas, respectivamente. No pecíolo, a amplitude de variação do IBN, para os mesmos vinhedos de produtividade acima de 27,3 t/ha foi de 08 a 13; 09 a 13 e 09 a 19, respectivamente.

Cabe ressaltar o fato de ser comum um vinhedo com IBN adequado $\mathrm{e}$ até mesmo inferior aos dos vinhedos com produtividade alta apresentarem produtividade baixa, sugerindo melhor equilibrio nutricional que os mesmos. Este fato sugere que a principal limitação na produtividade desse vinhedo seja de ordem não nutricional, o que está de acordo com o que SNOECK (1984) afirmou. A afirmação do autor em questão é a de que nem sempre que se tenha uma planta em equilíbrio nutricional, significa que mesma terá alta produtividade, sendo apenas o inverso verdadeiro, ou seja, alta produtividade das colheitas só é alcançada quando as plantas estiverem em equilíbrio nutricional. 
Quadro 19- Produção, Índices DRIS, Indices de Balanço Nutricional (IBN) e Sequência de deficiência a excesso nutricional para os vinhedos amostrados considerando limbo- 1 coleta (florescimento).

\begin{tabular}{|c|c|c|c|c|c|c|c|c|c|c|c|c|c|c|}
\hline \multirow[t]{2}{*}{ Vinhedo } & \multirow[t]{2}{*}{ Prod. } & \multicolumn{11}{|c|}{ Indice DRIS } & \multirow[t]{2}{*}{ IBN } & \multirow{2}{*}{$\begin{array}{c}\text { Sequência de } \\
\text { Deficência a Excesso }\end{array}$} \\
\hline & & $\mathrm{N}$ & $\mathrm{P}$ & $\mathrm{K}$ & $\mathrm{Ca}$ & $\mathrm{Mg}$ & $\mathrm{S}$ & B & $\mathrm{Cu}$ & $\mathrm{Fe}$ & $\mathrm{Mn}$ & $\mathrm{Zn}$ & & \\
\hline JAL 01 & 24 & 71 & 33 & 60 & 63 & 65 & -773 & 63 & 53 & 58 & 143 & 164 & 141 & $\mathrm{~S}>\mathrm{P}>\mathrm{Cu}>\mathrm{Fe}>\mathrm{K}>\mathrm{Ca}>\mathrm{B}>\mathrm{Mg}>\mathrm{N}>\mathrm{Mn}>\mathrm{Zn}$ \\
\hline JAL 02 & 27 & 48 & 22 & -30 & -1 & -5 & -7 & -19 & 3 & -11 & 4 & -5 & 14 & $\mathrm{~K}>\mathrm{B}>\mathrm{Fe}>\mathrm{S}>\mathrm{Mg}>\mathrm{Zn}>\mathrm{Ca}>\mathrm{Cu}>\mathrm{Mn}>\mathrm{P}>\mathrm{N}$ \\
\hline JAL 03 & 25 & 30 & 13 & -25 & 17 & 11 & -18 & 7 & -10 & 0 & -36 & 10 & 16 & $\mathrm{Mn}>\mathrm{K}>\mathrm{S}>\mathrm{Cu}>\mathrm{Fe}>\mathrm{B}>\mathrm{Zn}>\mathrm{Mg}>\mathrm{P}>\mathrm{Ca}>\mathrm{N}$ \\
\hline JAL 04 & 24 & -8 & -19 & -9 & 2 & -4 & -12 & 0 & 76 & -6 & -6 & -12 & 14 & $\mathrm{P}>\mathrm{S}>\mathrm{Zn}>\mathrm{K}>\mathrm{N}>\mathrm{Fe}>\mathrm{Mn}>\mathrm{Mg}>\mathrm{B}>\mathrm{Ca}>\mathrm{Cu}$ \\
\hline JAL 05 & 25 & 27 & -4 & -8 & -9 & 21 & -31 & 5 & -12 & 11 & 9 & -10 & 13 & $\mathrm{~S}>\mathrm{Cu}>\mathrm{Zn}>\mathrm{Ca}>\mathrm{K}>\mathrm{P}>\mathrm{B}>\mathrm{Mn}>\mathrm{Fe}>\mathrm{Mg}>\mathrm{N}$ \\
\hline JAL 06 & 33 & -12 & -41 & -17 & -19 & -7 & 18 & 6 & -13 & 2 & 22 & 22 & 16 & $\mathrm{P}>\mathrm{K}>\mathrm{Cu}>\mathrm{N}>\mathrm{Mg}>\mathrm{Fe}>\mathrm{B}>\mathrm{S}>\mathrm{Ca}>\mathrm{Mn}>\mathrm{Zn}$ \\
\hline JAL 07 & 24 & -54 & 1 & 1 & -22 & -21 & 37 & 20 & -32 & 14 & 31 & 26 & 24 & $\mathrm{~N}>\mathrm{Cu}>\mathrm{Ca}>\mathrm{Mg}>\mathrm{P}>\mathrm{K}>\mathrm{Fe}>\mathrm{B}>\mathrm{Zn}>\mathrm{Mn}>\mathrm{S}$ \\
\hline JAL 08 & 25 & 24 & 1 & -10 & -1 & 25 & -26 & -8 & 9 & 8 & 11 & -33 & 14 & $\mathrm{Zn}>\mathrm{S}>\mathrm{K}>\mathrm{B}>\mathrm{Ca}>\mathrm{P}>\mathrm{Fe}>\mathrm{Cu}>\mathrm{Mn}>\mathrm{N}>\mathrm{Mg}$ \\
\hline JAL 09 & 26 & 2 & -7 & -13 & -6 & 5 & 17 & -9 & 39 & -16 & -3 & -9 & 11 & $\mathrm{Fe}>\mathrm{K}>\mathrm{B}>\mathrm{Zn}>\mathrm{P}>\mathrm{Ca}>\mathrm{Mn}>\mathrm{N}>\mathrm{Mg}>\mathrm{S}>\mathrm{Cu}$ \\
\hline JAL 10 & 26 & -21 & 5 & -9 & -28 & -16 & 22 & 11 & -38 & 20 & 27 & 28 & 20 & $\mathrm{Cu}>\mathrm{Ca}>\mathrm{N}>\mathrm{Mg}>\mathrm{K}>\mathrm{P}>\mathrm{B}>\mathrm{Fe}>\mathrm{S}>\mathrm{Mn}>\mathrm{Zn}$ \\
\hline JAL 11 & 26 & 3 & -8 & -27 & -14 & -14 & $\overline{22}$ & 5 & -23 & 15 & 22 & 21 & 16 & $\mathrm{~K}>\mathrm{Cu}>\mathrm{Ca}>\mathrm{Mg}>\mathrm{P}>\mathrm{N}>\mathrm{B}>\mathrm{Fe}>\mathrm{Zn}>\mathrm{S}>\mathrm{Mn}$ \\
\hline JAL 12 & 30 & -3 & -6 & -7 & 1 & 16 & 17 & -9 & -6 & -11 & -6 & 0 & 7 & $\mathrm{Fe}>\mathrm{B}>\mathrm{K}>\mathrm{P}>\mathrm{Cu}>\mathrm{N}>\mathrm{Zn}>\mathrm{Ca}>\mathrm{Mn}>\mathrm{Mg}>\mathrm{S}$ \\
\hline JAL 13 & 36 & -8 & 0 & -1 & -7 & -26 & -18 & 4 & 34 & 13 & 7 & 2 & 11 & $\mathrm{Mg}>\mathrm{S}>\mathrm{N}>\mathrm{Ca}>\mathrm{K}>\mathrm{P}>\mathrm{Zn}>\mathrm{B}>\mathrm{Mn}>\mathrm{Fe}>\mathrm{Cu}$ \\
\hline JAL 14 & 30 & 8 & 15 & 14 & 13 & -3 & -8 & 11 & -12 & 0 & -21 & 16 & 11 & $\mathrm{Mn}>\mathrm{Zn}>\mathrm{Cu}>\mathrm{S}>\mathrm{Mg}>\mathrm{Fe}>\mathrm{N}>\mathrm{B}>\mathrm{Ca}>\mathrm{K}>\mathrm{P}$ \\
\hline JAL 15 & 31 & -5 & -5 & -2 & 2 & -5 & -9 & 10 & -3 & $\overline{-2}$ & -2 & 19 & 6 & $\mathrm{~S}>\mathrm{N}>\mathrm{P}>\mathrm{Mg}>\mathrm{Cu}>\mathrm{K}>\mathrm{Fe}>\mathrm{Mn}>\mathrm{Ca}>\mathrm{B}>\mathrm{Zn}$ \\
\hline JAL 16 & 24 & -58 & 6 & -73 & -19 & -55 & -11 & 49 & 9 & 21 & 28 & -12 & 31 & $\mathrm{~K}>\mathrm{Mg}>\mathrm{Ca}>\mathrm{Zn}>\mathrm{S}>\mathrm{P}>\mathrm{Cu}>\mathrm{Fe}>\mathrm{Mn}>\mathrm{B}>\mathrm{N}$ \\
\hline JAL 17 & 24 & -8 & 28 & -14 & -18 & -86 & -31 & 31 & 90 & 0 & 14 & -6 & 30 & $\mathrm{Mg}>\mathrm{S}>\mathrm{Ca}>\mathrm{K}>\mathrm{N}>\mathrm{Zn}>\mathrm{Fe}>\mathrm{Mn}>\mathrm{P}>\mathrm{B}>\mathrm{Cu}$ \\
\hline JAL 18 & 24 & -4 & 10 & -8 & 15 & 23 & -15 & 2 & -24 & 19 & 6 & -24 & 14 & $\mathrm{Cu}>\mathrm{Zn}>\mathrm{S}>\mathrm{K}>\mathrm{N}>\mathrm{B}>\mathrm{Mn}>\mathrm{P}>\mathrm{Ca} . \mathrm{Fe}>\mathrm{Mg}$ \\
\hline JAL 19 & 26 & 27 & 19 & -87 & 0 & -17 & 17 & 17 & -15 & 15 & 16 & 9 & 22 & $\mathrm{~K}>\mathrm{Mg}>\mathrm{Cu}>\mathrm{Ca}>\mathrm{Zn}>\mathrm{Fe}>\mathrm{Mn}>\mathrm{S}>\mathrm{B}>\mathrm{P}>\mathrm{N}$ \\
\hline JAL 20 & 36 & 8 & 16 & 5 & 28 & 17 & -7 & -9 & 4 & 0 & -5 & 0 & 9 & $\mathrm{Ca}>\mathrm{B}>\mathrm{S}>\mathrm{Mn}>\mathrm{Fe}>\mathrm{Zn}>\mathrm{Cu}>\mathrm{K}>\mathrm{N}>\mathrm{P}>\mathrm{Mg}$ \\
\hline
\end{tabular}



Quadro 20. Produção, Índices DRIS, Indices de Balanço Nutricional (IBN) e Sequência de deficiência a excesso nutricional para os vinhedos amostrados considerando limbo- $2^{\mathrm{a}}$ coleta (fruto entre ervilha e meia- baga).

\begin{tabular}{|c|c|c|c|c|c|c|c|c|c|c|c|c|c|c|}
\hline \multirow[t]{2}{*}{ Vinhedo } & \multirow[t]{2}{*}{ Prod. } & \multicolumn{11}{|c|}{ Indice DRIS } & \multirow[t]{2}{*}{ IBN } & \multirow{2}{*}{$\begin{array}{c}\text { Sequência de } \\
\text { Deficência a Excesso }\end{array}$} \\
\hline & & $\mathrm{N}$ & $\mathrm{P}$ & K & $\mathrm{Ca}$ & $\mathrm{Mg}$ & $\mathrm{S}$ & $\mathrm{B}$ & $\mathrm{Cu}$ & $\mathrm{Fe}$ & $\mathrm{Mn}$ & $\mathrm{Zn}$ & & \\
\hline JAL 01 & 24 & 9 & 1 & -13 & -22 & -18 & 24 & -11 & 4 & -4 & 10 & 21 & 12 & $\mathrm{Ca}>\mathrm{Mg}>\mathrm{K}>\mathrm{B}>\mathrm{Fe}>\mathrm{P}>\mathrm{Cu}>\mathrm{N}>\mathrm{Mn}>\mathrm{Zn}>\mathrm{S}$ \\
\hline JAL 02 & 27 & 9 & 45 & -16 & 6 & -4 & -1 & -18 & -16 & -12 & 3 & 5 & 12 & $\mathrm{~B}>\mathrm{K}>\mathrm{Cu}>\mathrm{Fe}>\mathrm{Mg}>\mathrm{S}>\mathrm{Mn}>\mathrm{Zn}>\mathrm{Ca}>\mathrm{N}>\mathrm{P}$ \\
\hline JAL 03 & 25 & 19 & 8 & -29 & 23 & 10 & -45 & 4 & 38 & 5 & -22 & -12 & 20 & $\mathrm{~S}>\mathrm{K}>\mathrm{Mn}>\mathrm{Zn}>\mathrm{B}>\mathrm{Fe}>\mathrm{P}>\mathrm{Mg}>\mathrm{N}>\mathrm{Ca}>\mathrm{Cu}>$ \\
\hline JAL 04 & & 7 & -22 & -11 & 15 & 11 & -29 & -13 & 78 & -8 & -21 & -28 & 20 & $\mathrm{~S}>\mathrm{Zn}>\mathrm{P}>\mathrm{Mn}>\mathrm{Fe}>\mathrm{B}>\mathrm{K}>\mathrm{N}>\mathrm{Mg}>\mathrm{Ca}>\mathrm{Cu}$ \\
\hline JAL 05 & & 39 & -24 & -26 & -2 & 13 & -7 & -19 & $\overline{53}$ & 19 & -9 & -37 & 23 & $\mathrm{Zn}>\mathrm{K}>\mathrm{P}>\mathrm{B}>\mathrm{Mn}>\mathrm{S}>\mathrm{Ca}>\mathrm{Mg}>\mathrm{Fe}>\mathrm{N}>\mathrm{Cu}$ \\
\hline JAL 06 & 33 & 9 & -33 & 14 & 4 & -6 & 16 & 0 & -12 & -5 & 10 & & 10 & $\mathrm{P}>\mathrm{Cu}>\mathrm{Mg}>\mathrm{Fe}>\mathrm{B}>\mathrm{Ca}>\mathrm{Zn}>\mathrm{N}>\mathrm{Mn}>\mathrm{K}>\mathrm{S}$ \\
\hline JAL 07 & 24 & 8 & -11 & 9 & -18 & -18 & 27 & 10 & -19 & -12 & 16 & & 14 & $\mathrm{Cu}>\mathrm{Ca}>\mathrm{Mg}>\mathrm{Fe}>\mathrm{P}>\mathrm{N}>\mathrm{K}>\mathrm{Zn}>\mathrm{B}>\mathrm{Mn}>\mathrm{S}$ \\
\hline JAL 08 & 25 & -9 & 0 & -11 & 11 & 13 & -12 & -9 & 66 & 9 & -6 & -53 & 18 & $\mathrm{Zn}>\mathrm{S}>\mathrm{K}>\mathrm{N}>\mathrm{B}>\mathrm{Mn}>\mathrm{P}>\mathrm{Fe}>\mathrm{Ca}>\mathrm{Mg}>\mathrm{Cu}$ \\
\hline JAL 09 & 26 & -6 & -17 & -16 & 1 & -17 & -1 & -3 & 64 & 0 & -7 & 2 & 2 & $\mathrm{P}>\mathrm{Mg}>\mathrm{K}>\mathrm{Mn}>\mathrm{N}>\mathrm{B}>\mathrm{S}>\mathrm{Fe}>\mathrm{Ca}>\mathrm{Zn}>\mathrm{Cu}$ \\
\hline & 26 & 12 & -5 & 2 & -43 & -28 & 37 & 7 & -4 & -21 & 14 & 30 & 18 & $\mathrm{Ca}>\mathrm{Mg}>\mathrm{Fe}>\mathrm{P}>\mathrm{Cu}>\mathrm{K}>\mathrm{B}>\mathrm{N}>\mathrm{Mn}>\mathrm{Zn}>\mathrm{S}$ \\
\hline JAL 11 & 26 & 22 & 1 & 17 & -1 & $\sqrt{4}$ & -4 & -14 & -18 & 11 & 3 & $\overline{0}$ & 9 & $\mathrm{Cu}>\mathrm{B}>\mathrm{Fe}>\mathrm{S}>\mathrm{Ca}>\mathrm{Zn}>\mathrm{P}>\mathrm{Mn}>\mathrm{Mg}>\mathrm{K}>\mathrm{N}$ \\
\hline JAL 12 & 30 & -16 & -24 & -36 & 3 & 4 & 20 & -18 & 49 & 1 & & 14 & 17 & $\mathrm{~K}>\mathrm{P}>\mathrm{B}>\mathrm{N}>\mathrm{Fe}>\mathrm{Ca}>\mathrm{Mg}>\mathrm{Mn}>\mathrm{Zn}>\mathrm{S}>\mathrm{Cu}$ \\
\hline JAL 13 & 36 & 13 & 2 & 14 & 17 & 3 & -8 & 2 & -16 & -15 & 0 & -12 & 9 & $\mathrm{Cu}>\mathrm{Fe}>\mathrm{Zn}>\mathrm{S}>\mathrm{Mn}>\mathrm{P}>\mathrm{B}>\mathrm{Mg}>\mathrm{N}>\mathrm{K}>\mathrm{Ca}$ \\
\hline JAL 14 & 30 & -2 & 12 & -1 & 1 & -19 & -30 & 16 & -2 & 20 & -2 & & 10 & $\mathrm{~S}>\mathrm{Mg}>\mathrm{N}>\mathrm{Cu}>\mathrm{Mn}>\mathrm{K}>\mathrm{Ca}>\mathrm{Zn}>\mathrm{P}>\mathrm{B}>\mathrm{Fe}$ \\
\hline & 31 & 2 & 4 & 0 & 39 & 14 & -15 & 0 & 19 & -29 & -17 & -17 & 14 & $\mathrm{Fe}>\mathrm{Mn}>\mathrm{Zn}>\mathrm{S}>\mathrm{K}>\mathrm{B}>\mathrm{N}>\mathrm{P}>\mathrm{Mg}>\mathrm{Cu}>\mathrm{Ca}$ \\
\hline & 2 & 6 & -11 & 13 & 10 & & -36 & 20 & -2 & 12 & -1 & -25 & 14 & $\mathrm{~S}>\mathrm{Zn}>\mathrm{P}>\mathrm{Cu}>\mathrm{Mn}>\mathrm{N}>\mathrm{Ca}>\mathrm{Fe}>\mathrm{K}>\mathrm{Mg}>\mathrm{B}$ \\
\hline & 2 & -3 & 20 & -3 & 8 & -21 & -27 & 4 & 44 & 0 & -14 & -9 & 14 & $\mathrm{~S}>\mathrm{Mg}>\mathrm{Mn}>\mathrm{Zn}>\mathrm{N}>\mathrm{K}>\mathrm{Fe}>\mathrm{B}>\mathrm{Ca}>\mathrm{P}>\mathrm{Cu}$ \\
\hline 18 & 24 & -16 & 42 & -11 & 36 & 26 & -28 & 14 & -13 & 37 & -12 & -73 & 28 & $\mathrm{Zn}>\mathrm{S}>\mathrm{N}>\mathrm{Cu}>\mathrm{Mn}>\mathrm{K}>\mathrm{B}>\mathrm{Mg}>\mathrm{Ca}>\mathrm{Fe}>\mathrm{P}$ \\
\hline JAL 19 & 26 & -6 & 5 & 1 & 8 & 6 & -8 & -2 & 53 & -12 & -17 & -28 & 13 & $\mathrm{Zn}>\mathrm{Mn}>\mathrm{Fe}>\mathrm{S}>\mathrm{N}>\mathrm{B}>\mathrm{K}>\mathrm{P}>\mathrm{Mg}>\mathrm{Ca}>\mathrm{Cu}$ \\
\hline JAL 20 & 36 & -16 & 21 & -3 & -30 & 19 & 4 & 0 & 3 & 8 & -3 & -4 & 10 & $\mathrm{Ca}>\mathrm{N}>\mathrm{Zn}>\mathrm{K}>\mathrm{Mn}>\mathrm{B}>\mathrm{Cu}>\mathrm{S}>\mathrm{Fe}>\mathrm{Mg}>\mathrm{P}$ \\
\hline
\end{tabular}


Quadro 21. Produção, Índices DRIS, Indices de Balanço Nutricional (IBN) e Sequência de deficiência a excesso nutricional para os vinhedos amostrados considerando limbo- 3 a coleta (inicio de maturação das bagas).

\begin{tabular}{|c|c|c|c|c|c|c|c|c|c|c|c|c|c|c|}
\hline \multirow[t]{2}{*}{ Vinhedo } & \multirow[t]{2}{*}{ Prod. } & \multicolumn{11}{|c|}{ Indice DRIS } & \multirow[t]{2}{*}{ IBN } & \multirow{2}{*}{$\begin{array}{c}\text { Sequência de } \\
\text { Deficência a Excesso }\end{array}$} \\
\hline & & $\mathrm{N}$ & $\mathrm{P}$ & $\mathrm{K}$ & $\mathrm{Ca}$ & $\mathrm{Mg}$ & $\mathrm{S}$ & $\overline{\mathrm{B}}$ & $\mathrm{Cu}$ & $\mathrm{Fe}$ & Mn & $\mathrm{Zn}$ & & \\
\hline JAL 01 & 24 & -9 & -5 & -16 & -16 & -12 & 24 & 0 & 5 & 7 & 6 & 17 & 11 & $\mathrm{~K}>\mathrm{Ca}>\mathrm{Mg}>\mathrm{N}>\mathrm{P}>\mathrm{B}>\mathrm{Cu}>\mathrm{Mn}>\mathrm{Fe}>\mathrm{Zn}>\mathrm{S}$ \\
\hline JAL 02 & 27 & -12 & 24 & 33 & -5 & 18 & -82 & 2 & 32 & -26 & 16 & 0 & 23 & $\mathrm{~S}>\mathrm{Fe}>\mathrm{N}>\mathrm{Ca}>\mathrm{Zn}>\mathrm{B}>\mathrm{Mn}>\mathrm{Mg}>\mathrm{P}>\mathrm{Cu}>\mathrm{K}$ \\
\hline JAL 03 & 25 & -1 & 3 & -17 & 7 & -9 & -17 & 0 & 25 & 8 & 4 & -3 & 9 & $\mathrm{~K}>\mathrm{S}>\mathrm{Mg}>\mathrm{Zn}>\mathrm{N}>\mathrm{B}>\mathrm{P}>\mathrm{Mn}>\mathrm{Ca}>\mathrm{Fe}>\mathrm{Cu}$ \\
\hline JAL 04 & 24 & -11 & -31 & -28 & 19 & -8 & 4 & -2 & 53 & 3 & -8 & 8 & 16 & $\mathrm{P}>\mathrm{K}>\mathrm{N}>\mathrm{Mg}>\mathrm{Mn}>\mathrm{B}>\mathrm{Fe}>\mathrm{S}>\mathrm{Zn}>\mathrm{Ca}>\mathrm{Cu}$ \\
\hline JAL 05 & 25 & -3 & -10 & -25 & 0 & -1 & 3 & 0 & 41 & 8 & -5 & -9 & 10 & $\mathrm{~K}>\mathrm{P}>\mathrm{Zn}>\mathrm{Mn}>\mathrm{N}>\mathrm{Mg}>\mathrm{Ca}>\mathrm{B}>\mathrm{S}>\mathrm{Fe}>\mathrm{Cu}$ \\
\hline JAL 06 & 33 & -18 & -51 & -13 & 16 & -1 & 28 & -11 & 21 & 4 & 8 & 17 & 17 & $\mathrm{P}>\mathrm{N}>\mathrm{K}>\mathrm{B}>\mathrm{Mg}>\mathrm{Fe}>\mathrm{Mn}>\mathrm{Ca}>\mathrm{Zn}>\mathrm{Cu}>\mathrm{S}$ \\
\hline JAL 07 & 24 & -8 & -8 & -8 & -7 & -33 & 22 & 6 & -11 & 12 & 13 & 22 & 14 & $\mathrm{Mg}>\mathrm{Cu}>\mathrm{N}>\mathrm{P}>\mathrm{K}>\mathrm{Ca}>\mathrm{B}>\mathrm{Fe}>\mathrm{Mn}>\mathrm{S}>\mathrm{Zn}$ \\
\hline JAL 08 & 25 & -3 & -11 & -26 & 3 & 1 & -5 & -1 & 46 & 9 & 8 & -20 & 12 & $\mathrm{~K}>\mathrm{Zn}>\mathrm{P}>\mathrm{S}>\mathrm{N}>\mathrm{B}>\mathrm{Mg}>\mathrm{Ca}>\mathrm{Mn}>\mathrm{Fe}>\mathrm{Cu}$ \\
\hline JAL 09 & 26 & -4 & -15 & -25 & -5 & -13 & 3 & -2 & 41 & 6 & 10 & 3 & 12 & $\mathrm{~K}>\mathrm{P}>\mathrm{Mg}>\mathrm{Ca}>\mathrm{N}>\mathrm{B}>\mathrm{S}>\mathrm{Zn}>\mathrm{Fe}>\mathrm{Mn}>\mathrm{Cu}$ \\
\hline JAL 10 & 26 & -7 & 1 & -14 & -12 & 24 & 12 & 2 & -2 & 6 & 14 & 25 & 11 & $\mathrm{Mg}>\mathrm{K}>\mathrm{Ca}>\mathrm{N}>\mathrm{Cu}>\mathrm{P}>\mathrm{B}>\mathrm{Fe}>\mathrm{S}>\mathrm{Mn}>\mathrm{Zn}$ \\
\hline JAL 11 & 26 & 1 & -5 & -8 & 3 & -11 & 11 & 0 & -8 & 6 & 8 & -4 & 6 & $\mathrm{Mg}>\mathrm{K}>\mathrm{Cu}>\mathrm{P}>\mathrm{B}>\mathrm{N}>\mathrm{Ca}>\mathrm{Zn}>\mathrm{Fe}>\mathrm{Mn}>\mathrm{S}$ \\
\hline JAL 12 & 30 & -2 & -10 & -29 & -10 & -4 & 21 & -10 & 37 & 4 & -12 & 14 & 14 & $\mathrm{~K}>\mathrm{Mn}>\mathrm{P}>\mathrm{Ca}>\mathrm{B}>\mathrm{Mg}>\mathrm{N}>\mathrm{Fe}>\mathrm{Zn}>\mathrm{S}>\mathrm{Cu}$ \\
\hline JAL 13 & 36 & -3 & -11 & -9 & 7 & -14 & 14 & 13 & -7 & 18 & 7 & 4 & 11 & $\mathrm{Cu}>\mathrm{Mg}>\mathrm{P}>\mathrm{K}>\mathrm{Zn}>\mathrm{N}>\mathrm{Ca}>\mathrm{Mn}>\mathrm{B}>\mathrm{S}>\mathrm{Fe}$ \\
\hline JAL 14 & 30 & 1 & 12 & -13 & 6 & -20 & -8 & 6 & 11 & 4 & 7 & -6 & 9 & $\mathrm{Mg}>\mathrm{K}>\mathrm{S}>\mathrm{Zn}>\mathrm{N}>\mathrm{Fe}>\mathrm{Ca}>\mathrm{B}>\mathrm{Mn}>\mathrm{Cu}>\mathrm{P}$ \\
\hline JAL 15 & 31 & -19 & -1 & -20 & 7 & -12 & 8 & 13 & 11 & 6 & -5 & 10 & 10 & $\mathrm{~K}>\mathrm{N}>\mathrm{Mg}>\mathrm{Mn}>\mathrm{P}>\mathrm{Fe}>\mathrm{Ca}>\mathrm{S}>\mathrm{Zn}>\mathrm{Cu}>\mathrm{B}$ \\
\hline JAL 16 & 24 & 3 & -9 & 0 & -5 & -11 & 17 & 20 & 0 & 15 & -13 & -16 & 10 & $\mathrm{Zn}>\mathrm{Mn}>\mathrm{Mg}>\mathrm{P}>\mathrm{Ca}>\mathrm{K}>\mathrm{Cu}>\mathrm{N}>\mathrm{Fe}>\mathrm{S}>\mathrm{B}$ \\
\hline JAL 17 & 24 & -14 & 36 & -16 & 5 & -34 & 17 & -7 & 33 & -11 & -14 & -5 & 17 & $\mathrm{Mg}>\mathrm{K}>\mathrm{N}>\mathrm{Mn}>\mathrm{B}>\mathrm{Zn}>\mathrm{Fe}>\mathrm{Ca}>\mathrm{S}>\mathrm{Cu}>\mathrm{P}$ \\
\hline JAL 18 & 24 & -8 & 14 & 24 & 21 & 33 & -72 & 21 & -5 & -14 & -6 & -8 & 21 & $\mathrm{~S}>\mathrm{Fe}>\mathrm{N}>\mathrm{Zn}>\mathrm{Mn}>\mathrm{Cu}>\mathrm{P}>\mathrm{Ca}>\mathrm{B}>\mathrm{K}>\mathrm{Mg}$ \\
\hline JAL 19 & 26 & -22 & 2 & -18 & 0 & -13 & 11 & 7 & 42 & 4 & -5 & -8 & 12 & $\mathrm{~N}>\mathrm{K}>\mathrm{Mg}>\mathrm{Zn}>\mathrm{Mn}>\mathrm{Ca}>\mathrm{P}>\mathrm{Fe}>\mathrm{B}>\mathrm{S}>\mathrm{Cu}$ \\
\hline JAL 20 & 36 & -2 & 18 & 37 & -28 & 36 & -43 & 9 & -25 & -13 & 10 & 2 & 20 & $\mathrm{~S}>\mathrm{Ca}>\mathrm{Cu}>\mathrm{Fe}>\mathrm{N}>\mathrm{Zn}>\mathrm{B}>\mathrm{Mn}>\mathrm{P}>\mathrm{Mg}>\mathrm{K}$ \\
\hline
\end{tabular}


Quadro 22. Produção, Índices DRIS, Indices de Balanço Nutricional (IBN) e Sequência de deficiência a excesso nutricional para os vinhedos amostrados considerando Pecíolo- 1 a coleta (florescimento).

\begin{tabular}{|c|c|c|c|c|c|c|c|c|c|c|c|c|c|c|}
\hline \multirow[t]{2}{*}{ Vinhedo } & \multirow[t]{2}{*}{ Prod. } & \multicolumn{11}{|c|}{ Indice DRIS } & \multirow[t]{2}{*}{ IBN } & \multirow{2}{*}{$\begin{array}{c}\text { Sequência de } \\
\text { Deficência a Excesso }\end{array}$} \\
\hline & & $\mathrm{N}$ & $\mathrm{P}$ & $\mathrm{K}$ & $\mathrm{Ca}$ & $\mathrm{Mg}$ & $\mathrm{S}$ & $\mathrm{B}$ & $\mathrm{Cu}$ & $\mathrm{Fe}$ & Mn & $\mathrm{Zn}$ & & \\
\hline JAL 01 & 24 & -11 & 11 & 4 & -15 & -18 & 16 & -12 & -6 & -2 & 12 & 13 & 10 & $\mathrm{Ca}>\mathrm{B}>\mathrm{N}>\mathrm{Mg}>\mathrm{Cu}>\mathrm{Fe}>\mathrm{K}>\mathrm{P}>\mathrm{Mn}>\mathrm{Zn}>\mathrm{S}$ \\
\hline JAL 02 & 27 & 10 & 16 & -1 & -3 & -1 & 2 & -21 & 19 & -6 & -2 & -14 & 9 & $\mathrm{~B}>\mathrm{Zn}>\mathrm{Fe}>\mathrm{Ca}>\mathrm{Mn}>\mathrm{K}>\mathrm{Mg}>\mathrm{S}>\mathrm{N}>\mathrm{P}>\mathrm{Cu}$ \\
\hline JAL 03 & 25 & 19 & 5 & 6 & 12 & 4 & 22 & -9 & -4 & 7 & -36 & -27 & 14 & $\mathrm{Mn}>\mathrm{Zn}>\mathrm{B}>\mathrm{Cu}>\mathrm{Mg}>\mathrm{P}>\mathrm{K}>\mathrm{Fe}>\mathrm{Ca}>\mathrm{N}>\mathrm{S}$ \\
\hline JAL 04 & 24 & -7 & -5 & -14 & 11 & 14 & -32 & 0 & 100 & 7 & -26 & -33 & 23 & $\mathrm{Zn}>\mathrm{S}>\mathrm{Mn}>\mathrm{K}>\mathrm{N}>\mathrm{Fe}>\mathrm{P}>\mathrm{B}>\mathrm{Ca}>\mathrm{Mg}>\mathrm{Cu}$ \\
\hline JAL 05 & 25 & 6 & -2 & 5 & -11 & 32 & -16 & -16 & 19 & -7 & -3 & -7 & 11 & $\mathrm{~S}>\mathrm{B}>\mathrm{Ca}>\mathrm{Fe}>\mathrm{Zn}>\mathrm{Mn}>\mathrm{P}>\mathrm{K}>\mathrm{N}>\mathrm{Cu}>\mathrm{Mg}$ \\
\hline JAL 06 & 33 & -20 & -37 & 4 & 19 & 0 & 8 & 2 & 28 & -10 & 0 & 8 & 12 & $\mathrm{P}>\mathrm{N}>\mathrm{Fe}>\mathrm{Mg}>\mathrm{Mn}>\mathrm{B}>\mathrm{K}>\mathrm{S}>\mathrm{Zn}>\mathrm{Ca}>\mathrm{Cu}$ \\
\hline JAL 07 & 24 & -11 & -6 & -2 & 0 & -11 & 11 & 7 & -19 & 14 & 2 & 15 & 9 & $\mathrm{Cu}>\mathrm{N}>\mathrm{Mg}>\mathrm{P}>\mathrm{K}>\mathrm{Ca}>\mathrm{Mn}>\mathrm{B}>\mathrm{S}>\mathrm{Fe}>\mathrm{Zn}$ \\
\hline JAL 08 & 25 & 24 & -6 & -17 & -41 & 13 & 3 & 11 & 18 & -9 & 16 & -12 & 14 & $\mathrm{Ca}>\mathrm{K}>\mathrm{Fe}>\mathrm{P}>\mathrm{Zn}>\mathrm{B}>\mathrm{S}>\mathrm{Mg}>\mathrm{Mn}>\mathrm{Cu}>\mathrm{N}$ \\
\hline JAL 09 & 26 & 5 & -4 & -27 & -26 & 4 & 23 & 2 & 28 & 0 & -1 & 4 & 11 & $\mathrm{~K}>\mathrm{Ca}>\mathrm{P}>\mathrm{Mg}>\mathrm{Mn}>\mathrm{Fe}>\mathrm{B}>\mathrm{Zn}>\mathrm{N}>\mathrm{S}>\mathrm{Cu}$ \\
\hline JAL 10 & 26 & -25 & 16 & -5 & 4 & 4 & 12 & 13 & -31 & 4 & 9 & 16 & 13 & $\mathrm{Cu}>\mathrm{N}>\mathrm{K}>\mathrm{Ca}>\mathrm{Mg}>\mathrm{Fe}>\mathrm{Mn}>\mathrm{S}>\mathrm{B}>\mathrm{P}>\mathrm{Zn}$ \\
\hline JAL 11 & 26 & -34 & 6 & 1 & 14 & 6 & -9 & -4 & -20 & 16 & 3 & 21 & 12 & $\mathrm{~N}>\mathrm{Cu}>\mathrm{S}>\mathrm{B}>\mathrm{K}>\mathrm{Mn}>\mathrm{P}>\mathrm{Mg}>\mathrm{Ca}>\mathrm{Fe}>\mathrm{Zn}$ \\
\hline JAL 12 & 30 & -4 & 0 & -41 & -13 & 24 & 25 & -2 & -4 & -3 & 13 & 4 & 12 & $\mathrm{~K}>\mathrm{Ca}>\mathrm{N}>\mathrm{Cu}>\mathrm{Fe}>\mathrm{B}>\mathrm{P}>\mathrm{Zn}>\mathrm{Mn}>\mathrm{Mg}>\mathrm{S}$ \\
\hline JAL 13 & 36 & -11 & 10 & 9 & 5 & -12 & -41 & 15 & -8 & 23 & 11 & -1 & 13 & $\mathrm{~S}>\mathrm{Mg}>\mathrm{N}>\mathrm{Cu}>\mathrm{Zn}>\mathrm{Ca}>\mathrm{K}>\mathrm{P}>\mathrm{Mn}>\mathrm{B}>\mathrm{Fe}$ \\
\hline JAL 14 & 30 & 18 & 2 & 7 & 9 & -21 & 3 & 3 & -13 & -2 & -5 & -2 & 8 & $\mathrm{Mg}>\mathrm{Cu}>\mathrm{Mn}>\mathrm{Fe}>\mathrm{Zn}>\mathrm{P}>\mathrm{S}>\mathrm{B}>\mathrm{K}>\mathrm{Ca}>\mathrm{N}$ \\
\hline JAL 15 & 31 & -11 & -3 & 15 & 17 & 7 & -20 & 19 & -32 & 14 & -9 & 1 & 13 & $\mathrm{Cu}>\mathrm{S}>\mathrm{N}>\mathrm{Mn}>\mathrm{P}>\mathrm{Zn}>\mathrm{Mg}>\mathrm{Fe}>\mathrm{K}>\mathrm{Ca}>\mathrm{B}$ \\
\hline JAL 16 & 24 & 15 & 16 & -24 & -8 & -30 & -9 & 61 & -19 & -40 & 18 & 20 & 24 & $\mathrm{Fe}>\mathrm{Mg}>\mathrm{K}>\mathrm{Cu}>\mathrm{S}>\mathrm{Ca}>\mathrm{N}>\mathrm{P}>\mathrm{Mn}>\mathrm{Zn}>\mathrm{B}$ \\
\hline JAL 17 & 24 & -18 & 19 & -1 & -25 & -76 & 10 & 34 & 62 & 10 & -3 & -11 & 24 & $\mathrm{Mg}>\mathrm{Ca}>\mathrm{N}>\mathrm{Zn}>\mathrm{Mn}>\mathrm{K}>\mathrm{S}>\mathrm{Fe}>\mathrm{P}>\mathrm{B}>\mathrm{Cu}$ \\
\hline JAL 18 & 24 & 4 & 6 & 1 & -5 & 10 & 1 & -16 & -2 & 3 & -5 & -8 & 6 & $\mathrm{~B}>\mathrm{Zn}>\mathrm{Ca}>\mathrm{Mn}>\mathrm{Cu}>\mathrm{K}>\mathrm{S}>\mathrm{N}>\mathrm{P}>\mathrm{Mg}>\mathrm{Fe}$ \\
\hline JAL 19 & 26 & 1 & 20 & -15 & -29 & 2 & -4 & 16 & -15 & 15 & 5 & 5 & 12 & $\mathrm{Ca}>\mathrm{K}>\mathrm{Cu}>\mathrm{S}>\mathrm{N}>\mathrm{Mg}>\mathrm{Mn}>\mathrm{Zn}>\mathrm{Fe}>\mathrm{B}>\mathrm{P}$ \\
\hline JAL 20 & 36 & 7 & 12 & 8 & -24 & 11 & 2 & -11 & 6 & 1 & -10 & 0 & 8 & $\mathrm{Ca}>\mathrm{B}>\mathrm{Mn}>\mathrm{Zn}>\mathrm{Fe}>\mathrm{S}>\mathrm{Cu}>\mathrm{N}>\mathrm{K}>\mathrm{Mg}>\mathrm{P}$ \\
\hline
\end{tabular}


Quadro 23. Produção, Índices DRIS, Indices de Balanço Nutricional (IBN) e Sequência de deficiência a excesso nutricional para os vinhedos amostrados considerando Pecíolo- 2 coleta (fruto entre ervilha e meiabaga).

\begin{tabular}{|c|c|c|c|c|c|c|c|c|c|c|c|c|c|c|}
\hline \multirow[t]{2}{*}{ Vinhedo } & \multirow[t]{2}{*}{ Prod. } & \multicolumn{11}{|c|}{ Indice DRIS } & \multirow[t]{2}{*}{$\mathrm{IBN}$} & \multirow{2}{*}{$\begin{array}{c}\text { Sequência de } \\
\text { Deficência a Excesso }\end{array}$} \\
\hline & & $\mathrm{N}$ & $\mathrm{P}$ & K & $\mathrm{Ca}$ & $\mathrm{Mg}$ & $\mathrm{S}$ & $\mathrm{B}$ & $\mathrm{Cu}$ & $\mathrm{Fe}$ & Mn & $\mathrm{Zn}$ & & \\
\hline JAL 01 & 24 & 55 & 4 & -7 & -12 & -13 & -22 & -8 & -13 & -9 & 6 & 20 & 15 & $\mathrm{~S}>\mathrm{Mg}>\mathrm{Cu}>\mathrm{Ca}>\mathrm{Fe}>\mathrm{B}>\mathrm{K}>\mathrm{P}>\mathrm{Mn}>\mathrm{Zn}>\mathrm{N}$ \\
\hline JAL 02 & 27 & 73 & 26 & -16 & 0 & 1 & -19 & -21 & -20 & -8 & 0 & -17 & 18 & $\mathrm{~B}>\mathrm{Cu}>\mathrm{S}>\mathrm{Zn}>\mathrm{K}>\mathrm{Fe}>\mathrm{Ca}>\mathrm{Mn}>\mathrm{Mg}>\mathrm{P}>\mathrm{N}$ \\
\hline JAL 03 & 25 & 155 & 5 & -10 & 4 & $\overline{3}$ & -106 & -12 & -14 & $\overline{2}$ & -10 & -45 & 33 & $\mathrm{~S}>\mathrm{Zn}>\mathrm{B}>\mathrm{K}>\mathrm{Mn}>\mathrm{Fe}>\mathrm{Mg}>\mathrm{Ca}>\mathrm{P}>\mathrm{Cu}>\mathrm{N}$ \\
\hline JAL 04 & 24 & 16 & -21 & -3 & 14 & 12 & -9 & -10 & 57 & 4 & -40 & -26 & 19 & $\mathrm{Mn}>\mathrm{Zn}>\mathrm{P}>\mathrm{B}>\mathrm{S}>\mathrm{K}>\mathrm{Fe}>\mathrm{Mg}>\mathrm{Ca}>\mathrm{N}>\mathrm{Cu}$ \\
\hline JAL 05 & 25 & 106 & -14 & -20 & -11 & 12 & -55 & -26 & 30 & 7 & -4 & -25 & 28 & $\mathrm{~S}>\mathrm{B}>\mathrm{Zn}>\mathrm{K}>\mathrm{P}>\mathrm{Ca}>\mathrm{Mn}>\mathrm{Fe}>\mathrm{Mg}>\mathrm{Cu}>\mathrm{N}$ \\
\hline JAL 06 & 33 & 21 & -33 & 15 & 2 & -13 & 28 & -5 & -11 & -7 & -4 & 6 & 13 & $\mathrm{P}>\mathrm{Mg}>\mathrm{Cu}>\mathrm{Fe}>\mathrm{B}>\mathrm{Mn}>\mathrm{Ca}>\mathrm{Zn}>\mathrm{K}>\mathrm{N}>\mathrm{S}$ \\
\hline JAL 07 & 24 & 1 & -6 & 10 & -10 & -48 & 19 & 8 & -14 & 8 & 14 & 16 & 14 & $\mathrm{Mg}>\mathrm{Cu}>\mathrm{Ca}>\mathrm{P}>\mathrm{N}>\mathrm{B}>\mathrm{Fe}>\mathrm{K}>\mathrm{Mn}>\mathrm{Zn}>\mathrm{S}$ \\
\hline JAL 08 & 25 & 17 & -9 & -14 & 2 & 16 & -16 & -20 & 45 & -5 & 16 & -30 & 17 & $\mathrm{Zn}>\mathrm{B}>\mathrm{S}>\mathrm{K}>\mathrm{P}>\mathrm{Fe}>\mathrm{Ca}>\mathrm{Mg}>\mathrm{Mn}>\mathrm{N}>\mathrm{Cu}$ \\
\hline JAL 09 & 26 & 0 & $\overline{-2}$ & -8 & 4 & 9 & -29 & 0 & 50 & -2 & -19 & -3 & 11 & $\mathrm{~S}>\mathrm{Mn}>\mathrm{K}>\mathrm{Zn}>\mathrm{P}>\mathrm{Fe}>\mathrm{N}>\mathrm{B}>\mathrm{Ca}>\mathrm{Mg}>\mathrm{Cu}$ \\
\hline JAL 10 & 26 & 10 & 0 & 10 & -39 & -42 & 17 & 7 & -11 & -4 & 18 & 34 & 17 & $\mathrm{Mg}>\mathrm{Ca}>\mathrm{Cu}>\mathrm{Fe}>\mathrm{P}>\mathrm{B}>\mathrm{N}>\mathrm{K}>\mathrm{S}>\mathrm{Mn}>\mathrm{Zn}$ \\
\hline JAL 11 & 26 & 6 & 2 & 11 & -3 & 0 & -3 & -13 & -20 & 4 & 6 & 10 & 7 & $\mathrm{Cu}>\mathrm{B}>\mathrm{Ca}>\mathrm{S}>\mathrm{Mg}>\mathrm{P}>\mathrm{Fe}>\mathrm{N}>\mathrm{Mn}>\mathrm{Zn}>\mathrm{K}$ \\
\hline JAL 12 & 30 & -2 & -7 & -34 & -1 & 15 & 0 & -13 & 34 & -2 & 7 & 2 & 11 & $\mathrm{~K}>\mathrm{B}>\mathrm{P}>\mathrm{N}>\mathrm{Fe}>\mathrm{Ca}>\mathrm{S}>\mathrm{Zn}>\mathrm{Mn}>\mathrm{Mg}>\mathrm{Cu}$ \\
\hline JAL 13 & 36 & 1 & 4 & 19 & 10 & -9 & -10 & 14 & -23 & -11 & 1 & 4 & 10 & $\mathrm{Cu}>\mathrm{Fe}>\mathrm{S}>\mathrm{Mg}>\mathrm{N}>\mathrm{Mn}>\mathrm{P}>\mathrm{Zn}>\mathrm{Ca}>\mathrm{B}>\mathrm{K}$ \\
\hline JAL, 14 & 30 & -19 & 3 & -11 & 16 & -10 & -8 & 3 & 4 & 16 & 4 & 2 & 9 & $\mathrm{~N}>\mathrm{K}>\mathrm{Mg}>\mathrm{S}>\mathrm{Zn}>\mathrm{P}>\mathrm{B}>\mathrm{Cu}>\mathrm{Mn}>\mathrm{Ca}>\mathrm{Fe}$ \\
\hline JAL 15 & 31 & 5 & -6 & 10 & 25 & 1 & -13 & 7 & 8 & 3 & -27 & -13 & 11 & $\mathrm{Mn}>\mathrm{S}>\mathrm{Zn}>\mathrm{P}>\mathrm{Mg}>\mathrm{Fe}>\mathrm{N}>\mathrm{B}>\mathrm{Cu}>\mathrm{K}>\mathrm{Ca}$ \\
\hline JAL 16 & 24 & 60 & 19 & 25 & 28 & 32 & -224 & 35 & -15 & 29 & 12 & -1 & 44 & $\mathrm{~S}>\mathrm{Cu}>\mathrm{Zn}>\mathrm{Mn}>\mathrm{P}>\mathrm{K}>\mathrm{Ca}>\mathrm{Fe}>\mathrm{Mg}>\mathrm{B}>\mathrm{N}$ \\
\hline JAL 17 & 24 & 19 & 29 & 1 & 30 & -43 & -70 & 7 & 42 & 17 & -13 & -17 & 26 & $\mathrm{~S}>\mathrm{Mg}>\mathrm{Zn}>\mathrm{Mn}>\mathrm{K}>\mathrm{B}>\mathrm{Fe}>\mathrm{N}>\mathrm{P}>\mathrm{Ca}>\mathrm{Cu}$ \\
\hline JAL 18 & 24 & -1 & 23 & -9 & 3 & 19 & -28 & 1 & 9 & 19 & 3 & -39 & 14 & $\mathrm{Zn}>\mathrm{S}>\mathrm{K}>\mathrm{N}>\mathrm{B}>\mathrm{Ca}>\mathrm{Mn}>\mathrm{Cu}>\mathrm{Mg}>\mathrm{Fe}>\mathrm{P}$ \\
\hline JAL 19 & 26 & -1 & 8 & 1 & 15 & -15 & -14 & -11 & 48 & 6 & -18 & -20 & 1 & $\mathrm{Zn}>\mathrm{Mn}>\mathrm{Mg}>\mathrm{S}>\mathrm{B}>\mathrm{N}>\mathrm{K}>\mathrm{Fe}>\mathrm{P}>\mathrm{Ca}>\mathrm{Cu}$ \\
\hline JAL 20 & 36 & -11 & 20 & 0 & -34 & 18 & -8 & 3 & 7 & 11 & 0 & -7 & 11 & $\mathrm{Ca}>\mathrm{N}>\mathrm{S}>\mathrm{Zn}>\mathrm{K}>\mathrm{Mn}>\mathrm{B}>\mathrm{Cu}>\mathrm{Fe}>\mathrm{Mg}>\mathrm{P}$ \\
\hline
\end{tabular}


Quadro 24. Produção, Índices DRIS, Indices de Balanço Nutricional (IBN) e Sequência de deficiência a excesso nutricional para os vinhedos amostrados considerando Pecíolo - 3a coleta (inicio de maturação das bagas).

\begin{tabular}{|c|c|c|c|c|c|c|c|c|c|c|c|c|c|c|}
\hline \multirow[t]{2}{*}{ Vinhedo } & \multirow[t]{2}{*}{ Prod. } & \multicolumn{11}{|c|}{ Indice DRIS } & \multirow[t]{2}{*}{ IBN } & \multirow{2}{*}{$\begin{array}{c}\text { Sequência de } \\
\text { Deficência a Excesso }\end{array}$} \\
\hline & & $\mathrm{N}$ & $\mathrm{P}$ & $\mathrm{K}$ & $\mathrm{Ca}$ & $\mathrm{Mg}$ & $\mathrm{S}$ & $\mathrm{B}$ & $\mathrm{Cu}$ & $\mathrm{Fe}$ & $\mathrm{Mn}$ & $\mathrm{Zn}$ & & \\
\hline JAL 01 & 24 & -10 & 5 & 24 & -29 & -7 & -4 & -2 & 0 & -5 & 8 & -19 & 10 & $\mathrm{Ca}>\mathrm{N}>\mathrm{Mg}>\mathrm{Fe}>\mathrm{S}>\mathrm{B}>\mathrm{Cu}>\mathrm{P}>\mathrm{Mn}>\mathrm{Zn}>\mathrm{K}$ \\
\hline JAL 02 & 27 & -4 & 18 & -73 & -15 & -82 & 65 & -27 & 73 & 14 & -2 & 33 & 37 & $\mathrm{Mg}>\mathrm{K}>\mathrm{B}>\mathrm{Ca}>\mathrm{N}>\mathrm{Mn}>\mathrm{Fe}>\mathrm{P}>\mathrm{Zn}>\mathrm{S}>\mathrm{Cu}$ \\
\hline JAL 03 & 25 & 60 & 41 & 62 & 30 & 23 & -499 & 62 & 79 & 48 & 50 & 44 & 91 & $\mathrm{~S}>\mathrm{Mg}>\mathrm{Ca}>\mathrm{P}>\mathrm{Zn}>\mathrm{Fe}>\mathrm{Mm}>\mathrm{N}>\mathrm{K}>\mathrm{B}>\mathrm{Cu}$ \\
\hline JAL 04 & 24 & -10 & -25 & -23 & 6 & 14 & 20 & 1 & 46 & -5 & -18 & -6 & 16 & $\mathrm{P}>\mathrm{K}>\mathrm{Mn}>\mathrm{N}>\mathrm{Zn}>\mathrm{Fe}>\mathrm{B}>\mathrm{Ca}>\mathrm{Mg}>\mathrm{S}>\mathrm{Cu}$ \\
\hline JAL 05 & 25 & 6 & -8 & 12 & -29 & 24 & -51 & -8 & 49 & -1 & -3 & 10 & 18 & $\mathrm{~S}>\mathrm{Ca}>\mathrm{P}>\mathrm{B}>\mathrm{Mn}>\mathrm{Fe}>\mathrm{N}>\mathrm{Zn}>\mathrm{K}>\mathrm{Mg}>\mathrm{Cu}$ \\
\hline JAL 06 & 33 & -14 & -45 & 2 & -4 & 1 & 28 & 1 & 18 & -5 & 7 & 11 & 2 & $\mathrm{P}>\mathrm{N}>\mathrm{Fe}>\mathrm{Ca}>\mathrm{Mg}>\mathrm{B}>\mathrm{K}>\mathrm{Mn}>\mathrm{Zn}>\mathrm{Cu}>\mathrm{S}$ \\
\hline JAL 07 & 24 & -20 & -15 & -5 & -13 & 31 & 18 & 11 & -9 & -7 & 5 & 4 & 13 & $\mathrm{~N}>\mathrm{P}>\mathrm{Ca}>\mathrm{Cu}>\mathrm{Fe}>\mathrm{K}>\mathrm{Zn}>\mathrm{Mn}>\mathrm{B}>\mathrm{S}>\mathrm{Mg}$ \\
\hline JAL 08 & 25 & 0 & -7 & 9 & -17 & 29 & -83 & -10 & 65 & 3 & 6 & 4 & 2 & $\mathrm{~S}>\mathrm{Ca}>\mathrm{B}>\mathrm{P}>\mathrm{N}>\mathrm{Fe}>\mathrm{Zn}>\mathrm{Mn}>\mathrm{K}>\mathrm{Mg}>\mathrm{Cu}$ \\
\hline JAL 09 & 26 & -6 & -4 & 21 & -12 & -2 & -63 & 11 & 52 & -6 & $\overline{2}$ & 7 & 17 & $\mathrm{~S}>\mathrm{Ca}>\mathrm{N}>\mathrm{Fe}>\mathrm{P}>\mathrm{Mg}>\mathrm{Mn}>\mathrm{Zn}>\mathrm{B}>\mathrm{K}>\mathrm{Cu}$ \\
\hline JAL 10 & 26 & -14 & -3 & -4 & -17 & -2 & 31 & 3 & -10 & -5 & 7 & 12 & 10 & $\mathrm{~K}>\mathrm{N}>\mathrm{Cu}>\mathrm{Fe}>\mathrm{K}>\mathrm{P}>\mathrm{Mg}>\mathrm{B}>\mathrm{Mn}>\mathrm{Zn}>\mathrm{S}$ \\
\hline JAL 11 & 26 & -10 & 0 & 3 & -4 & 9 & 6 & 10 & -26 & -2 & 9 & 3 & 7 & $\mathrm{Cu}>\mathrm{N}>\mathrm{Ca}>\mathrm{Fe}>\mathrm{P}>\mathrm{K}>\mathrm{Zn}>\mathrm{S}>\mathrm{Mg}>\mathrm{Mn}>\mathrm{B}$ \\
\hline JAL 12 & 30 & -6 & -2 & $\overline{2}$ & -24 & 27 & -23 & -15 & 40 & -8 & $\overline{3}$ & 7 & 14 & $\mathrm{Ca}>\mathrm{S}>\mathrm{B}>\mathrm{Fe}>\mathrm{N}>\mathrm{P}>\mathrm{K}>\mathrm{Mn}>\mathrm{Zn}>\mathrm{Mg}>\mathrm{Cu}$ \\
\hline JAL 13 & 36 & -12 & -14 & 11 & -4 & -1 & 8 & 22 & -23 & 7 & 7 & 0 & 10 & $\mathrm{Cu}>\mathrm{P}>\mathrm{N}>\mathrm{Ca}>\mathrm{Mg}>\mathrm{Zn}>\mathrm{Fe}>\mathrm{Mn}>\mathrm{S}>\mathrm{K}>\mathrm{B}$ \\
\hline JAL 14 & 30 & 5 & 20 & -68 & 24 & -28 & 24 & 2 & -1 & 29 & 0 & -7 & 19 & $\mathrm{~K}>\mathrm{Mg}>\mathrm{Zn}>\mathrm{Cu}>\mathrm{Mn}>\mathrm{B}>\mathrm{N}>\mathrm{P}>\mathrm{Ca}>\mathrm{S}>\mathrm{Fe}$ \\
\hline JAL 15 & 31 & -17 & -15 & 12 & 10 & -9 & 9 & 17 & 6 & -6 & -7 & $\overline{0}$ & 10 & $\mathrm{~N}>\mathrm{P}>\mathrm{Mg}>\mathrm{Mn}>\mathrm{Fe}>\mathrm{Zn}>\mathrm{Cu}>\mathrm{S}>\mathrm{Ca}>\mathrm{K}>\mathrm{B}$ \\
\hline JAL 16 & 24 & 1 & 4 & 39 & -61 & -26 & 6 & 36 & 13 & 3 & 6 & -12 & 19 & $\mathrm{Ca}>\mathrm{Mg}>\mathrm{Zn}>\mathrm{P}>\mathrm{N}>\mathrm{Fe}>\mathrm{S}>\mathrm{Mn}>\mathrm{Cu}>\mathrm{B}>\mathrm{K}$ \\
\hline JAL 17 & 24 & -10 & 17 & 17 & -12 & -47 & 43 & 9 & 36 & -28 & -5 & -21 & 22 & $\mathrm{Mg}>\mathrm{Fe}>\mathrm{Zn}>\mathrm{CA}>\mathrm{N}>\mathrm{Mn}>\mathrm{B}>\mathrm{P}>\mathrm{K}>\mathrm{Cu}>\mathrm{S}$ \\
\hline JAL 18 & 24 & 15 & 12 & -58 & -19 & -37 & 47 & -6 & 8 & 27 & -3 & $\overline{13}$ & 22 & $\mathrm{~K}>\mathrm{Mg}>\mathrm{Ca}>\mathrm{B}>\mathrm{Mn}>\mathrm{Cu}>\mathrm{P}>\mathrm{Zn}>\mathrm{N}>\mathrm{Fe}>\mathrm{S}$ \\
\hline JAL 19 & 26 & -11 & -3 & 4 & -19 & -9 & 3 & 10 & 45 & -2 & -2 & -16 & 11 & $\mathrm{Ca}>\mathrm{Zn}>\mathrm{N}>\mathrm{Mg}>\mathrm{P}>\mathrm{Fe}>\mathrm{Mn}>\mathrm{S}>\mathrm{K}>\mathrm{B}>\mathrm{Cu}$ \\
\hline JAL 20 & 36 & 12 & 9 & 15 & 6 & -2 & -29 & -2 & -10 & -4 & -1 & 6 & 9 & $\mathrm{~S}>\mathrm{Cu}>\mathrm{Fe}>\mathrm{Mg}>\mathrm{B}>\mathrm{Mn}>\mathrm{Ca}>\mathrm{Zn}>\mathrm{P}>\mathrm{N}>\mathrm{K}$ \\
\hline
\end{tabular}

Outro dado que pode-se obter, através da calibração dos índices de balanço nutricional, é o valor de IBN que poderá ser usado como referência de equilibrio nutricional para vinhedos da região em estudo. A calibração dos índices foi realizada através de enquadramento dos valores de IBN dos seis vinhedos selecionados, para cada uma das três coletas e para os dois órgãos amostrados (Quadros 25 a 30). 
Quadro 25.Índice de Balanço Nutricional de referência para os vinhedos amostrados limbo - 19 coleta (florescimento)

\begin{tabular}{|c|c|c|}
\hline \multirow{2}{*}{ Indice de Balanço Nutricional } & \multicolumn{2}{|c|}{ Número de vinhedos } \\
\cline { 2 - 3 } & Produtividade Baixa & Produtividade Alta \\
\hline Adequado $(0-11)$ & 00 & 05 \\
\hline Desequilibrado $(>11)$ & 14 & 01 \\
\hline
\end{tabular}

Quadro 26.Índice de Balanço Nutricional de referência para os vinhedos amostrados limbo - 2 coleta (frutos entre ervilha e meia-baga.)

\begin{tabular}{|c|c|c|}
\hline \multirow{2}{*}{ İndice de Balanço Nutricional } & \multicolumn{2}{|c|}{ Número de vinhedos } \\
\cline { 2 - 3 } & Produtividade Baixa & Produtividade Alta \\
\hline Adequado $(0-8)$ & 01 & 02 \\
\hline Desequilibrado $(>8)$ & 13 & 04 \\
\hline
\end{tabular}

Quadro 27.Índice de Balanço Nutricional de referência para os vinhedos amostrados limbo - 3a coleta (início de maturação das bagas)

\begin{tabular}{|c|c|c|}
\hline \multirow{2}{*}{ Indice de Balanço Nutricional } & \multicolumn{2}{|c|}{ Número de vinhedos } \\
\cline { 2 - 3 } & Produtividade Baixa & Produtividade Alta \\
\hline Adequado $(0-11)$ & 01 & 04 \\
\hline Desequilibrado $(>11)$ & 13 & 02 \\
\hline
\end{tabular}


Quadro 28.Índice de Balanço Nutricional de referência para os vinhedos amostrados pecíolo - 1 coleta (florescimento)

\begin{tabular}{|c|c|c|}
\hline \multirow{2}{*}{ İndice de Balanço Nutricional } & \multicolumn{2}{|c|}{ Número de vinhedos } \\
\cline { 2 - 3 } & Produtividade Baixa & Produtividade Alta \\
\hline Adequado $(0-11)$ & 02 & 05 \\
\hline Desequilibrado $(>11)$ & 12 & 01 \\
\hline
\end{tabular}

Quadro 29. Índice de Balanço Nutricional de referência para os vinhedos amostrados pecíolo - $2^{\mathrm{a}}$ coleta (frutos entre ervilha e meia-baga)

\begin{tabular}{|c|c|c|}
\hline \multirow{2}{*}{ Ïndice de Balanço Nutricional } & \multicolumn{2}{|c|}{ Número de vinhedos } \\
\cline { 2 - 3 } & Produtividade Baixa & Produtividade Alta \\
\hline Adequado $(0-8)$ & 01 & 02 \\
\hline Desequilibrado $(>8)$ & 13 & 04 \\
\hline
\end{tabular}

Quadro 30.Índice de Balanço Nutricional de referência para os vinhedos amostrados pecíolo - 3a coleta (início de maturação das bagas)

\begin{tabular}{|c|c|c|}
\hline \multirow{2}{*}{ İndice de Balanço Nutricional } & \multicolumn{2}{|c|}{ Número de vinhedos } \\
\cline { 2 - 3 } & Produtividade Baixa & Produtividade Alta \\
\hline Adequado $(0-10)$ & 03 & 03 \\
\hline Desequilibrado $(>10)$ & 11 & 04 \\
\hline
\end{tabular}

De acordo com os valores de referência obtidos, o limbo foi o orgão que apresentou enquadramento mais coerente, pois os valores de referência foram semelhantes para as três épocas estudadas, enquanto que os valores para 
pecíolo variaram muito de época para época. Baseado nesse fato, o valor do índice de balanço nutricional onze (11) pode ser considerado uma referência para vinhedos de alta produtividade.

Da mesma forma, obteve-se que o florescimento ( 1 coleta) e o início da maturação dos frutos (3 coleta) foram consideradas as épocas mais adequadas para amostragem de folhas (limbo + pecíolo), pelo fato da maior coerência dos índices de balanço nutricional adotados como referência. Estes resultados estão de acordo com os de CHRISTENSEN et al. (1982), que afirma que a coleta do orgão para amostragem deve ser realizada no florescimento, onde ocorre um pico de concentração da maioria dos nutrientes nos tecidos, e com os de DAL BÓ et al. (1992), que afirma que a melhor época de coleta é a do início da maturação dos frutos, quando há maior estabilidade nos teores dos nutrientes nos tecidos.

A partir da definição do melhor órgão e das melhores épocas de amostragem procedeu-se ao estudo de cada vinhedo em particular, considerando-se portanto, apenas os dados de limbo no florescimento (1 $1^{\mathrm{a}}$ coleta) e início de maturação das bagas ( 3 a coleta). Através da interpretação desses dados, verificouse desordens nutricionais ligadas à deficiência dos macronutrientes potássio, magnésio e enxofre. Quanto aos micronutrientes as deficiências nutricionais foram pouco significativas. Desordens nutricionais ligadas a excesso se deram para o macronutriente nitrogênio na fase de florescimento (1 1 coleta) e para 0 micronutriente cobre nos dois estádios de desenvolvimento da videira nos vinhedos selecionados.

Da mesma forma, SCHALLER (1988) verificou a superioridade do Sistema Integrado de Diagnose e Recomendação (DRIS) para análise de folhas de videira.

A importância do DRIS para a cultura da videira cv. Itália se dá, principalmente pelo fato de ser uma cultura perene onde as desordens nutricionais ocorridas durante o seu ciclo afetam as plantas cumulativamente ao longo dos anos, além do fato destas correções de deficiência ou excesso, muitas vezes não poderem serem feitas durante o ciclo da cultura tornando a diagnose um fator fundamental no início do mesmo. 


\section{CONCLUSÕES}

O método foi considerado adequado para a avaliação do estado nutricional da videira em questão, pois permitiu determinar quais as melhores épocas e o melhor órgão de amostragem, as desordens nutricionais e os índices de referência para balanço nutricional. Os vinhedos número $06,12,13,14,15$ e 20 estão em equilibrio nutricional adequado pois apresentaram produção superior à média de $27,3 \mathrm{t} / \mathrm{ha}$, considerada adequada para a cultura da videira $\mathrm{cv}$. Itália, além de apresentarem índices de balanço nutricional em torno de 11 que foi o valor obtido como sendo referência para os vinhedos de alta produtividade.

O órgão de amostragem selecionado como mais adequado para a realização da avaliação do estado nutricional foi o limbo pois apresentou maior coerência no enquadramento do IBN de referência. Da mesma forma confirmou-se que o florescimento (1 ${ }^{\text {a }}$ coleta) e o início da maturação dos frutos (3 coleta) são épocas mais adequadas para a amostragem de folhas de videira, pois apresentaram resultados semelhantes e mais coerentes do que os dados obtidos quando os frutos estiveram entre ervilha e meia-baga ( 2 coleta).

Finalmente, quanto às limitações nutricionais os vinhedos selecionados apresentaram, no geral, deficiência dos macronutrientes potássio, magnésio e enxofre. $\mathrm{O}$ excesso de micronutrientes, com quase unanimidade para o cobre, também pode ser considerado um fator de baixa produtividade de alguns vinhedos estudados. 


\section{REFERÊNCIAS BIBLIOGRÁFICAS}

AHMED, S.H. A comparative study of petiole and leaf blade analysis in Anab-eShashi grape (Vitis vinifera L.). South Indian Horticulture, Coimbatore, 37(6): 317-22, 1989. Apud Horticultural Abstracts, Farnham Royal, 61(5): 420, may. 1991. (Resumo)

ALEXANDER, K.Mc.E. \& WOODHAM, R.C. Chemical composition on leaf tissues of sultana vines grown in solutions deficients in macroelements. Vitis, Siebeldigen, 9(3): 207,1970.

ANUÁRIO ESTATÍSTICO DO BRASIL - 1990/91, Rio de Janeiro, 53:321-38,1993.

ATALAY, I.Z. Petiole and leaf blade relationships for the determination of phosphorus status of Thompson Seedless grapes. Fertilizer and Agriculture, Paris, 42(97): 13-8,1988.

ATALAY, I.Z. The petiole and leaf blade relationships for the determination of phosphorus and zinc status of vineyards. Vitis, Siebeldigen, 17(2): 147-51, 1978.

BÁlO, E; PRILESZKY, G; HAPP, I; KOHALMI, M; VARGA, L. Soil improvement an the use of leaf analysis for forecasting nutrient requirements of grapes. Potash Review, Berne, (6):1-7,1988. Apud Horticultural Abstracts, Farnham Royal, 59(7):641, jul.1989. (Resumo)

CIFERRI, R. L. Acinellatura dell'uva in relazione alla criptocarenza di boro. Notice, Mal. Piante, 56: 25-32, 1961. Apud Horticultural Abstracts, Farnham Royal, 32(1): 86, mar. 1962. (Resumo) (No prelo)

CHRISTENSEN, L. P.; KASIMATIS, A.N.; JENSEN, F.L. Grapevine nutrition and fertilization in San Joaquim Valley. Berkely, Universidade of California, 1982.40p. (Publication, 4087)

COOK, A.; LYNN, C.D.; KISSLER, J.J. Boron deficiency in California vineyards. American Journal Enology and Viticulture, Sta Joseph, 11(4): 185-94,1960.

COUTINHO, J.F.; AHLRICHS, J.L.; MAGALHÃES, N.P. Nutrition in magnésium, potassium e calcium dans les vignobles à sols acides de la Vallée du Douro (Portugual). Progrés Agricole e Viticole, Montpellier,101(5):128-35,1984.

CUMMINGS, G.A. Variation in the concentration of certain elements in muscadine grape leaves related to season, leaf portion and age. Journal of the American Society for Horticultural Science, Santa Joseph, 102(3): 339-42,1977. Apud Horticultural Abstracts, Farnham Royal, 47(12):943, dec.1977. (Resumo) 
CRUZ, M.C.P. \& FERREIRA, M.E. Seleção de métodos para avaliação do boro disponível em solos. Pesquisa Agropecuária Brasileira, Brasília, 19:145764,1984 .

DAL BÓ, M.A.; BECKER, M.; BASSO, C.; STUKER, H. Levantamento do estado nutricional da videira em Santa Catarina por análise de solo e tecido. Revista Brasileira de Ciência do Solo, Campinas, 13:335-40,1989.

DECHEN, A.R. \& CARMELLO, Q.A. Interpretação para macro e micronutrientes no solo e na folha. $1^{\text {a }}$ ed. Piracicaba, ESALQ, Departamento de Química, $1985,2 \mathrm{p}$.

DELMAS, J. Recherches sur la nutrition minérale de la vigne, Vitis vinifera var. Merlot, em aquiculture. Bordeaux, 1971,266p. (D. S. Universidade de Bordeaux I).

DEPARDON, L. \& BURON, P. Av sujet du diagnostic foliare de la vigne. Cas particulier de la potasse. Comptes Rendus des Séances de l'Academie di Agriculture de France, Paris, 40:652-56,1954.

DIETRICH, J.V.; LEVY, J.F.; BRECHBUHLER, C. Próblems de la fertilation dans le vignoble alsacien. Resultats $d$ 'un essai sur alluvious récents. In: COLLOQUIUM EUROPEAN CONTRÔLE NUTRITION MINERALE FERTILITY VITICULTURE ARBORICULTURE, 1., Montpellier, 1964. Comptes Rendus, s.n.t., p.181-5. Apud Horticultural Abstracts, Farnham Royal, 36(3):508, sept.1966. (Resumo)

DULAC, J. Quinze ans a'essair de jumure sur la vigne à cruscades (Aude). In: COLLOQUIUM EUROPEAN CONTRÔLE NUTRITION MINERALE FERTILITY VITICULTURE ARBORICULTURE, 1., Montpellier,1964. Comptes Rendus, s.n.t., p.197-200,1965. Apud Horticultural Abstracts, Farnham Royal,36(3):507, sept.1965. (Resumo)

ESCANO, C.R.; JONES, C.A.; VEHARA, G. Nutrient diagnosis in corn grown on Hydric Dystrandepts: II Comparition of two sistems of tissue diagnosis. Soil Science Society American Journal, Madison,45:1140-4,1981.

FREGONI, M. Importanza del boro nella nutrizione dela vite. Vignevini, Bologna,4(6/7):35-7,1977.

GALLO, J.R. \& RIBAS, W.C. Análise foliar de diferentes combinações enxertocavalo para dez variedades de videira, Bragantia, Campinas, 21:397-410,1962.

GÜARTEL, W. A report on the recognition of magnesium deficiency in vines. Landwirtschaftliche Forschung Sonderheff., Frankfurt, 13:45-58,1959. Apud Horticultural Abstracts, Farnham Royal, 33(4):775, dec.,1961. (Resumo) 
GÜARTEL, W. The diagnostic value of leaf analysis for identifying nutritional disorders in vines. In: COLLOQUIUM EUROPEAN CONTRÔLE NUTRITION MINERALE FERTILITY VITICULTURE ARBORICULTURE, 1., Montpellier, 1964. Comptes Rendus, s.n.t., p.197-200,1965. Apud Horticultural Abstracts, Farnham Royal, 36(3):507, sept.,1966.

GONZALO GIL, S.; RODRIGUEZ, S.J.; GONZÁLEZ, M.S.; SUÁREZ, F.D.; URZÚA, H. Evolución estacional de nutrients minerales en hojas de vid (Vitis vinifera L.). Agricultura Técnica, Santiago do Chile, 33(2):45-53,1973.

GROMAKOVSKIJ, K.J. Diagnosis of the nutrient status of grape vines by means of leaf analysis. Sadovodstvo, Moscow, 7:30-2,1962. Apud Horticultural Abstracts, Farnham Royal, 33(1):67, mar., 1963.(Resumo)

GUILLÉN, M.G.; FERNANDEZ, F.G.\& CARO, M. Evolución anual de nutrients en hojas de frutales. IV: vid (parral). Anales de Edafologia y Agrobiologia, Madrid, 24:327-41,1965.

HANSON, R.G. DRIS evaluation of N,P,K status of determinent soybeans in Brazil. Communications Soil Science Plant Analysis, New York, 12(9):933-48,1981.

HERNANDO, V. \& MENDIOLA, J. Yields in a acordance with foliar analysis of vineyards in two different areas (La mancha and la rioja). In:COLLOQUIUM EUROPEAN CONTRÔLE NUTRITION MINERALE FERTILITY VITICULTURE ARBORICULTURE, 1., Montpellier, 1964. Comptes Rendus,s.n.t.,p.201-5,1965. Apud Horticultural Abstracts, Farnham Royal,36(3):507, sept.,1966. (Resumo)

HIROCE,R. \& TERRA, M.M. Teores de macronutrientes em pecíolo e limbo na videira "Niagara Rosada". In: CONGRESSO BRASILEIRO DE FRUTICULTURA, 7., Florianópolis, 1983. Anais. Florianópolis, SBF/EMPASC, 1984.P.1184-87.

JONES, C.A. Proposed modifications of the diagnosis and recomendation integrated system (DRIS) for interpreting plant analyses. Communications Soil Science Plant Analysis, New York, 12:785-974,1981.

JONES, C.A. \& BOWEN, J.E. Comparative DRIS and crop log analysis diagnosis of sugarcane tissue analysis. Agronomy Journal, Madison,73:941-4,1981.

JONES, M.B.; CENTER,D. M.; VAUGHN, C.E.; BELL, F.L. Using DRIS to asssay nutrients in subclover. Californy Agricultural, Berkeley, 40:19-21,1986.

KANNEMBERG,J. Leaf analysis in viticulture as an aid for diagnosi $g$ nitrogen requirement. Mitteilungen Klosterneuburg Rebe und Wein, Obstbau und Früchteverwertung, Klosterneuburg, 40(1):23-8,1990. Apud Horticultural Abstracts, Farnham Royal, 62(3): 240, mar.,1992. (Resumo) 
KOSMA, P.; PÓLYÁK, D.; DIOFÁSI, L. The effect of the metod of training and severity of pruning vines on the NPK content of the leaves. Kértészeti Eggytem Kozteményei, Budapest, 33(1):135-54,1969. Apud Horticultural Abstracts, Farnham Royal, 40(4);985, dec., 1970. (Resumo)

KOVANCI, I \& ATALAY, I.Z. Petiole and leaf blade relationships for the determination of phosphorus status in Thompson Seedless grapes. Dogã Turk Tarim ve Ormancilik Devgisi, Ankara, 11(1):30-5,1987. Apud Horticultural Abstracts, Farnham Royal, 57(12):986, dec.,1987. (Resumo)

KUNIYUKI, H.; TERRA, M.M. HIROCE, R.; COSTA, A.S. Clorose das folhas e escurecimento dos frutos da videira associados à deficiência de boro. Summa Phytopathologica, Campinas, 8(1/2):27-9,1982.

LAVIN, A.A. \& VALENZUELA, B.J. Fuentes y dosis de nitrogênio aplicados sobre vides cv. Pedro Jimenez, bajo secano. II. Efectos sobre niveles de macronutrientes a plena flor y madurez del fruto. Agricultura Técnica, Santiago do Chile, 46(3):267-1-70,1986.

LAVY, J.F. L'appliction du diagnostic foliare à la determination des besoinsallimentaires des vignes. In: MEM. GEN. COLLOQUIUM EUROPEAN MEDIT. CONTRÔLE FERT. PLANT CULT.,2., Seville, 1968. Memoirs generales, s.n.t., p.295-305.

LEITE, R.A. avaliação do estado nutricional do cafeeiro Conilon no Estado do Espírito Santo utilizando diferentes métodos de interpretação de análise foliar. Viçosa, 1993, 87p. (D.S. Universidade Federal de Viçosa).

LINDSAY, W.L. \& NORVELL, W.A. Development of a DTPA soil test for zinc, iron, manganese and copper. Soil Science American Journal, Madison, 42:42128,1978 .

MALAVOLTA, E.; VITTI, G.C.; DE OLIVEIRA, S.A. Avaliação do Estado Nutricional das Plantas. Piracicaba, POTAFOS,1989.201p.

MELLO de, A.F.; BRASIL SOBRINHO, M.O.C.; ARZOLLA, S.; SILVEIRA,R.I;; COBRA NETTO, A.; KIEHL, J.C. Fertilidade do Solo. 3a ed. São Paulo, Livraria Nobel S.A., 1981.400p.

MERINO, H.R.; ETCHEVERS, B.J.; MATAMALA, E.P. Efectos de la época de muestro sobre los contenidos de boro del suelo y hojas en viñedos de secano del centro sur de Chile (34-36 ${ }^{\circ}$ S). Turialba, Santiago do Chile, 24(4):38792,1974. Apud Horticultural Abstracts, Farnham Royal,46(3):97, mar. 1976. (Resumo)

MEYER, J.H. Advances in the interpretation of foliar analysis of sugarcane in the South African Sugar Industry. South African Sugar Journal, Durban,59(11):569-85, 1975. 
NARS, T.A. \& ABO-HASSAN, A.A. Fruitfulness of Taefigrapes as influenced by cane thickness and nitrogen level in Riyadh, Sand i Arabia. In: ST. INTERNATIONAL HORTICULTURAL CONGRESS,21.,Hamburg, 1980. Abstracts. s.1., International Society for Horticultural Science, 1982. Vol I.

RAIJ, B. van. Análise química do solo para fins de fertilidade. Campinas, Fundação Cargill, 1987. 170p.

RODRIGUEZ, T.P. \& GONZÁLEZ-GARCIA, F. Equilíbrio nutritivo em vinhedos de Andalucia Ocidental, zonas de El Condado y Jerez de la frontera (Espãnã). In: COLLOQUIUM EUROPEAN CONTRÔLE NUTRITION MINERALE FERTILITY VITICULTURE ARBORICULTURE, 1., Montpellier, 1964. Comptes Rendus,s.l., s.ed,, p.227-333,1965. Apud Horticultural Abstracts, Farnham Royal,36(3):507, sept.,1966. (Resumo)

SARIC, M.R.; ZORZIC,M.; BURIC,D. The influence of the rootstock and scion on ion uptake and distribution. Vitis, Siebeldingen, 16(3):174-83,1977.

SAROSI, M. Etudes effectuées en Hongrie en connexion avec le contrôle de la nutrition de la vigne par l'analyse des jenilles. In: COLLOQUIUM EUROPEAN CONTRÔLE NUTRITION MINERALE FERTILITY VITICULTURE ARBORICULTURE, 1.,Montpellier,1964. Comptes Rendus, s.1. ,s.ed.,p.242-49,1965. Apud Horticultural Abstracts, Farnham Royal, 36(3):508, sept.,1966. (Resumo)

SCHALLER,K. Assessment of nutrient status of grapevines by leaf analysis in four P-fertilization studies with special regard to the DRIS system. Mitteilungen Klosterneuburg rebe und Wein, Obstbau und Fruchteverwertung, Klosterneuburg, 38(4):151-63,1988. Apud Horticultural Abstracts, Farnham Royal, 58(11):920, nov.,1988. (Resumo)

SAUER, M.R. Boron content of sultana vines in the Mildura área. Australian Journal Agriculture Research, East Melbourne, 9:123-8,1958. Apud Horticultural Abstracts, Farnham Royal,28(3):374, sept.,1959. (Resumo)

SHAGAVI, K.U. \& NIJJAR, G.S. Effect of factorial combinations of nitrogen, phosphorus and potassium on the yield and quality of Himrod grape. Punjab Horticultural Journal, Patiola, 18(1/2):48-52,1978. Apud Horticultural Abstracts, Farnham Royal, 50(5): 273, mai.,1980. (Resumo)

SHIKHAMANY, S.D. \& SATYANARAYANA, G. Comparative study of petiole and leaf blade analysis in Anab-e-Shahigrape (Vitis vinifera L.). Indian Journal of Horticulture, Bangalore, 28(4):264-69,1971. Apud Horticultural Abstracts, Farnham Royal, 43(12):829, dec., 1973. (Resumo)

SOUSA, J.S. I. de. Uvas para o Brasil. São Paulo, Melhoramentos, 1969.454 p. 
STANIMIROVIC, P. The use of foliar diagnosis for determining the nutrient requirements of vines. Zbornik Biotehniske Institute Vinogrado Voc. Sremski Karlouci, Lybljana, (1):49-61,1968. Apud Horticultural Abstrcts, Farnham Royal, 40(1);717, mar.,1970. (Resumo)

SUMNER, M.E. A new aproach for predicting nutrients needs for increase crop yields. Fertilizer Soil, Peoria, (22):68-78,1978.

SUMNER, M.E. Application of Beaufils'Diagnostic índices to maize data published in the literature irrespective of age and conditions. Plant and Soil, The Hague, (46):359-69,1977.

SUMNER, M.E. Preliminary NPK foliar diagnostic norms for wheatl Communications in Soil Science Plant Analysis, New York, 8(2):149$67,1977 \mathrm{a}$.

SUMNER, M.E. Use of the DRIS system in foliar diagnosis of crops at high yield level. Communications Soil Science Plant Analysis, New York, 8:252$68,1977 \mathrm{~b}$.

SUMNER, M.E. Effect of corn leaf sampled or N,P,K,Ca and $\mathrm{Mg}$ content and calculated Dris índices. Communications Soil Science Plant Analysis, New York, 8:269-80,1977c.

SUMNER, M.E. \& BEAUFILS, E.R. Diagnosis of the NPK requirements of sugarcane irrespective of plant age and season using Beaufils'System (DRIS), Proceedings of South African Sugar Technologistis Association, Mounth Edgecombe, (6/7):1-5,1975.

SNOECK, J. Caféier. In: MARTIN-PRÉVEL, P; GAGNARD, J; GAUTIER,P. L'Analyse végétale dans le contrôle de l'alimentation des plantes. Paris, Techinique que et Documentation-Lavousier, 1984.p.473-95.

TERRA, M.M.; PIRES, E.J.P.; NOGUEIRA, N.A.M. Tecnologia para produção de uva Itália na região noroeste do Estado de São Paulo. Campinas, CATI, 1993.51p. (Documento Técnico, 97)

TRANI, P.E. \& DRUGOWICH, M.I.,comp. Análise do solo e análise foliar. Campinas, SAA/CATI, Centro de Comunicação Rural,1989. 4p.

URETA, C.F. Fertilizacion de la vid. El Campesino, Santiago do Chile, 6:25$34,1981$.

ULRICH, A. Potassium content of grape leach petioles and blades contrasted with soil analysis as an indicator of the potassium status of the plant. Proceedings of Horticultural Science, Santa Joseph, 41:204-12,1942.

VALENZUELA, B.J. \& NARVAEZ, S.C. Algunos factores associados a excessos de boro en viñedos del Valle de Elqui. Agricultura Técnica, Santiago do Chile, 43(2):145-49,1983. 
VALENZUELA, B.J. \& SEPÚLVEDA, R.G. Excesso de Boro em vinhedos del Valle de Elqui. Agricultura Técnica, Santiago do Chile, 37(2):93-6,1977. Apud Horticultural Abstracts, Farnham Royal, 48(4):289, abr.,1978. (Resumo)

VANEK, G.; MOSNÝ,V.; KOLÓYOVÁ, V. Evidence of magnesium deficiency in vines. Pol'nohospodárstvo, Bratislava, 13:185-92,1967. Apud Horticultural Abstrcts, Farnham Royal, 38(11):773, mar.,1967. (Resumo)

VERMA, H.S. \& NIJJAR, G.S. Response surface studies on the effect of N,P and K fertilizers on vine growth, yield and fruit quality. Journal of Horticultural Science, Ashford, 53(3):163-66,1978. Apud Horticultural Abstracts, Farnham Royal, 48(12):923, dec., 1978. (Resumo)

WALWORTH,J.L. \& SUMNER, M.E. The diagnosis and recomendation integrated system. In: STEWART, B.A. Advances in Soil Science, New York, SpringerVerlag, p.150-88,1987.

ZAMBELLO JR., E. Aplicação do Sistema Integrado de Diagnose e Recomendação para diferentes solos e épocas de amostragem foliar em soqueiras de cana-de açúcar (Saccharum ssp.). Piracicaba, 1979,95p. (Mestrado - Escola Superior de Agricultura "Luiz de Queiróz"- USP).

ZAMBELLO JR, E. \& ORLANDO F , J. Aplicação do Sistema Integrado de Diagnose e Recomendação (DRIS) em soqueiras de três variedades de cana-de açúcar. STAB. Açucar, Álcool e Subprodutos, Piracicaba, (3):23-8,1979.

ZAMBELLO JR. E. \& ORLANDO $\mathrm{F}^{\circ}$, J. Sistema Integrado de Diagnose e Recomendação (DRIS) aplicado a cana-planta com e sem irrigação. In: CONGRESSO NACIONAL DOS TÉCNICOS AÇUCAREIROS DO BRASIL, 1., Maceió, 1979. Anais. Maceió, STAB, 1980. p.353-56

ZAMBELLO JR. E. \& ORLANDO F ${ }^{\circ}, J$. Diagnosis and Recomendation Integrated System (DRIS) applied to various sugarcane tissues. In: CONGRESS OF THE INTERNATIONAL SOCIETY OF SUGARCANE TECHNOLOGISTS, 17. Manila, 1979. Proceedings. Manila, The Executive Committee of the ISSCT, p.446-57,1980. 
A P E E N I C E S 
APÊNDICE 1. Resultados das análises químicas de macro e micronutrientes de solo para os vinhedos amostrados, na profundidade de $0-20 \mathrm{~cm}$, em levantamento nutricional na região de Jales, ano de 1991.

\begin{tabular}{|c|c|c|c|c|c|c|c|c|c|c|c|c|c|c|c|}
\hline \multirow{2}{*}{$\begin{array}{l}\text { JALES } \\
0-20 \mathrm{~cm}\end{array}$} & $\mathrm{pH}$ & M.O. & $\mathrm{P}$ & $\mathrm{K}$ & $\mathrm{Ca}$ & $\mathrm{Mg}$ & $\mathrm{H}+\mathrm{Al}$ & SB & CTC & \multirow{2}{*}{$\begin{array}{l}\mathrm{V} \\
\%\end{array}$} & $\mathrm{~B}$ & $\mathrm{Cu}$ & & $\mathrm{Mn}$ & $\mathrm{Zn}$ \\
\hline & $\mathrm{CaCl}_{2}$ & $\%$ & $\mu / \mathrm{cm}^{3}$ & & & $\mathrm{meq} / 1$ & $00 \mathrm{~cm}^{3}$ & & & & \multicolumn{5}{|c|}{ ppm } \\
\hline JAL 01 & 6,4 & 3,2 & 370 & 0,18 & 9,4 & 3,3 & 1,1 & 12,9 & 14,0 & 92 & 4 & 24 & 62 & 138 & 40 \\
\hline JAL 02 & 6,4 & 2,8 & 26 & 0,32 & 7,7 & 2,9 & 1,1 & 10,9 & 12,0 & 91 & 2 & 22 & 76 & 166 & 15 \\
\hline JAL 03 & 6,5 & 2,3 & 300 & 0,49 & 6,7 & 2,0 & 1,1 & 9,2 & 10,3 & 89 & 2 & 9 & 25 & 129 & 16 \\
\hline JAL 04 & 6,4 & 2,7 & 54 & 0,29 & 4,4 & 1,5 & 1,2 & 6,2 & 7,4 & 84 & 3 & 6 & 38 & 114 & 7 \\
\hline JAL 05 & 6,0 & 3,4 & 43 & 0,76 & 4,3 & 1,8 & 1,3 & 6,9 & 8,2 & 84 & $\overline{3}$ & 10 & 137 & 139 & 10 \\
\hline JAL 06 & 4,2 & 2,8 & 53 & 0,29 & 1,8 & 0,4 & 3,8 & 2,5 & 6,3 & 40 & 1 & 5 & 39 & 92 & 51 \\
\hline JAL 07 & 6,0 & 4,2 & 80 & 0,60 & 5,9 & 2,5 & 1,5 & 9,0 & 10,5 & 86 & 38 & 8 & 61 & 141 & 25 \\
\hline JAL 08 & 4,9 & 2,3 & 108 & 1,34 & 3,2 & 0,9 & 3,1 & 5,4 & 8,5 & 64 & 5 & 17 & 50 & 145 & 11 \\
\hline JAL 09 & 6,2 & 3,1 & 211 & 0,29 & 5,9 & 2,1 & 1,1 & 8,3 & 9,4 & 88 & 4 & 38 & 69 & 111 & 22 \\
\hline JAL 10 & 6,2 & 3,1 & 31 & 0,14 & 4,7 & 2,2 & 1,1 & 7,0 & 8,1 & 86 & 3 & 4 & 61 & 61 & 8 \\
\hline JAL 11 & 3,7 & 3,3 & 145 & 0,28 & 1,2 & 0,2 & 5,2 & 1,7 & 6,9 & 25 & 3 & 3 & 44 & 44 & 6 \\
\hline JAL 12 & 6,3 & 4,0 & 233 & 0,46 & 7,3 & 2,3 & 1,2 & 10,1 & 11,3 & 89 & 3 & 11 & 121 & 121 & 18 \\
\hline JAL 13 & 5,7 & 4,5 & 37 & 0,49 & 3,8 & 1,1 & 1,6 & 5,4 & 7,0 & 77 & 4 & 14 & 137 & 137 & 10 \\
\hline $\mathrm{JAL} 14$ & 4,9 & 4,5 & 48 & 0,75 & 6,0 & 1,9 & 3,8 & 8,7 & 12,5 & 70 & 4 & 9 & 185 & 185 & 4 \\
\hline JAL 15 & 5,5 & 3,7 & 68 & 0,58 & 3,3 & 1,0 & 1,3 & 4,9 & 6,2 & 79 & 3 & 7 & 136 & 136 & 7 \\
\hline JAL 16 & 5,5 & 3,3 & 11 & 0,22 & 1,9 & 0,7 & 1,2 & 2,8 & 4,0 & 70 & 2 & 5 & 87 & 87 & 4 \\
\hline JAL 17 & 6,1 & 4,4 & 300 & 0,29 & 8,5 & 1,9 & 1,2 & 10,7 & 11,9 & 90 & 4 & 37 & 130 & 130 & 22 \\
\hline JAL 18 & 6,4 & 1,4 & 33 & 0,26 & 4,8 & 2,5 & 0,9 & 7,6 & 8,5 & 89 & 3 & 2 & 89 & 89 & 6 \\
\hline JAL 19 & 6,4 & 2,8 & 259 & 0,49 & 8,1 & 2,1 & 1,2 & 10,7 & 11,9 & 90 & 4 & 35 & 122 & 122 & 26 \\
\hline JAL 20 & 6,8 & 2,8 & 173 & 2,40 & 8,5 & 3,7 & 1,0 & 14,6 & 15,6 & 94 & 4 & 9 & 128 & 128 & 17 \\
\hline
\end{tabular}


APÊNDICE 2. Resultados das análises químicas de macro e micronutrientes de solo para os vinhedos amostrados, na profundidade de $20-40 \mathrm{~cm}$, em levantamento nutricional na região de Jales, ano de 1991.

\begin{tabular}{|c|c|c|c|c|c|c|c|c|c|c|c|c|c|c|c|}
\hline JALES & $\mathrm{pH}$ & M.O. & $P$ & $\mathrm{~K}$ & $\mathrm{Ca}$ & $\mathrm{Mg}$ & $\mid \mathrm{H}+\mathrm{Al}$ & SB & CTC & V & B & $\mathrm{Cu}$ & $\mathrm{Fe}$ & Mn & $\mathrm{Zn}$ \\
\hline $0-20 \mathrm{~cm}$ & $\mathrm{CaCl}_{2}$ & $\%$ & $\mu / \mathrm{cm}^{3}$ & & & meq & $100 \mathrm{~cm}^{3}$ & & & $\%$ & & & $\mathrm{ppm}$ & & \\
\hline JAL 01 & 6,4 & 1,8 & 189 & 0,24 & 3,3 & 1,4 & 1,2 & 4,9 & 6,1 & 80 & 2 & 5 & 91 & 38 & 4 \\
\hline JAL 02 & 6,5 & 1,9 & 61 & 0,32 & 3,1 & 1,5 & 1,1 & 4,9 & 6,0 & 82 & 2 & 3 & 77 & 59 & 2 \\
\hline JAL 03 & 6,4 & 1,9 & 44 & 0,71 & 2,8 & 1,0 & 1,2 & 4,5 & 5,7 & 79 & 2 & 2 & 69 & 53 & 2 \\
\hline JAL 04 & 5,1 & 2,4 & 06 & 0,26 & 1,8 & 0,6 & 2,0 & 2,7 & 4,7 & 57 & 2 & 2 & 44 & 68 & 1 \\
\hline JAL 05 & 5,4 & 2,2 & 07 & 0,62 & 3,1 & 1,2 & 2,0 & 4,9 & 6,9 & 71 & 2 & 2 & 67 & 52 & 1 \\
\hline JAL 06 & 4,8 & 2,3 & 13 & 0,21 & 1,6 & 0,3 & 2,0 & 2,1 & 4,1 & 51 & 1 & 2 & 40 & 68 & 5 \\
\hline JAL 07 & 5,1 & 2,8 & 61 & 0,43 & 2,0 & 0,9 & 2,0 & 3,3 & 5,3 & 62 & 2 & 3 & 50 & 55 & 6 \\
\hline JAL 08 & 5,5 & 2,0 & 30 & 0,73 & 4,5 & 1,2 & 3,4 & 6,4 & 9,8 & 65 & 3 & 4 & 45 & 110 & 4 \\
\hline JAL 09 & 6,5 & 2,3 & 65 & 0,21 & 2,7 & 1,2 & 1,1 & 4,1 & 5,2 & 79 & 4 & 5 & 55 & 42 & 5 \\
\hline JAL 10 & 4,2 & 2,6 & 02 & 0,10 & 0,6 & 0,6 & 2,5 & 1,3 & 3,8 & 34 & 3 & 2 & 87 & 27 & 1 \\
\hline JAL 11 & 4,5 & 3,3 & 96 & 0,36 & 1,7 & 0,6 & 3,1 & 2,7 & 5,8 & 47 & 4 & 2 & 75 & 59 & 6 \\
\hline JAL 12 & 6,0 & 3,1 & 24 & 0,48 & 2,3 & 0,7 & 1,5 & 3,5 & 5,0 & 70 & 3 & 3 & 63 & 74 & 2 \\
\hline JAL 13 & 5,6 & 3,3 & 04 & 0,38 & 2,7 & 0,8 & 1,5 & 3,9 & 5,4 & 72 & 3 & 2 & 137 & 83 & 2 \\
\hline JAL 14 & 5,1 & 3,7 & 09 & 0,67 & 5,5 & 2,4 & 3,4 & 8,6 & 12,0 & 72 & 3 & 6 & 51 & 91 & 3 \\
\hline JAL 15 & 5,3 & 3,5 & 23 & 0,67 & 3,0 & 1,0 & 2,0 & 4,7 & 6,7 & 70 & 4 & 2 & 67 & 76 & $\overline{2}$ \\
\hline JAL 16 & 5,5 & 3,2 & 03 & 0,29 & 1,9 & 0,6 & 1,3 & 2,8 & 4,1 & 68 & 2 & 1 & 51 & 49 & 2 \\
\hline JAL 17 & 6,2 & 3,6 & 195 & 0,35 & 5,0 & 1,3 & 1,2 & 6,7 & 7,9 & 85 & 3 & 10 & 99 & 106 & 6 \\
\hline JAL 18 & 5,9 & 1,2 & 03 & 0,37 & 2,6 & 1,4 & 1,6 & 4,4 & 6,0 & 73 & 3 & 3 & 50 & 33 & 2 \\
\hline JAL 19 & 6,2 & 1,4 & 30 & 0,62 & 2,6 & 0,9 & 1,5 & 4,1 & 5,6 & 73 & 3 & 3 & 50 & 41 & 3 \\
\hline JAL 20 & 6,7 & 1,5 & 43 & 1,15 & 2,2 & 1,4 & 1,1 & 4,8 & 5,9 & 81 & 3 & 2 & 144 & 57 & 7 \\
\hline
\end{tabular}


APÊNDICE 3. Resultados das análises químicas de macro e micronutrientes de limbo, no florescimento (1 1 coleta), para os vinhedos amostrados, em levantamento nutricional na região de Jales, ano de 1991.

\begin{tabular}{|c|c|c|c|c|c|c|c|c|c|c|c|}
\hline \multirow{3}{*}{ Vinhedos } & \multicolumn{11}{|c|}{ Nutrientes } \\
\hline & $\mathrm{N}$ & $\mathrm{P}$ & $\mathrm{K}$ & $\mathrm{Ca}$ & $\mathrm{Mg}$ & $\mathrm{S}$ & B & $\mathrm{Cu}$ & $\mathrm{Fe}$ & $\mathrm{Mn}$ & $\mathrm{Zn}$ \\
\hline & \multicolumn{6}{|c|}{$\%$} & \multicolumn{5}{|c|}{ ppm } \\
\hline JAL 01 & 4,40 & 0,57 & 2,24 & 2,28 & 0,46 & 0,09 & 36 & 36 & 292 & 3205 & 511 \\
\hline JAL 02 & 5,49 & 0,80 & 2,16 & 2,57 & 0,48 & 0,72 & 33 & 41 & 318 & 1674 & 207 \\
\hline JAL 03 & 4,89 & 0,69 & 2,07 & 2,93 & 0,53 & 0,63 & 49 & 22 & 385 & 318 & 157 \\
\hline JAL 04 & 4,32 & 0,50 & 2,22 & 2,66 & 0,48 & 0,69 & 504 & 661 & 428 & 1050 & 159 \\
\hline JAL 05 & 4,77 & 0,54 & 2,16 & 2,17 & 0,55 & 0,55 & 41 & 18 & 432 & 916 & 113 \\
\hline JAL 06 & 3,64 & 0,35 & 1,83 & 2,82 & 0,41 & 0,81 & 36 & 16 & 259 & 3040 & 377 \\
\hline JAL 07 & 3,12 & 0,55 & 1,94 & 2,00 & 0,37 & 0,92 & 49 & 11 & 398 & 5225 & 502 \\
\hline JAL 08 & 4,71 & 0,58 & 2,15 & 2,36 & 0,58 & 0,57 & 32 & 38 & 387 & 744 & 68 \\
\hline JAL 09 & 4,82 & 0,61 & 2,35 & 2,67 & 0,57 & 0,94 & 51 & 245 & 414 & 2351 & 285 \\
\hline JAL 10 & 3,64 & 0,58 & 1,96 & 1,89 & 0,39 & 0,84 & 44 & 10 & 511 & 4571 & 520 \\
\hline JAL 11 & 3,84 & 0,48 & 1,77 & 2,04 & 0,38 & 0,81 & 34 & 12 & 353 & 2488 & 320 \\
\hline JAL 12 & 4,53 & 0,59 & 2,30 & 2,78 & 0,61 & 0,92 & 44 & 32 & 379 & 3210 & 353 \\
\hline JAL 13 & 4,04 & 0,57 & 2,14 & 2,24 & 0,36 & 0,61 & 42 & 95 & 502 & 1218 & 177 \\
\hline JAL 14 & 4,87 & 0,74 & 2,59 & 2,93 & 0,48 & 0,70 & 65 & 23 & 521 & 485 & 110 \\
\hline JAL 15 & 4,04 & 0,53 & 2,11 & 2,46 & 0,43 & 0,60 & 45 & 24 & 291 & 1095 & 277 \\
\hline JAL 16 & 4,13 & 0,49 & 1,39 & 1,69 & 0,24 & 0,53 & 49 & 19 & 240 & 600 & 62 \\
\hline JAL 17 & 3,76 & 0,71 & 1,91 & 1,92 & 0,23 & 0,52 & 54 & 412 & 261 & 827 & 104 \\
\hline JAL 18 & 4,24 & 0,67 & 2,16 & 2,90 & 0,59 & 0,65 & 46 & 15 & 706 & 977 & 100 \\
\hline JAL 19 & 4,28 & 0,70 & 1,52 & 2,50 & 0,40 & 0,84 & 56 & 18 & 555 & 2853 & 314 \\
\hline JAL 20 & 4,90 & 0,77 & 2,51 & 2,04 & 0,60 & 0,73 & 44 & 46 & 526 & 1380 & 241 \\
\hline
\end{tabular}


APÊNDICE 4. Resultados das análises químicas de macro e micronutrientes de limbo, na fase de frutos entre ervilha e meia-baga ( 2 coleta), para os vinhedos amostrados, em levantamento nutricional na região de Jales, ano de 1991.

\begin{tabular}{|c|c|c|c|c|c|c|c|c|c|c|c|}
\hline \multirow{3}{*}{ Vinhedos } & \multicolumn{11}{|c|}{ Nutrientes } \\
\hline & $\mathrm{N}$ & $\mathrm{P}$ & $\mathrm{K}$ & $\mathrm{Ca}$ & $\mathrm{Mg}$ & $\mathrm{S}$ & $\mathrm{B}$ & $\mathrm{Cu}$ & $\mathrm{Fe}$ & $\mathrm{Mn}$ & $\mathrm{Zn}$ \\
\hline & \multicolumn{6}{|c|}{$\%$} & \multicolumn{5}{|c|}{ ppm } \\
\hline JAL 01 & 4,23 & 0,65 & 2,09 & 1,85 & 0,39 & 0,95 & 36 & 44 & 834 & 3066 & 592 \\
\hline JAL 02 & 4,34 & 1,17 & 2,08 & 2,41 & 0,44 & 0,70 & 31 & 16 & 518 & 1942 & 267 \\
\hline JAL 03 & 4,44 & 0,70 & 1,79 & 2,68 & 0,47 & 0,43 & 46 & 311 & 892 & 427 & 104 \\
\hline JAL 04 & 4,19 & 0,46 & 2,32 & 2,56 & 0,49 & 0,52 & 41 & 4121 & 449 & 442 & 68 \\
\hline JAL 05 & 4,93 & 0,43 & 1,82 & 2,15 & 0,49 & 0,64 & 26 & 727 & 1677 & 638 & 53 \\
\hline JAL 06 & 4,15 & 0,36 & 2,57 & 2,24 & 0,40 & 0,80 & 40 & 14 & 758 & 1853 & 201 \\
\hline JAL 07 & 4,00 & 0,48 & 2,44 & 1,80 & 0,36 & 0,89 & 50 & 11 & 336 & 2341 & 226 \\
\hline JAL 08 & 3,56 & 0,63 & 2,05 & 2,37 & 0,49 & 0,61 & 31 & 1928 & 945 & 616 & 36 \\
\hline JAL 09 & 3,75 & 0,49 & 2,01 & 2,26 & 0,39 & 0,71 & 42 & 2060 & 817 & 953 & 217 \\
\hline JAL 10 & 4,44 & 0,60 & 2,49 & 1,63 & 0,37 & 1,09 & 66 & 30 & 412 & 4804 & 971 \\
\hline JAL 11 & $\overline{4,47}$ & 0,58 & 2,64 & 2,12 & 0,43 & 0,62 & 26 & 11 & 297 & 1098 & 137 \\
\hline JAL 12 & 3,66 & 0,47 & 1,79 & 2,41 & 0,51 & 0,97 & 35 & 1218 & 1437 & 3043 & 575 \\
\hline JAL 13 & 4,31 & 0,61 & 2,62 & 2,53 & 0,43 & 0,69 & 42 & 12 & 271 & 978 & 98 \\
\hline JAL 14 & 3,43 & 0,69 & 2,10 & 2,01 & 0,33 & 0,44 & 51 & 19 & 463 & 612 & 143 \\
\hline JAL 15 & 4,35 & 0,70 & 2,51 & 3,31 & 0,53 & 0,62 & 55 & 150 & 243 & 855 & 122 \\
\hline JAL 16 & 3,65 & 0,44 & 2,31 & 2,12 & 0,43 & 0,40 & 47 & 46 & 597 & 461 & 45 \\
\hline JAL 17 & 3,89 & 0,87 & 2,30 & 2,40 & 0,37 & 0,52 & 53 & 555 & 817 & 636 & 129 \\
\hline JAL 18 & 3,22 & 1,00 & 1,93 & 2,65 & 0,49 & 0,46 & 44 & 13 & 2818 & 331 & 21 \\
\hline JAL 19 & 4,24 & 0,78 & 2,65 & 2,68 & 0,53 & 0,73 & 64 & 2630 & 769 & 1093 & 113 \\
\hline JAL 20 & 3,49 & 0,91 & 2,30 & 1,71 & 0,55 & 0,77 & 49 & 44 & 1835 & 1377 & 202 \\
\hline
\end{tabular}


APÊNDICE 5. Resultados das análises químicas de macro e micronutrientes de limbo, no início de maturação das bagas (3a coleta), para os vinhedos amostrados, em levantamento nutricional na região de Jales, ano de 1991.

\begin{tabular}{|c|c|c|c|c|c|c|c|c|c|c|c|}
\hline \multirow{3}{*}{ Vinhedos } & \multicolumn{11}{|c|}{ Nutrientes } \\
\hline & $\mathrm{N}$ & $\mathrm{P}$ & $\mathrm{K}$ & $\mathrm{Ca}$ & $\mathrm{Mg}$ & $\mathrm{S}$ & $B$ & $\mathrm{Cu}$ & $\mathrm{Fe}$ & $\mathrm{Mn}$ & $\mathrm{Zn}$ \\
\hline & \multicolumn{6}{|c|}{$\%$} & \multicolumn{5}{|c|}{$\mathrm{ppm}$} \\
\hline JAL 01 & 3,09 & 0,58 & 1,44 & 2,60 & 0,56 & 0,62 & 34 & 51 & 1709 & 1919 & 472 \\
\hline JAL 02 & 3,15 & 1,14 & 5,28 & 2,53 & 1,21 & 0,10 & 28 & 199 & 81 & 1413 & 61 \\
\hline JAL 03 & 3,30 & 0,69 & 1,36 & 3,29 & 0,55 & 0,25 & 32 & 295 & 1503 & 1368 & 90 \\
\hline JAL 04 & 2,83 & 0,34 & 1,11 & 3,75 & 0,54 & 0,40 & 25 & 4316 & 1158 & 498 & 193 \\
\hline JAL 05 & 3,27 & 0,52 & 1,25 & 3,15 & 0,67 & 0,41 & 34 & 2193 & 1958 & 807 & 80 \\
\hline JAL 06 & 2,72 & 0,27 & 1,52 & 3,79 & 0,65 & 0,65 & 21 & 229 & 1516 & 1610 & 413 \\
\hline JAL 07 & 2,82 & 0,48 & 1,43 & 2,59 & 0,32 & 0,52 & 22 & 11 & 1206 & 1455 & 309 \\
\hline JAL 08 & 3,15 & 0,49 & 1,19 & 3,15 & 0,67 & 0,33 & 30 & 2200 & 1615 & 1552 & 39 \\
\hline JAL 09 & 3,21 & 0,46 & 1,19 & 2,94 & 0,50 & 0,40 & 32 & 1758 & 1465 & 2311 & 164 \\
\hline JAL 10 & 3,08 & 0,64 & 1,39 & 2,63 & 0,40 & 0,46 & 35 & 23 & 1213 & 2827 & $\overline{635}$ \\
\hline JAL 11 & 2,88 & 0,48 & 1,40 & 2,66 & 0,45 & 0,39 & 20 & 10 & 453 & 641 & 70 \\
\hline JAL 12 & 3,30 & 0,54 & 1,21 & 2,92 & 0,64 & 0,62 & 26 & 1953 & 1692 & 589 & 442 \\
\hline JAL 13 & 2,86 & 0,42 & 1,36 & 2,90 & 0,42 & 0,41 & 32 & 7 & 1374 & 736 & 50 \\
\hline JAL 14 & 3,50 & 0,88 & 1,53 & 3,30 & 0,45 & 0,30 & 46 & 81 & 1307 & 2250 & 87 \\
\hline JAL 15 & 2,52 & 0,57 & 1,17 & 3,07 & 0,46 & 0,40 & 33 & 60 & 845 & 450 & 158 \\
\hline JAL 16 & 3,22 & 0,48 & 1,95 & 2,62 & 0,51 & 0,48 & 48 & 21 & 1376 & 311 & 34 \\
\hline JAL 17 & 3,26 & 1,45 & 1,73 & 3,68 & 0,43 & 0,62 & 37 & 2382 & 1960 & 917 & 184 \\
\hline JAL 18 & 3,22 & 0,94 & 4,55 & 3,29 & 1,52 & 0,10 & 46 & 11 & 141 & 419 & 40 \\
\hline JAL 19 & 2,79 & 0,73 & 1,47 & 3,23 & 0,55 & 0,51 & 43 & 3509 & 1725 & 941 & 101 \\
\hline JAL 20 & 3,35 & 0,99 & 5,59 & 1,93 & 1,99 & 0,13 & 32 & 5 & 102 & 764 & 53 \\
\hline
\end{tabular}


APÊNDICE 6. Resultados das análises químicas de macro e micronutrientes de pecíolo, no florescimento ( $1^{\mathrm{a}}$ coleta), para os vinhedos amostrados, em levantamento nutricional na região de Jales, ano de 1991.

\begin{tabular}{|c|c|c|c|c|c|c|c|c|c|c|c|}
\hline \multirow{3}{*}{ Vinhedos } & \multicolumn{11}{|c|}{ Nutrientes } \\
\hline & $\mathrm{N}$ & $\mathrm{P}$ & $\mathrm{K}$ & $\mathrm{Ca}$ & $\mathrm{Mg}$ & $\mathrm{S}$ & $\mathrm{B}$ & $\mathrm{Cu}$ & $\mathrm{Fe}$ & $\mathrm{Mn}$ & $\mathrm{Zn}$ \\
\hline & \multicolumn{6}{|c|}{$\%$} & \multicolumn{5}{|c|}{ ppm } \\
\hline JAL 01 & 1,41 & 0,79 & 6,21 & 1,57 & 0,44 & 0,28 & 33 & 12 & 62 & 778 & 97 \\
\hline JAL 02 & 1,89 & 0,91 & 6,33 & 1,91 & 0,52 & 0,25 & 33 & 33 & 72 & 635 & $\overline{64}$ \\
\hline JAL 03 & 2,09 & 0,84 & 7,09 & 2,27 & 0,57 & 0,34 & 42 & 10 & 111 & 258 & 51 \\
\hline JAL 04 & 1,58 & 0,74 & 5,62 & 2,22 & 0,61 & 0,16 & 47 & 388 & 66 & 305 & 45 \\
\hline JAL 05 & 1,77 & 0,75 & 6,71 & 1,74 & 0,73 & 0,19 & 35 & 31 & 65 & 594 & 74 \\
\hline JAL 06 & 1,26 & 0,50 & 6,15 & 2,20 & 0,48 & 0,25 & 41 & 33 & 46 & 494 & 83 \\
\hline JAL 07 & 1,34 & 0,64 & 5,55 & 1,75 & 0,40 & 0,25 & 43 & 8 & 83 & 492 & 88 \\
\hline JAL 08 & 1,82 & 0,64 & 4,58 & 1,18 & 0,53 & 0,22 & 32 & 19 & 40 & 551 & $\overline{52}$ \\
\hline JAL 09 & 1,58 & 0,66 & 4,28 & 1,37 & 0,45 & 0,30 & 36 & 28 & 54 & 392 & 66 \\
\hline JAL 10 & 1,24 & 0,82 & 5,47 & 1,72 & 0,45 & 0,26 & 55 & 7 & 76 & 795 & 106 \\
\hline JAL 11 & 1,04 & 0,67 & 5,38 & 1,88 & 0,46 & 0,17 & 28 & 7 & 65 & 340 & 76 \\
\hline JAL 12 & 1,46 & 0,69 & 3,82 & 1,55 & 0,62 & 0,31 & 35 & 12 & 52 & 680 & 70 \\
\hline JAL 13 & 1,24 & 0,69 & 5,78 & 1,69 & 0,35 & 0,11 & 36 & 8 & 74 & 371 & 43 \\
\hline JAL 14 & 1,96 & 0,77 & 6,76 & 2,11 & 0,39 & 0,24 & 51 & 11 & 77 & 574 & 81 \\
\hline JAL 15 & 1,30 & 0,64 & 6,48 & 2,00 & 0,47 & 0,15 & 44 & 6 & 71 & 265 & 52 \\
\hline JAL 16 & 4,13 & 0,49 & 1,39 & 1,69 & 0,24 & 0,53 & 41 & 5 & 13 & 198 & 37 \\
\hline JAL 17 & 3,76 & 0,71 & 1,91 & 1,92 & 0,28 & 0,52 & 50 & 48 & 55 & 264 & 38 \\
\hline JAL 18 & 1,68 & 0,78 & 6,12 & 1,76 & 0,56 & 0,23 & 31 & 14 & 99 & 440 & 59 \\
\hline JAL 19 & 1,40 & 0,81 & 4,61 & 1,28 & 0,45 & 0,19 & 44 & 8 & 76 & 437 & 60 \\
\hline JAL 20 & 1,77 & 0,85 & 6,83 & 1,50 & 0,58 & 0,24 & 36 & 19 & 78 & 452 & 79 \\
\hline
\end{tabular}


APÊNDICE 7. Resultados das análises químicas de macro e micronutrientes de pecíolo, na fase dos frutos entre ervilha e meia-baga ( 2 coleta), para os vinhedos amostrados, em levantamento nutricional na região de Jales, ano de 1991.

\begin{tabular}{|c|c|c|c|c|c|c|c|c|c|c|c|}
\hline \multirow{3}{*}{ Vinhedos } & \multicolumn{11}{|c|}{ Nutrientes } \\
\hline & $\mathrm{N}$ & $\mathrm{P}$ & $\mathrm{K}$ & $\mathrm{Ca}$ & $\mathrm{Mg}$ & $\mathrm{S}$ & $\mathrm{B}$ & $\mathrm{Cu}$ & $\mathrm{Fe}$ & $\mathrm{Mn}$ & $\mathrm{Zn}$ \\
\hline & \multicolumn{6}{|c|}{$\%$} & \multicolumn{5}{|c|}{$\mathrm{ppm}$} \\
\hline JAL 01 & 1,91 & 0,75 & 5,65 & 1,48 & 0,46 & 0,24 & 39 & 11 & 52 & 994 & 124 \\
\hline JAL 02 & 2,18 & 0,97 & 5,26 & 1,71 & 0,54 & 0,26 & 29 & 10 & 58 & 690 & 52 \\
\hline JAL 03 & 2,66 & 0,75 & 5,41 & 1,70 & 0,53 & 0,16 & 29 & 33 & 62 & 325 & 26 \\
\hline JAL 04 & 1,57 & 0,65 & 7,00 & 2,08 & 0,65 & 0,27 & 42 & 444 & 99 & 251 & 45 \\
\hline JAL 05 & 2,55 & 0,68 & 5,26 & 1,62 & 0,64 & 0,22 & 30 & 99 & 114 & 817 & 53 \\
\hline JAL 06 & 1,66 & 0,52 & 7,60 & 1,75 & 0,46 & 0,35 & 41 & 12 & 53 & 645 & 86 \\
\hline JAL 07 & 1,26 & 0,63 & 6,73 & 1,44 & 0,33 & 0,29 & 49 & 9 & 66 & 922 & 92 \\
\hline JAL 08 & 1,41 & 0,67 & 5,09 & 1,69 & 0,62 & 0,23 & 26 & 162 & 57 & 934 & 36 \\
\hline JAL 09 & 1,13 & 0,70 & 5,27 & 1,65 & 0,56 & 0,19 & 36 & 158 & 52 & 259 & 48 \\
\hline JAL 10 & 1,37 & 0,69 & 6,77 & 1,12 & 0,35 & 0,29 & 49 & 10 & 50 & 1219 & 150 \\
\hline JAL 11 & 1,26 & 0,71 & 6,80 & 1,52 & 0,49 & 0,24 & 28 & 8 & 61 & 650 & 73 \\
\hline JAL 12 & 1,25 & 0,70 & 4,16 & 1,67 & 0,63 & 0,26 & 34 & 104 & 70 & 1005 & 80 \\
\hline JAL 13 & 1,17 & 0,71 & 7,33 & 1,73 & 0,44 & 0,22 & 53 & 7 & 37 & 471 & 60 \\
\hline JAL 14 & 1,04 & 0,76 & 5,28 & 1,97 & 0,48 & 0,23 & 51 & 21 & 120 & 869 & 77 \\
\hline JAL 15 & 1,34 & 0,71 & 7,29 & 2,21 & 0,55 & 0,24 & 60 & 30 & 82 & 306 & 53 \\
\hline JAL 16 & 1,08 & 0,72 & 6,20 & 1,68 & 0,54 & 0,07 & 47 & 7 & 67 & 292 & 81 \\
\hline JAL 17 & 1,32 & 0,99 & 6,29 & 2,22 & 0,39 & 0,16 & 57 & 123 & 121 & 464 & 49 \\
\hline JAL 18 & 1,11 & 0,91 & 5,18 & 1,60 & 0,61 & 0,19 & 37 & 25 & 104 & 451 & 26 \\
\hline JAL 19 & 1,34 & 0,88 & 6,81 & 2,11 & 0,52 & 0,25 & 45 & 287 & 119 & 539 & 56 \\
\hline JAL 20 & 1,05 & 0,89 & 5,79 & 1,11 & 0,60 & 0,22 & 40 & 22 & 80 & 477 & 47 \\
\hline
\end{tabular}


APÊNDICE 8. Resultados das análises químicas de macro e micronutrientes de pecíolo, no início de maturação das bagas (3a coleta), para os vinhedos amostrados, em levantamento nutricional na região de Jales, ano de 1991.

\begin{tabular}{|c|c|c|c|c|c|c|c|c|c|c|c|}
\hline \multirow{3}{*}{ Vinhedos } & \multicolumn{11}{|c|}{ Nutrientes } \\
\hline & $\mathrm{N}$ & $\mathrm{P}$ & $\mathrm{K}$ & $\mathrm{Ca}$ & $\mathrm{Mg}$ & $\mathrm{S}$ & $\mathrm{B}$ & $\mathrm{Cu}$ & $\mathrm{Fe}$ & $\mathrm{Mn}$ & $\mathrm{Zn}$ \\
\hline & \multicolumn{6}{|c|}{$\%$} & \multicolumn{5}{|c|}{$\mathrm{ppm}$} \\
\hline JAL 01 & 0,88 & 0,84 & 5,33 & 2,21 & 1,01 & 0,14 & 15 & 14 & 97 & 1744 & 122 \\
\hline JAL 02 & 1,17 & 1,27 & 1,59 & 3,12 & 0,52 & 0,42 & 12 & 1410 & 571 & 1869 & 261 \\
\hline JAL 03 & 1,16 & 0,83 & 4,84 & 2,64 & 1,04 & 0,01 & 15 & 29 & 102 & 452 & 32 \\
\hline JAL 04 & 1,08 & 0,63 & 2,82 & 3,69 & 1,69 & 0,27 & 25 & 741 & 267 & 694 & 65 \\
\hline JAL 05 & 1,06 & 0,69 & 4,42 & 2,28 & 1,75 & 0,07 & 12 & 261 & 112 & 692 & 71 \\
\hline JAL 06 & 0,98 & 0,47 & 4,24 & 3,22 & 1,36 & 0,30 & 25 & 80 & 212 & 4563 & 170 \\
\hline JAL 07 & 0,86 & 0,64 & 3.55 & 2,75 & 1,99 & 0,24 & 28 & 12 & 138 & 2172 & 87 \\
\hline JAL 08 & 0,97 & 0,67 & 4,01 & 2,44 & 1,77 & 0,05 & 10 & 393 & 108 & 735 & 47 \\
\hline JAL 09 & 0,92 & 0,71 & 4,93 & 2,56 & 1,13 & 0,06 & 19 & 232 & 86 & 744 & 57 \\
\hline JAL 10 & 0,93 & 0,81 & 3,50 & 2,71 & 1,18 & 0,30 & 23 & 11 & 166 & 2877 & 130 \\
\hline JAL 11 & 0,88 & 0,75 & 3,59 & 2,80 & 1.25 & 0,17 & 21 & 5 & 124 & 1351 & 53 \\
\hline JAL 12 & 1,03 & 0,84 & 4,10 & 2,57 & 2,02 & 0,11 & 13 & 303 & 130 & 2024 & 104 \\
\hline JAL 13 & 0,83 & 0,57 & 4,02 & 2,73 & 1,00 & 0,17 & 29 & 5 & 167 & 958 & 41 \\
\hline JAL 14 & 1,17 & 1,19 & 1,35 & 4,01 & 0,67 & 0,23 & 17 & 12 & 1034 & 649 & 33 \\
\hline JAL 15 & 0,84 & 0,60 & 4,38 & 3,31 & 0,96 & 0,19 & 28 & 21 & 123 & 564 & 49 \\
\hline JAL 16 & 0,89 & 0,65 & 5,74 & 1,64 & 0,70 & 0,16 & 35 & 21 & 88 & 646 & 26 \\
\hline JAL 17 & 1,04 & 1,20 & 5,09 & 3,04 & 0,68 & 0,36 & 30 & 234 & 82 & 1137 & 36 \\
\hline JAL 18 & 1,32 & 1,09 & 1,58 & 2,83 & 0,66 & 0,34 & 16 & 23 & 921 & 1025 & 90 \\
\hline JAL 19 & 0,90 & 0,84 & 4,19 & 2,75 & 1,10 & 0,19 & 30 & 460 & 20 & 1158 & 38 \\
\hline JAL 20 & 1,23 & 0,98 & 4,80 & 3,42 & 1,10 & 0,09 & 17 & 9 & 181 & 1024 & 72 \\
\hline
\end{tabular}

